Axisymmetric Magnetic Mirror Fusion-Fission Hybrid

R. W. Moir, N. N. Martovetsky, A. W. Molvik, D. D. Ryutov, T. C. Simonen

May 13, 2011 
This document was prepared as an account of work sponsored by an agency of the United States government. Neither the United States government nor Lawrence Livermore National Security, LLC, nor any of their employees makes any warranty, expressed or implied, or assumes any legal liability or responsibility for the accuracy, completeness, or usefulness of any information, apparatus, product, or process disclosed, or represents that its use would not infringe privately owned rights. Reference herein to any specific commercial product, process, or service by trade name, trademark, manufacturer, or otherwise does not necessarily constitute or imply its endorsement, recommendation, or favoring by the United States government or Lawrence Livermore National Security, LLC. The views and opinions of authors expressed herein do not necessarily state or reflect those of the United States government or Lawrence Livermore National Security, LLC, and shall not be used for advertising or product endorsement purposes.

This work performed under the auspices of the U.S. Department of Energy by Lawrence Livermore National Laboratory under Contract DE-AC52-07NA27344. 


\title{
Axisymmetric Magnetic Mirror Fusion-Fission Hybrid (LLNL-TR-484071)
}

\author{
R. W. Moir ${ }^{1}$, N. N. Martovetsky ${ }^{1}$, A. W. Molvik ${ }^{1}$, D. D. Ryutov ${ }^{1}$, T. C. Simonen ${ }^{2}$ \\ ${ }^{1}$ Lawrence Livermore National Laboratory, Livermore, CA USA, ralph@ralphmoir.com, \\ martovetskyn@ornl.gov,.AWMolvik@lbl.gov,ryutov1@,llnl.gov \\ ${ }^{2}$ University of California,Berkeley, CA USA, simonen42@yahoo.com
}

\begin{abstract}
The achieved performance of the gas dynamic trap version of magnetic mirrors and today's technology we believe are sufficient with modest further efforts for a neutron source for material testing $\left(\mathrm{Q}=\mathrm{P}_{\text {fusion }} / \mathrm{P}_{\text {input }} \sim 0.1\right)$. The performance needed for commercial power production requires considerable further advances to achieve the necessary high $\mathrm{Q}>>10$. An early application of the mirror, requiring intermediate performance and intermediate values of $\mathrm{Q} \sim 1$ are the hybrid applications. The Axisymmetric Mirror has a number of attractive features as a driver for a fusion-fission hybrid system: geometrical simplicity, inherently steady-state operation, and the presence of the natural divertors in the form of end tanks. This level of physics performance has the virtue of low risk and only modest R\&D needed and its simplicity promises economy advantages. Operation at $\mathrm{Q} \sim 1$ allows for relatively low electron temperatures, in the range of $4 \mathrm{keV}$, for the DT injection energy $\sim 80 \mathrm{keV}$. A simple mirror with the plasma diameter of $1 \mathrm{~m}$ and mirror-to-mirror length of $35 \mathrm{~m}$ is discussed. Simple circular superconducting coils are based on today's technology. The positive ion neutral beams are similar to existing units but designed for steady state. A brief qualitative discussion of three groups of physics issues is presented: axial heat loss, MHD stability in the axisymmetric geometry, microstability of sloshing ions.
\end{abstract}

Burning fission reactor wastes by fissioning actinides (transuranics: $\mathrm{Pu}, \mathrm{Np}, \mathrm{Am}, \mathrm{Cm}, .$. or just minor actinides: $\mathrm{Np}, \mathrm{Am}, \mathrm{Cm}, \ldots$ ) in the hybrid will multiply fusion's energy by a factor of $\sim 10$ or more and diminish the Q needed to less than 1 to overcome the cost of recirculating power for good economics. The economic value of destroying actinides by fissioning is rather low based on either the cost of long-term storage or even deep geologic disposal so most of the revenues of hybrids will come from electrical power. Hybrids that obtain revenues from sale of both electricity and production of fissile fuel with fissioning blankets might need $\mathrm{Q} \sim 1$ while suppressing fissioning might be the most economical application of fusion but will require $Q \geq 4$.

\section{Table of contents}

1. Introduction

2. Low Technology, Low Q Axisymmetric Mirror Driver .................................................. 4

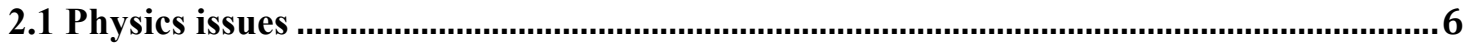

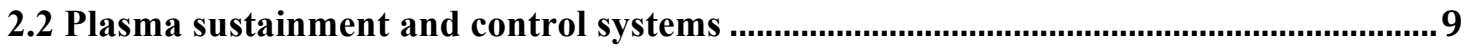

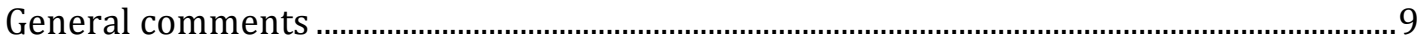

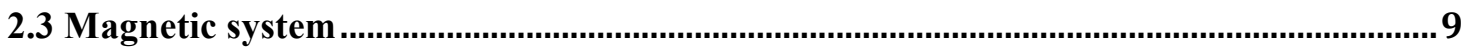

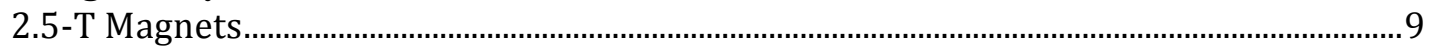

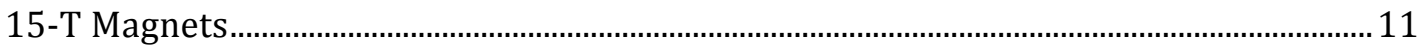




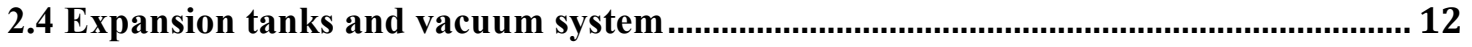

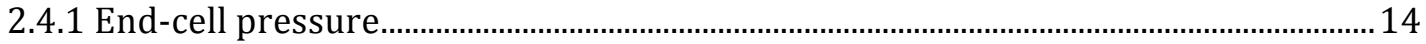

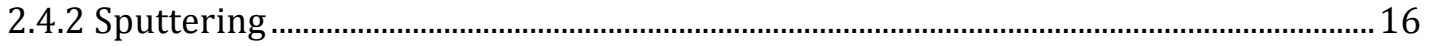

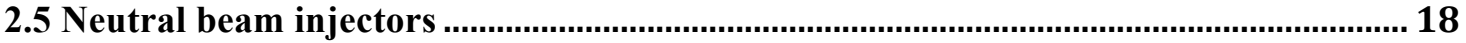

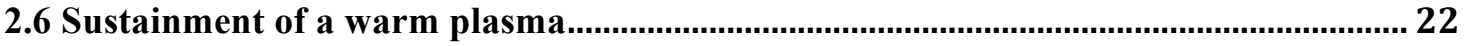

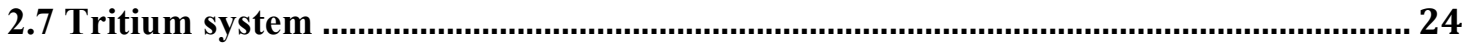

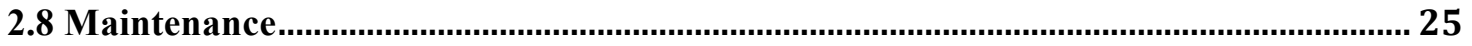

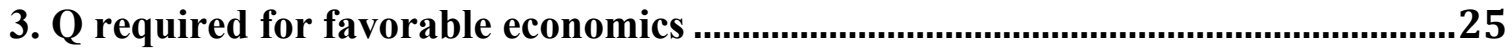

3.1 Value of the two products: electricity and fissile material produced or destroyed. 31

3.1.1 Electricity value ............................................................................................................................ 31

3.1.2 Fissile material value.................................................................................................................... 32

3.2 Summary of $Q$ and other parameters for various blanket options ............................... 36

4. Hybrid Blanket Designs: actinide burner, fuel producer and power producer ....37

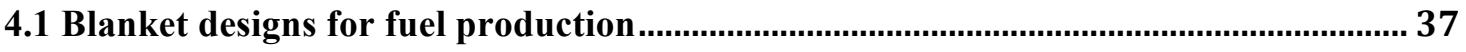

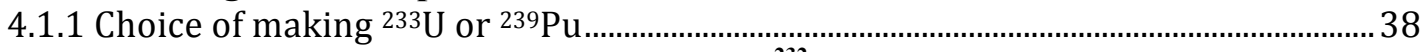

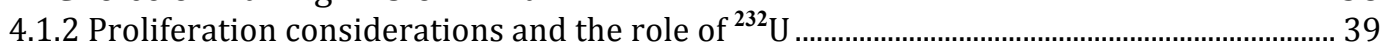

4.2 Molten-Salt Blanket Designs-Fission-suppressed fusion breeder................................... 39

4.3 Fission-suppressed blanket based on liquid lithium multiplier..................................... 41

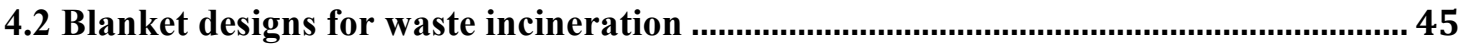

4.2.1 Hard spectrum sodium-cooled, minor-actinide burner (University of Texas) ...... 46

4.2.2 Hard spectrum, sodium cooled, all transuranics (Georgia Tech University) ........... 48

4.2.3 Molten salt waste burner, all transuranics...................................................................... 49

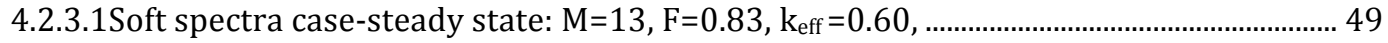

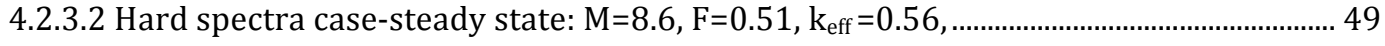

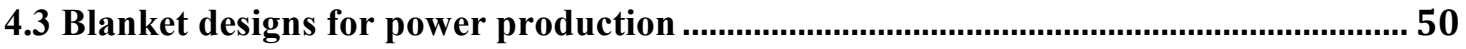

5. Axisymmetric mirror as a pure fusion device..............................................................50

6. Development path for neutron source, hybrid, and pure-fusion devices................51

7. Summary and discussion .........................................................................................52

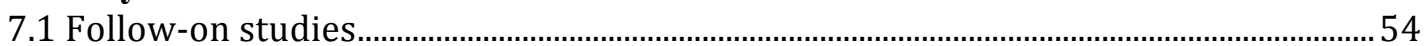

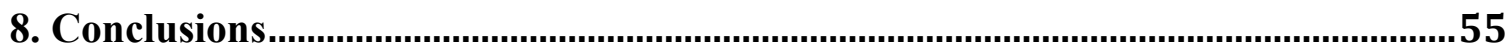

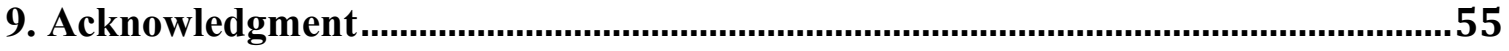

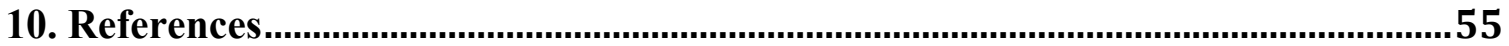




\section{Introduction}

Mirrors have a number of attractive features as future fusion devices: they have simple linear geometry to ease construction and maintenance, are inherently steady state and operate at high beta, have no externally driven currents, have natural divertors to handle heat loads external to the magnet system that also reduces first wall heat loads.

Over the past decades, largely after the termination of the mirror program in the US, several techniques have been suggested and, in some cases, tested experimentally, for making mirrors stable in axisymmetric geometry.

The confidence in the practicality of axisymmetric MHD-stable mirrors has increased significantly after a set of experiments conducted in 2005-2010 on the upgraded axisymmetric mirror machine GDT at Novosibirsk (Ivanov et al, 2010). It routinely operates at a plasma beta equal to 0.6 and average ion energy of a few $\mathrm{keV}$, with the plasma axial losses being in a good agreement with the classical predictions. Its important feature consists in that it is fully axisymmetric and, at the same type MHD - stable. A significant role in making this device, MHD stable is played by the outflowing plasma, which, on the one hand, provides a favorable contribution to the stability integral of Rosenbluth and Longmire (1957) and, on the other hand, provides an electric contact with the conducting end wall. Applying radial potential to the segmented limiter is transferred to the confinement zone along the field lines and may further improve stability (Bagryansky et al, 2003, 2007). This technique can be used in a fusion neutron source, which will operate at plasma Q of order of a few percent (Ryutov, 1990).

The attractive features of mirrors are tremendously amplified in the case of axial symmetry. In particular, neoclassical and resonant transport are completely eliminated; engineering simplicity and general flexibility of the device increase significantly; much higher magnetic fields become available for mirror throats, etc. Axisymmetry is thus a game-changer in mirror systems!

The parameters already attained in the GDT experiment make a strong case for the feasibility of a neutron source for materials and subcomponent testing (Ryutov, 1990). The neutron source version of this device is attractive with no (or with a minor) extrapolation of the plasma parameters from the existing experiment (Ivanov et al, 2010). It operates at a low level of the fusion gain $\mathrm{Q}$, of order of a few percent. This allows one to fully exploit the stabilization by the outflowing plasma and makes the operation scenario of the neutron source quite simple.

In this paper, we concentrate on the use of an axisymmetric mirror as a driver for a fusion-fission hybrid (Lidsky, 1975). In order to have a meaningful power balance of this system, the fusion driver has to have much higher value of $\mathrm{Q}$ than the neutron source. A physics background for this more challenging application has been assessed in Ryutov et al, 2010, where plausible stabilization techniques have been identified and other plasma 
physics issues affecting the driver performance have been analyzed. The result was a simple, single cell mirror device with large expansion tanks at the ends.

Fusion-fission hybrids can potentially be used to produce energy, to breed fuel for fission reactors, to "burn" most hazardous waste of fission reactors, or perform some combination of these functions (Freidberg, Finck, and Bolten, 2010). We do not try to be very specific with regard to a possible best application of a mirror driver. We show that it is compatible with a broad variety of blankets and can perform any of the aforementioned functions. We discuss the requirements for main systems of the facility: neutral beam injection system, gas feed and vacuum systems, magnetic system, tritium breeding and, of course, blanket and shield. We identify areas where the required technologies and components are available today and where some further development is needed.

The rest of the paper is structured as follows: In Sec. 2, a general scheme of the mirror driver is described and a summary of the physics issues and main plasma parameters is presented. In Sec. 2.2 the plasma sustainment and control systems are described. In Sec. 2.3, the superconducting magnetic system is presented. In Sec. 2.4, the structure of the end tanks is characterized, together with a vacuum and direct energy conversion systems; In Sec. 2.5, the neutral beam injection system is described and sustainment of warm plasma in Sec. 2.6. In Sec. 2.7, tritium system is briefly assessed. In Sec. 3, the Q required for favorable economics is discussed. In Sec. 4, the structure of the blanket is described. Finally, Sec. 7 and 8 contains summary and discussion and conclusions.

Our main conclusion is that the hybrid driver in the form of an axisymmetric mirrors can be built based mostly on either the existing technologies or technologies that will be needed in any of the fusion energy systems (like, e.g., tritium breeding).

\section{Low Technology, Low Q Axisymmetric Mirror Driver}

In this section we discuss the mirror driver appropriate to various hybrid applications. Because of the extra energy produced in the hybrid up to a factor of 50 or more and extra revenues from burning wastes or producing fuel, the fusion performance measured by $\mathrm{Q}$ $\left(\mathrm{P}_{\text {fusion }} / \mathrm{P}_{\text {injection }}\right)$ can be reduced to less than about 0.2 in some cases. The axisymmetry of the magnetic system facilitates modular blankets with maintenance advantages all especially important to the hybrid application. The physics needed for this low technology, low Q application is a modest extension of that already achieved. Similarly, the technologies of magnets, neutral beams, and other items are modest extensions of existing technologies.

General schematic of the driver is shown in Fig. 2.1 (not to scale). 


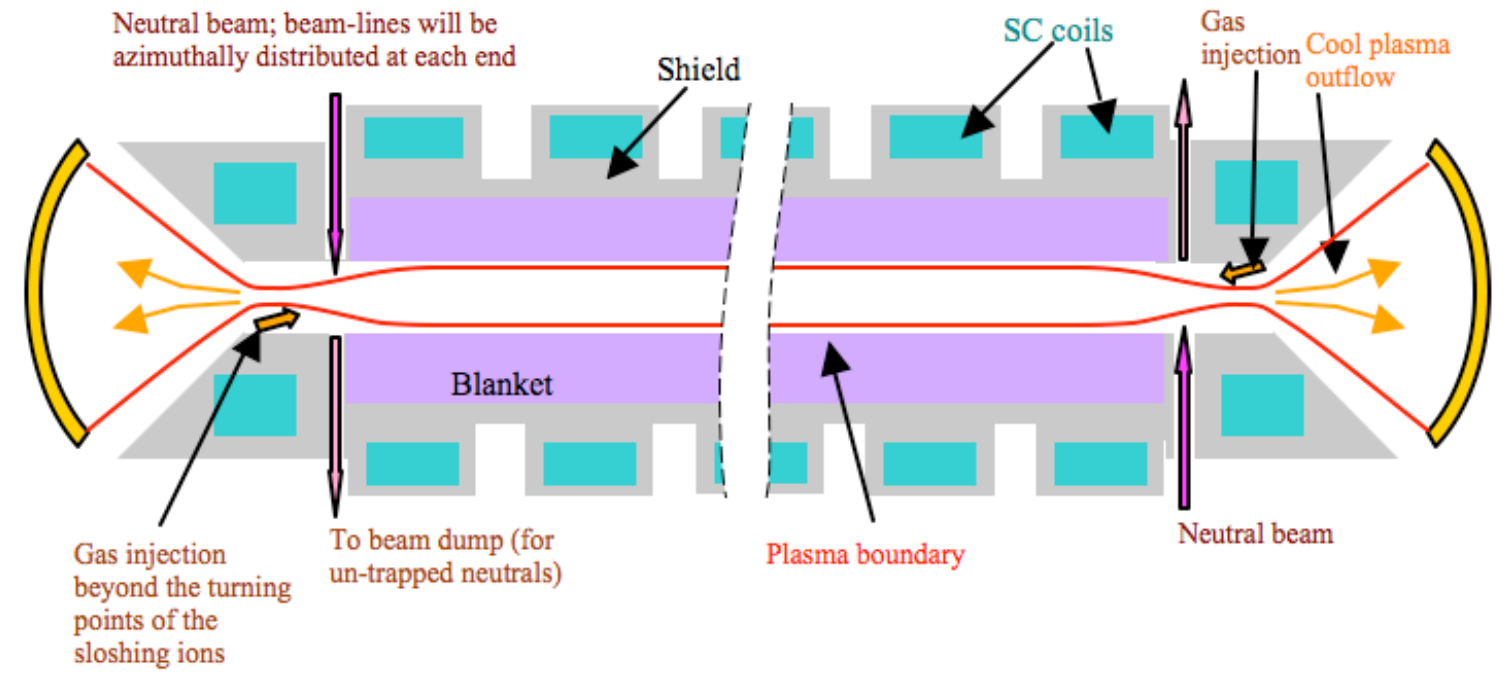

Fig. 2.1. Schematic of a simple axisymmetric mirror as a driver for fusion-fission hybrid. For better viewing the length-to-radius ratio and expander-to-central plasma radii ratios are shown smaller than actual. See Fig. 2.1.2 for a more realistic rendition of the plasma shape in the mirror region.

TABLE 2.1 Characteristic parameters of a mirror driver (the numbers presented in the Table are for the general orientation; one shouldn't expect an accuracy of better than $20-30 \%$ )

\begin{tabular}{|c|c|}
\hline Plasma radius $1, \mathrm{~m}$ & 0.5 \\
\hline Mirror-to-mirror length, $\mathrm{m}$ & 40 \\
\hline Length of a reacting plasma ${ }^{2}, \mathrm{~m}$ & 35 \\
\hline Volume of a reacting plasma ${ }^{2}, \mathrm{~m}^{3}$ & 25 \\
\hline Plasma surface area $^{2}, \mathrm{~m}^{2}$ & 100 \\
\hline Injected ion energy $^{3}, \mathrm{keV}$ & 80 \\
\hline Average ion energy ${ }^{3}, \mathrm{keV}$ & 40 \\
\hline Average ion density, $\mathrm{m}^{-3}$ & $10^{20}$ \\
\hline Electron temperature, $\mathrm{keV}$ & 3 \\
\hline Peak ion density, $\mathrm{m}^{-3}$ & $1.3 \times 10^{20}$ \\
\hline$Z_{\text {eff }}^{4}$ & 1.2 \\
\hline Magnetic field, $\mathrm{T}$ & 2.5 \\
\hline Mirror field, $\mathrm{T}$ & 15 \\
\hline Volume-averaged beta & 0.25 \\
\hline $\begin{array}{c}\mathrm{s}=\text { plasma radius/ } \\
\text { average ion gyroradius }\end{array}$ & 30 \\
\hline NBI trapped power, MW & 65 \\
\hline Plasma Q & 0.7 \\
\hline Fusion power, MW & 45 \\
\hline Neutron power, MW & 36 \\
\hline Neutron wall load, MW/m²@0.6m & 0.27 \\
\hline Bremsstrahlung radiation power, MW & 0.32 \\
\hline $\begin{array}{c}\text { Surface bremmstrahlung } \\
\text { load, } \mathrm{MW} / \mathrm{m}^{2} \\
\end{array}$ & 0.0027 \\
\hline Power to divertor, $\mathrm{MW}$ & 75 \\
\hline
\end{tabular}

${ }^{1}$ In the midplane 
${ }^{2}$ Between the turning points of the sloshing ions

${ }^{3}$ Ignoring $1 / 2$ and $1 / 3$ energies

${ }^{4}$ Based on the previous experience with large-scale mirror facilities and composition of the injected particle beams [Molvik, 1995].

\subsection{Physics issues}

It is tempting to apply for a driver the same stabilization technique as the one tested with the GDT and apparently suitable for future neutron sources. This technique allows for the simplest (and therefore most attractive) plasma configuration: a cigar-like object connected to the zones of a flaring magnetic field (flaring flow) at the ends. However, the plasma confinement in the hybrid application has to be much better than for a neutron source, with Q approaching 1. Good confinement means weaker outflow and, as was shown in Ryutov et al, 2010, this outflow becomes insufficient for the GDT-style curvature stabilization.

A possible solution was discussed in Ryutov et al, 2010, where it was suggested that, at even a weak outflow, the partial line-tying to the end walls (Kunkel \& Guillory, 1996; Molvik et al, 1987) may still lead to a strong stabilization of the most dangerous $m=1$ ( $m=$ azimuthal mode number) mode of a global lateral displacement of the plasma column. The higher- $m$ modes would then be stabilized by finite Larmor radius effects. The $m=1$ mode is not fully stabilized but the residual slow instability can be stabilized by other techniques, like a feedback via the end-plates segmentation, or even left weakly unstable: its contribution to cross-field transport may remain small.

What we achieve by this approach is an extreme simplicity of the geometry of the system, which is very important for good economics for the fusion-fission hybrid applications and aids design of safety systems.

An assessment of various physics constraints on the performance of a hybrid driver of this type was carried out in Ryutov et al, 2010, where a consistent set of parameters for the driver has been specified. Here we present a brief summary of the findings of that study.

If the MHD stability is assured, the next issue that has to be addressed is the microstability of the anisotropic ion population. The existing GDT facility and the neutron sources based on this facility solve this problem by using a "sloshing" ion technique, where the fast ions are injected at an angle of $\sim 45$ degrees with respect to the normal and bounce between the turning points. Such ion distributions are more stable with respect to the loss-cone instabilities than the ones obtained by injection normally to the magnetic axis Simonen et al, 1983. In addition, the GDT-based facilities are (or will be) operating at a relatively low electron temperature $T_{e}$, between 0.25 and $0.8 \mathrm{keV}$. At this relatively low temperature the ion distribution is largely determined by the electron drag and remains a slowing-down distribution until quite low energies are reached. 
On the other hand, so low an electron temperature makes the ion energy confinement time short, leading, again, to a low $\mathrm{Q}$ value $<0.1$. Increasing $\mathrm{Q}$ requires a higher electron temperature. However, raising electron temperature comparable to the ion temperature of a few tens of kiloelectron-volts, leads to a formation of a large "hole" in the ion velocity space at lower ion energies. This "hole" makes the ion distribution unstable with respect to velocity-space micro-instabilities and reduces the ion confinement time to unacceptably low values. The whole concept then falls apart.

A compromise that we propose to use is to keep the electron temperature at the level of $3 \mathrm{keV}$; for the ion injection energy of $\sim 80 \mathrm{keV}$, this would provide the $\mathrm{Q}$ value in the range of $0.7-1$. Such a value would be certainly inconsistent with the use of a magnetic mirror as a pure-fusion reactor but may prove to be acceptable for some versions of the hybrid, especially given a very attractive geometry and general engineering simplicity of the system. In terms of the physics involved, this is a modest step forward from the performance achieved in the GDT facility and therefore there is relatively low risk and a good chance that this approach will work.

Maintaining the electron temperature at a level of $3 \mathrm{keV}$ would require active measures: if we just inject $80 \mathrm{keV}$ neutrals into the system and assume that the ions behave classically, then the electron temperature found from a classical energy balance would be in the range of $10-15 \mathrm{keV}$, depending on the mirror ratio. So, to keep the electron temperature low, it was suggested (Ryutov, 2010) to continuously inject a cold gas in the zone beyond the turning points of the sloshing ions as shown in Figs. 1, 2. The plasma density in this zone would be low-enough to allow for the penetration of the low-energy neutrals to the axis; at the same time, this would not cause excessive charge-exchange loss of the hot ions, because the neutrals will be ionized before they reach the turning points.

The injection of neutral gas leads, on the one hand, to a reduced electron temperature and, on the other hand, to the increased plasma outflow required by the MHD stability constraints.

With regard to the ion injection, we suggest injection at a near-normal direction to the axis near the turning points. Injecting at an angle of 45 degrees at a solenoidal part of the device, as it is supposed to be done in a mirror-based neutron source, would lead to a significant loss of the blanket volume caused by the need of making large ports and cutting through the blanket by tilted beam-lines. Injection at near 90 degrees near the turning points is much more compatible with a general scheme of a hybrid driver. 


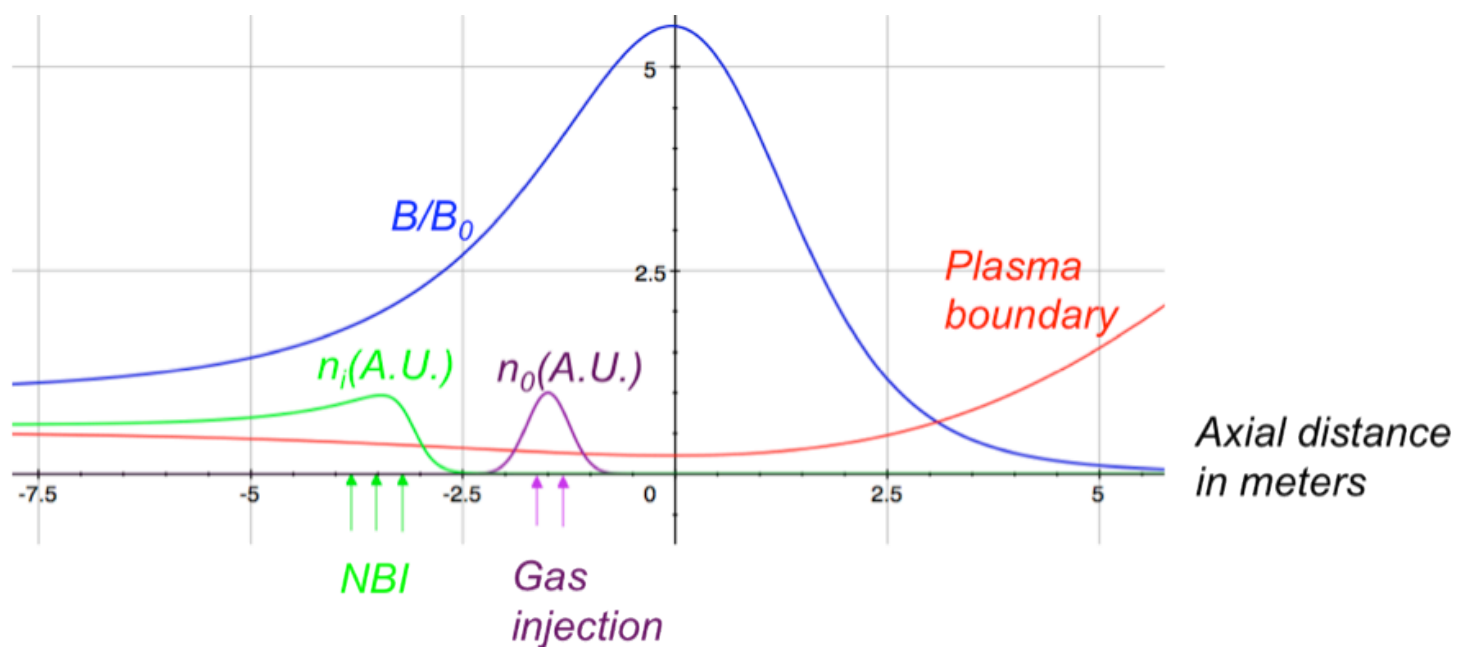

Fig. 2.1.2 The vicinity of the mirror. Horizontal coordinate is the distance from the mirror point in meters. Blue line: the magnetic field strength normalized to its value at the uniform part of the device. Red line: the plasma radius in meters; on the uniform part the plasma radius is $0.5 \mathrm{~m}$. Green arrows indicate injection zone of the neutral beams $80 \mathrm{~cm}$ long). The green line is the density of fast ions normalized to its maximum value. The magenta arrows indicate the injection zone of slow atomic particles ( $50 \mathrm{~cm}$ long). The magenta line is the density of these slow atoms. Note that there is no overlap between the fast ion and cold atom population.

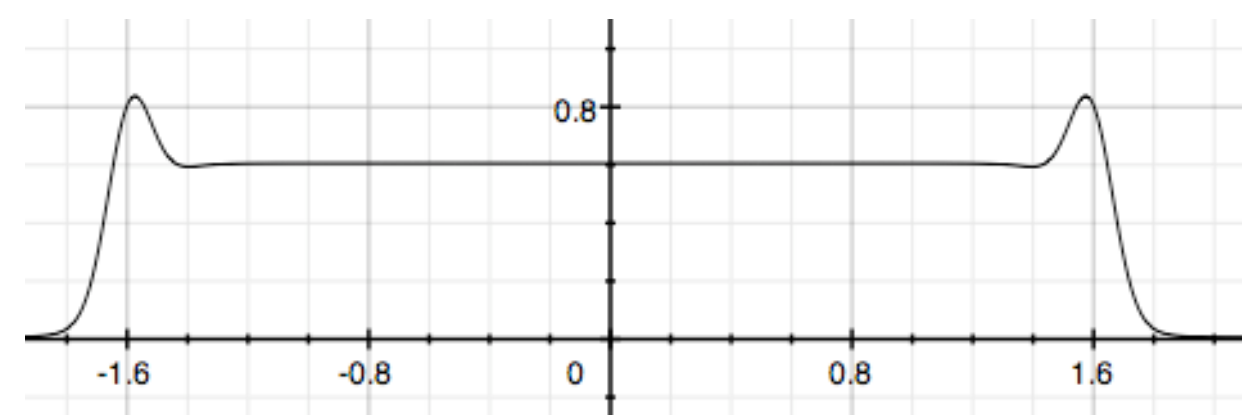

Fig. 2.1.3 A sketch of the neutron power per unit length (A.U.). Peaks are situated near the turning points.

Evaluation of the ion distribution function performed in conjunction with the analysis of Ryutov et al, 2010, has shown that the peaking of the ion density near the turning points will be modest, a factor of $\sim 1.5$ compared to the density in the middle of the facility. Combined with the $\sqrt{2}$ decrease of the plasma radius at this point, this leads to a peaking of the neutron output per unit length by only a factor $\sim 1.5$ compared to the uniform part. In this respect, this system is quite different from the neutron source, where the peaking would be $\sim 10$ (due to a much lower electron temperature). So, in our driver model, the neutron production per unit length has an almost rectangular profile along the axis, with a modest increase near the ends (Fig. 2.1.3).

Returning to the issue of microstability, one can note that the ion density peaking, although quite modest, allows for the accumulation of a small isotropic ion component between the ion density peaks, due to the presence of the ambipolar potential peaks near the ion density maxima. This should also have a favorable effect on the ion microstability. 


\subsection{Plasma sustainment and control systems}

\section{General comments}

In order to provide some insight into the technical readiness of various systems needed for the construction of the fusion 'core', we briefly outline a possible overall design. We expect a facility like this to be preceded by a neutron source that will develop steady-state neutral beams (possibly with direct conversion of the unneutralized ion beam), cryopanels with regeneration, tritium-generating lithium blankets, and fusion-fission hybrid blankets. The simplest neutron source is likely to be a magnetic mirror system based on the axisymmetric Gas Dynamic Trap (GDT) at the Budker Institute of Nuclear Physics, Novosibirsk, Russia [Ivanov 2010]. One such design is the Dynamic-Trap Neutron Source (DTNS) [Molvik 2010, Simonen 2010, Fischer 2000, Bagryansky 2004], which could function as a Fusion-Nuclear Science Facility (FSNF) [Greenwald 2007]. Tokamaks were suggested earlier as FSNF candidates [Garofalo 2010, Peng 2005]. In the following sections, we will outline requirements and possible ways to achieve them, knowing that by the time that construction begins on a hybrid facility that the necessary technologies will have been demonstrated on a mirror or tokamak neutron source, and in other facilities.

\subsection{Magnetic system}

Feasibility of the magnet system for a mirror fusion-fission hybrid

The main requirements for the magnet system are a strong, relatively uniform field of 2.5 $\mathrm{T}$ in the central section of the hybrid and $15 \mathrm{~T}$ peak field in the mirror.

\section{5-T Magnets}

Generation of the $2.5 \mathrm{~T}$ in a bore with $2.3 \mathrm{~m}$ radius or so in the central part is within the state-of-the art of the modern technology. The prime candidate for a conductor for such a system is a NbTi CICC (cable-in conduit conductor) that is capable of carrying $40-50 \mathrm{kA}$ in strong stainless steel jacket. If the winding is continuous, the approximate parameters of the solenoid are given in Table 2.3.1. As a basis we select the ITER PF3-4 conductor that is designed to operate at $4.5 \mathrm{~K}$ with supercritical helium flow of $4-10 \mathrm{~g} / \mathrm{s}$ per channel with a typical pressure drop of 0.3-0.5 bar per $200 \mathrm{~m}$ length of conductor.

Table 2.3.1. Parameters of the conductor for the central section of the hybrid magnet system on basis of ITER PF 3 conductor [Design Description Document: DDD 11 ITER_D_2NBKXY v1.2 Magnets 7. Conductors 09 September 2009].

Sc strand type

Cable pattern

Central spiral

Petal wrap

Cable wrap
NbTi (Type 2)

$(((2 \mathrm{sc}+1 \mathrm{Cu}$ strand $) \times 3 \times 4+1 \mathrm{Cu}$ core 1$) \times 5)+1 \mathrm{Cu}$ core 2

$10 \times 12 \mathrm{~mm}$

$0.05 \mathrm{~mm}$ thick, $50 \%$ cover

$0.10 \mathrm{~mm}$ thick, $40 \%$ overlap 
Number of sc strands

Non copper $\left(\mathrm{mm}^{2}\right)$, untwisted

[twisted]

Total copper $\left(\mathrm{mm}^{2}\right)$, untwisted

[twisted]

Copper strand/core

$\mathrm{Cu}$ core 1: 1.20

diameter ( $\mathrm{mm})$

Cu core 2: 2.70

Void fraction (annulus)

Cable diameter $(\mathrm{mm})$

316L Jacket square ( $\mathrm{mm})$

This conductor has a $1.5 \mathrm{~K}$ margin for $5 \mathrm{~T}$ operation, which makes it acceptable for the central section of the hybrid, even if reasonable access or service gaps between the magnet sections are required that will not run the peak field higher than $5 \mathrm{~T}$.

For such a large magnet we check feasibility of protective discharge of the magnet in the event of the quench. A protective discharge is required in order to prevent a meltdown of the magnet. As it is seen from Table 2.3.2, the ITER PF3 CICC allows having acceptable and even conservative parameters of the central solenoid in one section connected in series despite very large stored energy in a $40 \mathrm{~m}$ long central part.

Table 2.3.2. Parameters of the protection of the central section of the hybrid magnet system

Bmax
Current
Length
Inner radius
Magnetic volume
Stored energy
Voltage (max)
tau
Jcu $_{\text {Tauj }_{\text {Cu^}} \text { } 2}$
Adiabatic hot spot temperature $^{\text {a }}$

$\begin{array}{rl}2.5 & T \\ 5.00 \mathrm{E}+04 & \mathrm{~A} \\ 40 & \mathrm{~m} \\ 2 & \mathrm{~m} \\ 502.7 & \mathrm{~m}^{3} \\ 1.25 \mathrm{E}+09 & \mathrm{~J} \\ 5.00 \mathrm{E}+03 & \mathrm{~V} \\ 5 & \mathrm{~s} \\ 1.13 \mathrm{E}+08 & \mathrm{~A} / \mathrm{m}^{2} \\ 6.43 \mathrm{E}+16 & \mathrm{~A} 2 / \mathrm{m}^{4} \mathrm{~s} \\ 70 & \mathrm{~K}\end{array}$

Design of the magnet can be done also on the basis of the detector magnets constructed for large accelerators, like LHC CMS solenoid [Herve, 2000]. For steady state mode of operation with a low nuclear heating a less expensive magnet could be built, that would generate the required field in the required volume. In such a magnet, the cooling will be performed by an inexpensive thermo-syphon method and indirect cooling of the winding pack from the cooled support cylinder. Both of these features will significantly reduce the cost. 


\section{5-T Magnets}

Generation of $15 \mathrm{~T}$ in large volumes represents a significant challenge. From currently available materials, only $\mathrm{Nb}_{3} \mathrm{Sn}$ is the main candidate, although some HTS materials look more and more promising in the near future. Most difficult problem in such a magnet is the stress management for brittle superconductor $\mathrm{Nb}_{3} \mathrm{Sn}$.

Recently, it was demonstrated that a hybrid of low and high temperature superconductors may be attractive in generating high fields in the nearest future, but at the moment the HTS materials are too expensive to substitute LTS in the parameters area where they compete.

The largest relevant magnet to $15 \mathrm{~T}$ mirror design is the Central Solenoid Model Coil (CSMC) built during Engineering Design Activities by ITER collaboration with major contributions from Japan and the US.

This magnet was built for testing long conductors in one layer coil configuration and generates $13 \mathrm{~T}$ in a bore with a radius of $0.8 \mathrm{~m}$ (Martovetsky, J. Minervini, A. Radovinsky et al., 2002).

With new $\mathrm{Nb}_{3} \mathrm{Sn}$ superconducting materials it is conceivable to attain $15 \mathrm{~T}$ in similar bore, however, due to high sensitivity of the conductor to the lateral force, the design of the conductor would need to be modified and verified in a full scale tests to eliminate recently observed degradation of the $\mathrm{Nb}_{3} \mathrm{Sn}$ against strong EM lateral forces.

It is conceivable to look into resistive magnets, but there are no resistive magnets with such a field and apertures available in the world for a good reason - very high consumption of power.

There is a magnet at NHMFL [Bird, 2011] that generated $20 \mathrm{~T}$ in $200 \mathrm{~mm}$ diameter bore that consumes $20 \mathrm{MW}$.

Projections from recent studies of a large aperture magnets [4] showed that in order to have a $15 \mathrm{~T}$ magnet with $\mathrm{R}=1 \mathrm{~m}$, the power dissipation shall be expected to be on the order of $1 \mathrm{GW}$, that makes it impractical. Therefore, superconducting magnets or possibly, hybrid magnets seem to be the most practical solution to these specifications. 
Fig. 3. CSMC configuration

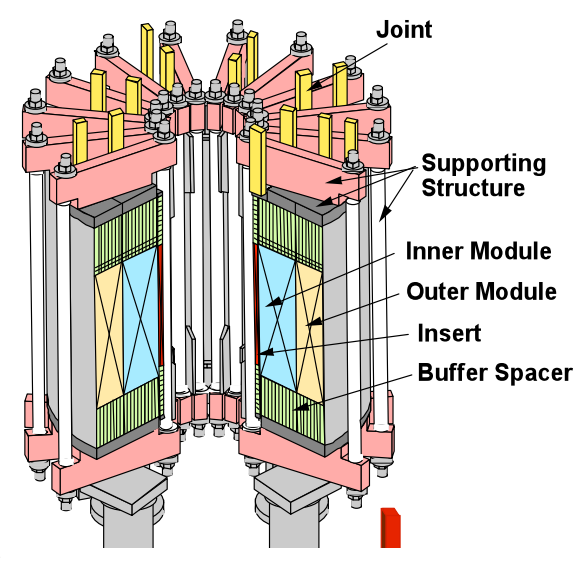

\subsection{Expansion tanks and vacuum system}

The power density to the end-wall is not an issue in mirror machines as it is to divertor strike surfaces in tokamaks, because we are free to expand the plasma cross section to a large area, to reduce the power density below any reasonable threshold desired. The necessary degree of expansion, and the resulting size of the expansion tanks is determined by several factors.

1. The expansion factor of the magnetic field beyond the mirror must exceed the square root of the ion to electron mass ratio, a factor of $\sim 70$, in order to prevent secondary electrons at the end wall from flowing along field lines to the hot plasma, which would reduce the electron temperature to below its classical value [Ryutov 2005]. With lower expansion ratios, $\mathrm{T}_{\mathrm{e}}$ will not reach classical values[Porter 1982].

2. The area for cryopumps must be sufficient to reduce the gas pressure below the level where ionization of gas by escaping plasma affects the electron power balance, and lowers the electron temperature too much. Additional pumping must be provided, so that at any time, a portion of the pumps can be isolated from the plasma volume and regenerated, while the remaining pumps are sufficient to keep the gas pressure low enough.

3. An optional requirement is that the power density at the end wall be low enough either for the strike area to be radiatively cooled, while remaining below temperatures where thermionic electron emission could occur; or, as a less stringent alternative, to be cooled by a low-technology tritium-compatible coolant.

4. The total amount of sputtering scales with the end-loss current; the sputtering erosion rate, per unit area, scales inversely with the square of the plasma radius at the end wall.

Once the magnetic field has expanded sufficiently for control of secondary electrons and reduction of the power density at the end wall; then, if further area is still needed for 
pumping, a weak solenoidal magnetic field can be added that will bring the magnetic field lines to a more distant end wall without further field expansion. This magnetic field could be produced with water-cooled magnets that would need little or no shielding. Increasing the separation between the end wall and the mirror decreases the solid angle of the mirror aperture, so fewer sputtered neutrals can reach the confined plasma. However, it also provides a greater length of end-loss plasma for sputtered and refluxed neutrals to penetrate, so that more pumping speed will be required to reduce the neutral gas density further.

Design of a steady-state cryopump regeneration system is beyond the scope of this paper; here we outline some of the requirements.

1. The maximum pressure during regeneration is limited by explosion safety constraints to be less than $1.5 \mathrm{Mol} / \mathrm{m}^{3}$ [Day 2006]. Below this limit, even in the worst case of an oxygen leak and an initiating spark, no explosion will occur. This corresponds to $1.5\left(6.02 \times 10^{23}\right.$ molecules $\left./ \mathrm{m}^{3}\right)\left(1\right.$ torr $/ 3.3 \times 10^{22}$ molecules $\left./ \mathrm{m}^{3}\right)=27$ torr. This is only $\sim 4 \%$ of an atmosphere, which enables regeneration valve designs that couldn't be considered for normal atmospheric-load applications.

2. The flammability limit could be significantly increased or eliminated if the entire vacuum vessel were to be immersed in a gas such as nitrogen, so that no source of oxygen could possibly reach the vacuum. Valves for regeneration would then have to hold more significant pressure loads.

3. The maximum hydrogen pressure allowed will determine the hydrogen accumulation allowed, based on the volume of each regeneration pump. This together with the fraction of end tank pump area in each separate regeneration region, and the total endloss ion current, will determine the length of time between regenerations.

4. A valve separating a regenerating cryopump from the plasma region must seal sufficiently that the gas pressure in the plasma remains below the threshold for ionization affecting the electron power balance.

We suggest arraying the cryopumps around the circumference of the expanding plasma, or far behind a venetian-blind or other transparent-to-gas end wall; then, valving off a few pumps for regeneration will not create a significant variation in gas density across the end-region cross section. However, if pumps were located close behind a transparent-togas end wall, then during regeneration, volumes in front of the areas valved off would increase in gas density; this could lead to azimuthal/radial variations in electron temperature, which could create plasma-convection cells that would increase the radial transport of hot plasma.

Cryopump designs for the ITER torus [Hauer 2007], or its neutral beam lines [Dremel 2009], provide a reasonable starting point for engineering design. Studies of ITER cryopump regeneration have found three regeneration temperature regimes: $90 \mathrm{~K}$ releases all hydrogen isotopes and helium, $300 \mathrm{~K}$ releases all other gases except water, and $475 \mathrm{~K}$ releases water [Hauer 2007]. Helium pumping with cryopanels requires special techniques have been developed [Sedgley 1988]. The regeneration system for a steady state facility is more challenging than for a low-duty factor facility like ITER, but should be addressed by neutron sources before a hybrid is built. 


\subsubsection{End-cell pressure}

In order to estimate the allowable end-cell gas pressure, we need to determine the ion current to each end; from that, and the ion energy, we can determine the ion density as a function of magnetic field strength. Ionization of the gas by ion or electron impact will increase the end-loss current, charge exchange will not change the ion current to the end wall, but does affect the viability of direct conversion of end-loss power and changes sputtering rates and locations. We point out that ionization of end-cell gas need not decrease the electron temperature further; first because much of it will occur after the magnetic field has expanded in area by more than 70 times, from where new electrons are prevented from reaching the hot plasma by the high mirror ratio; secondly because we can then inject less gas near the mirror. This injected-gas current can be feedback controlled to give us the desired end wall current density in the presence of end-cell ionization, or feedback controlled to maintain the desired electron temperature (after startup transients). Alternatively, we could use feedback control of the end-cell pumping rate, near the mirrors, to control the end-loss-ion current and electron temperature.

The end-loss current can be determined from the ratio of the trapped beam power ( 70 $\mathrm{MW}$ ), to the average neutral beam energy. The average energy is less than the nominal injected neutral energy because ion sources typically produce a mix of atomic ions, diatomic molecular ions, and triatomic molecular ions, that carry respectively full, half and third energy, when the molecular ions breakup after acceleration. We have not optimized the neutral-beam energy, but have selected $80 \mathrm{keV}$ as in a reasonable value for our evaluations. Higher energies would have the advantage of lower charge-exchange cross sections and less beam current needed, so $\mathrm{Q}$ (the ratio of fusion power to input power) should increase. A downside is lower neutralizer efficiency.

For existing $80 \mathrm{keV}$ neutral beams on DIII-D, the average particle energy can be estimated to be about $62 \mathrm{keV}$ before neutralization, and as high as $59 \mathrm{keV}$ after neutralization, assuming similar beam divergence for each energy species [Hong 2002]. As will be discussed in Section 2.5, development is required to achieve long-lived steadystate neutral beams, so we here assume that the atomic ion fraction increases sufficiently that the neutral beams inject an average neutral energy of $70 \mathrm{keV}$ into the plasma. Then the end-loss current to each end is

$$
\mathrm{I}(\text { one end })=0.5\left(7 \times 10^{7} \mathrm{~W}\right) /\left(7 \times 10^{4} \mathrm{eV}\right)=500 \mathrm{~A}
$$

To reduce the electron temperature from about $10 \%$ of the ion energy, $\sim 7 \mathrm{keV}$ to $3 \mathrm{keV}$, we have two alternatives that reduce the electron temperature by increasing the end-loss current. Either we adjust the end-cell pumping, near the mirror, so that approximately 500 $\mathrm{A}$ of the gas there is ionized, or we inject $500 \mathrm{~A}$ of gas near the magnetic mirror at each end, and pump harder so that an insignificant amount of gas becomes ionized $\left(\leq 10 \% \mathrm{n}_{\mathrm{i}}\right)$. Some intermediate case is likely to be optimum. As we discussed above, only the pumping between the mirror and the location where the magnetic field has decreased to 
$70^{-1}$ of the mirror value affects the electron temperature. Reduced pumping in this region may allow us to reduce the gas injection below $500 \mathrm{~A} / \mathrm{end}$. This yields a total ion current hot-ion losses plus ionized gas of $\leq 1000 \mathrm{~A}$ to each end. Escaping deuterium and tritium ions will be accelerated to $\sim 5 \mathrm{~T}_{\mathrm{e}}=15 \mathrm{keV}$, with a velocity of $1.2 \times 10^{6} \mathrm{~m} / \mathrm{s}$. The ion density then becomes

$\mathrm{n}_{\mathrm{i}}=1000 \mathrm{~A} /\left[\left(1.6 \times 10^{-19}\right.\right.$ Coul/ion $)\left(1.2 \times 10^{6} \mathrm{~m} / \mathrm{s}\right)(\pi) \mathrm{r}^{2}=1.66 \times 10^{15} / \mathrm{r}^{2}(\mathrm{~m})$.

For $\mathrm{r}=4 \mathrm{~m}, \mathrm{n}_{\mathrm{i}}=1.04 \times 10^{14} \mathrm{~m}^{-3}$, near the end wall.

Cross sections for proton impact near $6 \mathrm{keV}$ are $\sigma_{\mathrm{i}}=8.2 \times 10^{-20} \mathrm{~m}^{2}$ for producing $\mathrm{H}_{2}{ }^{+}$ and $0.5 \times 10^{-20} \mathrm{~m}^{2}$ for producing $\mathrm{H}^{+}$[Rudd 1983, Barnett 1990]. Summing and multiplying by the ion velocity, we get $\sigma_{i} v_{i}=10 \times 10^{-14} \mathrm{~m}^{3} / \mathrm{s}$. The cross sections and ion velocity will be the same for deuteron impact at $12 \mathrm{keV}$ and triton impact at $18 \mathrm{keV}$, which are in the energy range we expect. Charge exchange cross sections are about 1.2 times larger, $\sigma_{\mathrm{x}}=12 \times 10^{-20} \mathrm{~m}^{2}$ [Rothe 1962, Barnett 1990]. Electron impact at $\mathrm{T}_{\mathrm{e}}=3$ $\mathrm{keV}$ has $\sigma_{\mathrm{e}} \mathrm{v}_{\mathrm{e}}=1.5 \times 10^{-14} \mathrm{~m}^{3} / \mathrm{s}$ [Barnett 1990]. Near the wall, $\mathrm{T}_{\mathrm{e}}$ can decrease by a factor of a few, for example, for $T_{e}=0.75 \mathrm{keV}, \sigma_{\mathrm{e}} \mathrm{V}_{\mathrm{e}}=2.4 \times 10^{-14} \mathrm{~m}^{3} / \mathrm{s}$, which is less than a factor of two higher. We will use the value for $3 \mathrm{keV}$. Adding electron impact to ion impact yields a total ionization rate of

$\sum \sigma_{i} v_{i}=12 \times 10^{-14} \mathrm{~m}^{3} / \mathrm{s}$

The ionization rate of end-cell gas $\mathrm{n}_{0}$ is given by

$\Delta \mathrm{n}_{0} / \Delta \mathrm{t}=-\mathrm{n}_{0} \mathrm{n}_{\mathrm{i}} \Sigma(\sigma \mathrm{v})$

$\Delta \mathrm{n}_{0} / \mathrm{n}_{0}=-\mathrm{n}_{\mathrm{i}} \Sigma(\sigma \mathrm{v}) \Delta \mathrm{t}=-\left(1.04 \times 10^{14} \mathrm{~m}^{-3}\right)\left(11.7 \times 10^{-14} \mathrm{~m}^{3} / \mathrm{s}\right)\left(5 \times 10^{-3} \mathrm{~s}\right)=-0.06$

where, for a distance across the end plasma of about $5 \mathrm{~m}, \Delta \mathrm{t}=5 \mathrm{~m} / 1000 \mathrm{~m} / \mathrm{s}=0.005 \mathrm{~s}$ is the approximate time-of-flight of a hydrogen isotope gas molecule across the end plasma. Thus only about $6 \%$ of the gas is ionized in this one pass.

One limit on the gas pressure in end cells, is that if too many ions charge-exchange with the gas before reaching the direct converter; this will reduce the ion energy at the direct converter, resulting in lower efficiency. We pick $20 \%$ charge exchange as an upper limit for reasonable direct converter efficiency. Then

$\Delta \mathrm{n}_{\mathrm{i}} / \Delta \mathrm{t}=-\mathrm{n}_{0} \mathrm{n}_{\mathrm{i}} \Sigma(\sigma \mathrm{v})$

where here $\Sigma(\sigma \mathrm{v})$ includes not only ion and electron impact ionization, but also charge exchange. Including charge exchange increases the total cross section by a factor of 2.2 


$$
\begin{aligned}
& \Delta \mathrm{n}_{\mathrm{i}} / \mathrm{n}_{\mathrm{i}}=-\mathrm{n}_{0} \Sigma(\sigma \mathrm{v}) \Delta \mathrm{t}=0.2 \\
& \mathrm{n}_{0}=\left(\Delta \mathrm{n}_{\mathrm{i}} / \mathrm{n}_{\mathrm{i}}\right) /[\Sigma(\sigma \mathrm{v}) \Delta \mathrm{t}]=0.2 /\left[\left(2.6 \times 10^{-13} \mathrm{~m}^{3} / \mathrm{s}\right)\left(5 \times 10^{-6} \mathrm{~s}\right)=1.5 \times 10^{17} \mathrm{~m}^{-3}\right. \\
& \quad=4.7 \times 10^{-6} \text { torr. }
\end{aligned}
$$

The required pumping speed to maintain this pressure is given by

$\mathrm{S}(1 / \mathrm{s})=(1000 \mathrm{~A} / 5.3 \mathrm{~A} /$ torr $1 / \mathrm{s}) / 4.7 \times 10^{-6}$ torr $=4.0 \times 10^{7} 1 / \mathrm{s}=4.0 \times 10^{4} \mathrm{~m}^{3} / \mathrm{s}$.

ITER neutral beam line cryopanels achieve a pumping speed of $125 \mathrm{~m}^{3} / \mathrm{s}$ per square meter of panel for deuterium and tritium, so each end will require $320 \mathrm{~m}^{2}$ to maintain the required maximum pressure. For a 4 m radius, pumps around the circumference will require a length of $13 \mathrm{~m}$ to achieve the required speed. Further increases in length, or radius, will be required to allow regeneration of some pumps while the remainder continue pumping. We see that it is difficult achieving sufficient pumping to allow direct conversion of end losses, without degrading the efficiency from excessive charge exchange reducing ion energies to the direct converter.

End-cell pumping is an issue for this fusion-fission hybrid because we have selected a fusion gain of almost unity, $Q \leq 1$. This means that end losses are large. For pure fusion, where $Q$ needs to be in the range of 10-20, this ceases to be an issue, because the end-loss currents decrease nearly as $\mathrm{Q}^{-1}$. With $20 \%$ of the power in alpha particles, which are eventually lost to the ends,

$($ End Power $) /($ Fusion power $)=0.2+1 / \mathrm{Q}$.

One could also imagine adding gas at only one end, allowing the pressure to become large enough that most ions charge-exchanged with gas before reaching the end wall; e.g., a pressure of $6 \times 10^{-5}$ torr which would prohibit efficient direct conversion at that end. Even with the increased gas current of $\sim 1500 \mathrm{~A}$, the pumping speed decreases to $5 \times$ $10^{6} l / \mathrm{s}$, or a length of less than $2 \mathrm{~m}$ of $4 \mathrm{~m}$ radius cryopanels. The other end could then use $5 \mathrm{~m}$ length of similar cryopanels to achieve a charge-exchange loss of only $10 \%$, which would be compatible with direct conversion of the end-loss power to that end.

The mean-free-path for hydrogen isotopes at this pressure $\left(6 \times 10^{-5}\right.$ torr $)$ is $\sim 1.3 \mathrm{~m}$, which is less than the chamber dimensions, suggesting that we should not allow the pressure here to be much greater. In principle, one could reduce the pumping speed to maintain a higher pressure, which would cause more ionization of gas and require less injection of gas to maintain $\mathrm{Te}=3 \mathrm{keV}$. However, a mean-free-path that was significantly smaller would result in a boundary layer near the pumps, and less control of the pressure inside the plasma column. Control of $\mathrm{T}_{\mathrm{e}}$ by injection of gas also requires that the gas injection be comparable to the current injected by neutral beams.

\subsubsection{Sputtering}


We evaluate sputtering of the end walls for a warm plasma flow of $1000 \mathrm{~A}$ to each end. Tungsten provides the minimum sputtering coefficients. Sputtering coefficients of tungsten peak at $\mathrm{Y}=0.002$ for hydrogen incident at 5-20 keV energy [Bohdansky 1984, Anderson 1981]. Sputtering by deuterium has coefficients about 3-4 times that for hydrogen and sputtering by tritium is about 5 times that of hydrogen, with sputtering by alphas another factor of two to three higher, resulting in $\mathrm{Y}_{\mathrm{DT}}=0.009$ [Bohdansky 1984]. The net DT sputtering rate will then be

$\Delta \mathrm{M}(\mathrm{kg} / \mathrm{yr})=\mathrm{Y}_{\mathrm{DT}}\left(\mathrm{I}_{\mathrm{EL}}(\mathrm{A}) / 1.6 \times 10^{-19} \mathrm{coul} /\right.$ ion $)\left(3.16 \times 10^{7} \mathrm{~s} / \mathrm{yr}\right)(183.8 \mathrm{amu})(1.65 \times$ $\left.10^{-27} \mathrm{~kg} / \mathrm{amu}\right)=\mathrm{Y}_{\mathrm{DT}}(60,000 \mathrm{~kg} / \mathrm{yr})=540 \mathrm{~kg} / \mathrm{yr}$.

With the density of Tungsten $\left(19.3 \mathrm{~g} / \mathrm{cm}^{3}\right)$ this becomes $Y_{\mathrm{DT}}\left(3.1 \mathrm{~m}^{3} / \mathrm{yr}\right)=0.028 \mathrm{~m}^{3} / \mathrm{yr}$, see Table 2.1.

Expanding the plasma radius from $0.2 \mathrm{~m}$ at the mirrors to $2 \mathrm{~m}$ at the end wall reduces the magnetic field by a factor of 100, more than satisfying the factor of 70 expansion required for good electron energy confinement. This results in $80 \mathrm{~A} / \mathrm{m}^{2}$ current density, $4.3 \mathrm{MW} / \mathrm{m}^{2}$ power density, and an erosion rate of $0.22 \mathrm{~cm} / \mathrm{yr}$ at the end wall. Doubling the plasma radius to $4 \mathrm{~m}$ decreases all these values by a factor of four, decreasing the erosion rate of tungsten to $560 \mu \mathrm{m} / \mathrm{yr}$. These ranges appear tolerable. Again we note that a mirror neutron source with $\mathrm{T}_{\mathrm{e}}=0.8 \mathrm{keV}$ will have ions bombarding the end wall with up to $\sim 4 \mathrm{keV}$, near the peak of the sputtering coefficient. Many of these ions will chargeexchange in the end cell, resulting in lower ion energies at the wall, but most ions will have energy well above the sputtering threshold energy of $\sim 150 \mathrm{eV}$ resulting in significant sputtering [Bodansky 1984]. Therefore, sputtering issues will be faced first with steady-state neutron sources, either mirror or tokamak.

Self sputtering can result in a particularly dangerous situation; if the product of the sputtering coefficient times the ionization probability exceeds unity, then the sputtering can run away. The self-sputtering coefficient for tungsten exceeds unity for energies above $2 \mathrm{keV}$, reaching 3.8 at $10 \mathrm{keV}$ [Thomas 1985]. The latter would require that the tungsten be ionized near the mirror to achieve such a large energy, but the probability of tungsten, which is sputtered with a cosine distribution, reaching the $\leq 1 \mathrm{~ms}$ diameter flux tube several meters away is of order $0.5 \%$, so this is not a concern. On the other hand, if the probability of ionization (and we have to include charge exchange here) approached unity about a meter from the wall, then energies slightly in excess of $2 \mathrm{keV}$ might occur. A possible solution here is to add a weak solenoidal magnetic field to make the flux tube cylindrical. This causes the density and potential to be constant for the last several meters to the end wall. We expect the final sheath drop to the wall to be $\leq 1 \mathrm{kV}$; because $T_{\mathrm{e}}$ is expected to drop from $3 \mathrm{keV}$ in the hot plasma, to no more than $1 \mathrm{keV}$ near the end wall, and the final sheath drop should be $\sim \mathrm{T}_{\mathrm{e}}$. Most of the sputtered tungsten will be ionized in the cylindrical flux tube, and will strike the end wall at an energy of $\leq 1 \mathrm{keV}$, for which the sputtering coefficient is less than one. We conclude that self-sputtering can likely be mitigated. 
The end walls are far, perhaps $5 \mathrm{~m}$, from the hot plasma, and the fraction of sputtered material that can reach it through a small aperture ( $\sim 0.001$ sterrad) at the mirrors is very small and the power densities at the end wall can be made arbitrarily low by choosing the expansion factor; this gives the designers freedom in choosing the material to minimize both physical and chemical sputtering. In particular, impurities levels in mirror-confined plasmas are naturally low because the entire cross-section of the confined plasma functions like a divertor. This removes the incentives to use carbon, beryllium, or other low-Z materials. The designers can make use of the extensive studies of materials for plasma-facing-components in tokamaks, with the knowledge that materials rejected there may be useful at the walls surrounding the hot plasma, or at the end wall of a mirror. It is important that neutral beams inject very little impurities [Molvik 1995], because energetic impurity ions are confined in a magnetic mirror; although for shorter times than the singly-charged ions of hydrogen isotopes.

One possible end-wall geometry to mitigate sputtering is to shape the end wall to be venetian-blind like. From this, much of the sputtering would end on the back surface of the facing element. Either radiative cooling, or coolant lines on the backside are feasible, particularly if the end wall radius is in the range of $4 \mathrm{~m}$, resulting in $0.7 \mathrm{MW} / \mathrm{m}^{2}$ power density, for which tungsten sputtering rates are about $500 \mu \mathrm{m} /$ year. At low power densities, the coolant can be separated from the heat-input surface by $0.1 \mathrm{~m}$ or more. Radiative cooling is particularly attractive, because it eliminates the risk of disastrous leaks from sputtering a hole in a cooling line. Radiative cooling becomes feasible at power densities below $\sim 1 \mathrm{MW} / \mathrm{m}^{2}$, which is low enough that temperatures can remain below electron emission temperatures. Such end walls could last from several years to the life of the plant.

\subsection{Neutral beam injectors}

The neutral beam systems used in this hybrid concept are similar to those planned for steady-state mirror [Fischer 2000, Molvik 2010] or tokamak [Peng 2005, Garofalo 2010] based neutron sources. Such neutron sources are needed to develop materials and components for hybrid and pure fusion power plants; so their operation should precede the construction of this hybrid, and the development issues discussed below will have been settled. Here we suggest design changes to increase cathode lifetime, reduce acceleration electrode sputtering, and coincidentally to increase the full energy beam component.

Co-injection of $\mathrm{D}$ and $\mathrm{T}$ is planned, to minimize the need for isotope separation, and simplify the tritium processing, as is discussed further in a Section 2.7.

Long-pulse neutral beam accelerators on TFTR, and DIIID [Vella 1988, Kim 1987, Stevenson 1992] have demonstrated reliable operation at durations of a few seconds; these durations exceed ten thermal time constants of the accelerator electrodes, so they are effectively steady-state cooled. Ion source cathodes are estimated to last at least 12 days [Molvik 2010], and accelerator electrode erosion by sputtering could lead to similar lifetimes [Simonen 2010], as discussed below. The lifetime requirements for these 
elements will be determined by future detailed engineering studies; however lifetimes the order of one year, or more, are likely to be the desired range.

Acceleration electrodes have been molybdenum or tungsten, which have sputtering coefficients for $15 \mathrm{keV}$ deuterium and tritium ions that average to about 0.01 and 0.008 respectively [Bohdansky 1984]. Using the measured power of 400-700 W to each grid rail [Vella 1988], and assuming the ions (from ionization of intra-electrode gas) accelerate to energies of the order of 10-20 keV, we obtain an erosion rate of 25-40 $\mu \mathrm{m} /$ day for Mo or 20-35 $\mu \mathrm{m} /$ day for $\mathrm{W}$. These rates are high enough that we would not expect to achieve much more than a few weeks of steady-state operation. These values are quite uncertain, however, and could be lower if much of the power comes from electron bombardment of the electrodes, or our estimate of ion energy to the electrodes is wrong.

The first method to control erosion of accelerator electrodes is to shape the negative suppressor electrode so that electrons emitted from it will not strike other accelerator electrodes but will be dumped on the back wall of the ion source [Vella 1988]. Efforts can be made to expel as many cold ions (formed from ionization of gas by energetic ion impact) as possible from the accelerator, so that they don't hit electrodes and cause sputtering, but the ion-optics designer has little freedom here, as gas is ionized between nearly-planar electrode arrays. Beyond that, the major method to reduce sputtering is to reduce the gas pressure within the accelerator. A reduction of roughly two orders of magnitude should achieve lifetimes exceeding a year; this can be done first by reducing the gas pressure within the ion source, and downstream neutralizer, and secondly by separating these elements from the accelerator to allow space for gas pumping. For this to be possible, we must abandon the long-pulse magnetic-field-free ion source [Vella 1988], which is currently closely coupled to the accelerator. Then to avoid losing most of the ions between the ion source and accelerator, we much apply an axial magnetic field that will allow the ions to flow to the accelerator with little radial loss.

Ion source cathodes might be replaced by radio frequency antennas that have been used successfully to ionize gas [Hahto 2004]. These typically operate on volume sources at pressures of $10^{-3}$ to $10^{-2}$ torr. Electron-cyclotron ion sources can operate at pressures of about $10^{-3}$ torr [Xu 2008] and can achieve uniform plasmas [Fu 2006]. The ion density at the accelerator grids must be very uniform to produce multiple beamlets that are each well focused. Uniformity was achieved in the LBNL Long-pulse source by using a magnetic-field-free ion source [Vella 1988, Chan 1983], in which ions can flow freely to fill the volume uniformly. However, similarly large ion sources for plasma processing have axial magnetic fields, which can be uniformly filled by careful ion source design [Hopwood 1992, Wu 2000, Blackwell 1997]. An ion source with an axial magnetic field can be separated from the accelerator by a drift region that allows gas pumping to reduce the neutral pressure in the accelerator, without losing a large fraction of the ions.

The ion-optics design would then need to correct, as far as possible, for space-charge expansion of the beam in these extended drift regions. After the accelerator, the axial magnetic field is not needed, nor is it desirable in the neutralizer and direct convertor. 
After the beam exits the neutralizer, it is necessary to separate the unneutralized ions from the neutral beam. We expect neutralizer efficiencies of up to $58 \%$ for the deuteron beams and up to $70 \%$ ? for the triton beams at $80 \mathrm{keV}$, the remainder will be ions [Hovingh 1974, Barnett 1990]. To date, neutral beams in the $80-120 \mathrm{keV}$ class have used magnetic fields to deflect the ions to ion dumps. Alternatively, that could be done here by means of direct conversion [Barr 1982]. Then the ion energy can be recovered with an efficiency of about $60 \%$. The major limitation on efficiency is that only about $80 \%$ of the beam is full energy ions, the remainder come from acceleration of $\mathrm{H}_{2}^{+}$and $\mathrm{H}_{3}^{+}$, which then break up yielding half and third energy ions [Vella 1988], whose energy cannot be efficiently direct converted. Increasing the distance from the ion source to the accelerator grids, primarily to reduce sputtering of grids, also is expected to increase the full-energy fraction of the beam. This will make direct conversion of the un-neutralized beam more efficient; and as will be discussed in Section (?), small gains in efficiency can make a large difference on the output power when the fusion gain, $Q$, is near one.

Direct conversion was demonstrated on pulsed beams [Barr 1982]. The self-space charge of the ion beam expanded it into retarding electrodes located along both broad sides of the rectangular beam that then collect the ions at low energy of a few $\mathrm{keV}$.

The plasma that the beams heat and sustain is large in length and diameter, hence easy to hit with any size beam. The incentive to use focused beams is to be able to inject through the smallest possible aperture, that will be part of the neutron shield; thereby minimizing the neutron flux into the neutral beam lines. Minimizing neutrons is essential to minimize the neutron heat load to cryopanels, and to maximize the lifetime of beamline components, especially the insulators, against degradation by neutrons [Hodgson 2002, Zinkle 2002, Decreton 2004]. Care is required to ensure that the duct is completely outgassed, otherwise desorbed gas will reionize the beam, which will then be deflected by the magnetic field, possibly striking the duct which can then desorb more gas. The beam can thus be attenuated or completely blocked [Cox 2002]. This is expected to be less of a problem in steady-state, where surfaces cleaned by beam-halo bombardment will reflux one molecule for each two atoms incident, with no beam-free periods for redeposition to occur. If necessary, reflux can be reduced by scraping halo ions with limiting apertures before they enter the duct.

Focusing the neutral beams is conceptually simple. The long-pulse accelerator electrodes are hollow tubes, carrying coolant, which is tritium compatible (not water). By slightly curving the tubes, beams will be focused in one plane to the center of curvature. By also curving the surface the tubes are mounted on (as was done with short pulse $(20 \mathrm{~ms})$ neutral beams used on TMX-U [Molvik 1981], and tested with $500 \mathrm{~ms} 80 \mathrm{keV}$ neutral beams intended for MFTF-B [Molvik 1979]) ion beams can be focused in two planes. The minimum size beam achievable, in a source with electrodes accurately located (to tolerances the order of $50 \mu \mathrm{m}$ ) to aim every beamlet at the same point, is the same as the size that a single beamlet would expand to at that distance, which is determined by the beamlet divergence. 
The minimum beam divergence is limited by the temperature of ions in the ion source relative to the final energy of the beam. Acceleration and transport electrodes can increase the divergence further. With the long pulse source, the beam half-angle divergence is $0.4 \mathrm{deg}$ parallel to the accelerator slots by $0.7 \mathrm{deg}$ normal to the slots to the $\mathrm{e}^{-1}$ power density [Vella 1988]. Increasing the port opening to 1.5 times the size of the $\mathrm{e}^{-1}$ points, this divergence would result in a port size of $0.23 \times 0.40 \mathrm{~m}$ at a distance of $8 \mathrm{~m}$ from the ion source. (The final choice of injection port size requires engineering optimization to trade off maximizing the injected beam, minimizing neutrons into the beam line, and minimizing gas reflux from and heating of the beam duct.) We note that further ion source development is required for steady state, to increase electron 'cathode' lifetime and to decrease gas pressure within the accelerator that leads to sputtering of electrodes; with this development, ion cooling to provide lower divergence may be possible. Increasing the $\mathrm{D}_{1}{ }^{+}$(and $\mathrm{T}_{1}^{+}$) ion component beyond the long pulse fraction of $80 \%$ [Vella 1988], is likely, with reduced $\mathrm{D}_{2}{ }^{+}$and $\mathrm{D}_{3}{ }^{+}$that lead to fractional energy components of the beam, as was discussed.

With a neutron flux of $0.26 \mathrm{MW} / \mathrm{m}^{2}$, (Table 2.1) these apertures reduce the flux to 0.02 MW into each neutral beam line. The plasma diameter is about $0.3 \mathrm{~m}$ at the neutral beam injection location; for a constant radius wall $(0.6 \mathrm{~m})$, the plasma will subtend $60 \mathrm{deg}$, or about 1 radian across its diameter; the neutron production is decreasing axially towards the ends at the injection location, so an angle of 1 radian is roughly correct. The result of this is that the neutron flux through an injection port will subtend about two sterradian. At the neutral beam module, the unscattered neutron flux will decrease to about $0.3 \mathrm{~kW} / \mathrm{m}^{2}$ at the ion source, and up to about $3 \mathrm{~kW} / \mathrm{m}^{2}$ at the cryopanels. If necessary, high-voltage insulators could be partially shielded from neutrons by using very large insulators with architecture similar to neutral beams for JET [Duesing 1987], which could provide space for interior neutron shields.

Neutron power to the cryopanels can be significantly reduced if we replace the injection aperture with a neutron-shielded duct; then only scattered neutrons reach the cryopanels. The ducts to neutral-beam lines will be considerably smaller than the $\sim 1 \mathrm{~m}$ diameter ducts to torus pumps on ITER; therefore, neutron heating of cryopanels should be in the range of, or less than, that expected on ITER [Petrizzi 2009].

Separate vacuum vessels to serve as neutral-beam dumps are an option. The advantage of separate vessels is that they can use larger apertures to capture more of the transmitted beam, dump it onto actively-cooled surfaces, avoid increasing the gas pressure and neutron flux in the beam-line vessels, and pump most of the desorbed gas to minimize this gas reaching the hot plasma. The major disadvantage is that up to half of the available space in the end-injection regions, using normal-injection, is filled with dump tanks rather than injector tanks - the maximum power that can be injected could be reduced by as much as half. If beams are to inject into an opposite injector tank, we would offset the beams azimuthally so that the transmitted beam is aimed between injecting beams, to provide room for the transmitted beam dump. Alternatively, if we were to inject sufficiently off-normal, then separate apertures that were displaced axially and separate pumped volumes could be used for injection and dump tanks. An 
engineering optimization is required to determine the optimum compromise input/output duct size(s): large enough to allow as much beam as possible to reach the plasma and exit the plasma chamber into the dump region, rather than striking a wall in the plasma chamber; versus minimizing the duct size and the resultant neutron leakage into the injector/dump vessel(s).

To ensure steady-state operation with a satisfactory, assured power output, redundancy is required for all essential fueling and heating systems. Pulsed availabilities of 90-95\% were observed at DIII-D [Kim 1987] and TFTR [Stevenson 1992]; these do not directly translate to steady-state availability, but do suggest that a small degree of redundancy, perhaps the order of $10 \%$, might be sufficient. Directly applicable data should become available, during engineering design of a hybrid, to determine the required redundancy from steady-state mirror or tokamak based neutron sources that will use similar neutral beam injectors, cryopumps, and other technologies as required by this hybrid design. For neutral beams, adding one or more complete beam lines is a straightforward method that provides redundancy for all beam line systems, including ion sources, ion accelerators, power supplies, neutralizers, beam dumps or direct convertors, diagnostics, and cryopumps.

\subsection{Sustainment of a warm plasma}

A hot plasma with density of order $10^{20} \mathrm{~m}^{-3}$ is required to produce up to $40 \mathrm{MW}$ of fusion power; however beyond the neutral beam injection locations, the hot-ion density decreases rapidly towards the magnetic mirrors, until at the mirrors the density is about $10^{17} \mathrm{~m}^{-3}$, consisting of scattered hot ions (that have been dragged down by electrons to $\sim 10 \mathrm{keV}$ ) and warm ions from ionization of injected gas. This is computed for one end, for which the end loss current is

$\mathrm{I}=54 \times 10^{6} \mathrm{~W} /\left(10^{4} \mathrm{eV}\right)=5,400 \mathrm{~A}$.

Over an area of a $0.2 \mathrm{~m}$ radius flux tube at the mirror, $\mathrm{A}=\pi(0.2 \mathrm{~m})^{2}=0.126 \mathrm{~m}^{2}$.

Then the hot-ion density, which has been dragged down to an energy of $\sim 10 \mathrm{keV}$ is

$\mathrm{ni}=\left(5400 \mathrm{~A} /\left(1.6 \times 10^{-19} \mathrm{Coul} /\right.\right.$ ion $)\left(1 / 0.126 \mathrm{~m}^{2}\right)\left(1 / 10^{8} \mathrm{~cm} / \mathrm{s}\right)=2.7 \times 10^{17} \mathrm{~m}^{-3}$.

Because the warm plasma density near the mirrors is much lower than the hot ion density near the midplane, gas injection can provide fueling from the plasma edge, with a radius $\sim 0.2 \mathrm{~m}$, all the way to the axis. Gas molecules will penetrate to the axis in significant numbers; furthermore dissociation of the molecules produces Franck-Condon atoms of a few eV energy, which freely fill the low-density warm plasma, and charge-exchange of warm ions with gas causes a higher energy neutral population to fill the warm plasma cross section. 
The warm plasma density must be sufficient to lower the electron temperature from 10$15 \mathrm{keV}$ to $3 \mathrm{keV}$. This requires increasing the end-loss current by the factor (10-15)/3. The end-loss current from the neutral beam injection of $70 \mathrm{MW}$ trapped) at $80 \mathrm{keV}$ full energy, perhaps $70 \mathrm{keV}$ average energy, is $\left(7 \times 10^{7} / 7 \times 10^{4}\right)=1000 \mathrm{~A}$ or $500 \mathrm{~A} / \mathrm{end}$. We will assume injection currents to be $\sim 500 \mathrm{~A} / \mathrm{end}$. This corresponds to $\sim 100$ torr $1 / \mathrm{s}$ of gas flow at each end.

Gas injection will be located beyond the turning point of energetic beam-injected ions, and inside the peak magnetic field at the mirror [or alternatively centered on the mirrors, or located just outside the mirrors]. This axial location minimizes charge exchange of energetic ions on cold gas as a significant energy loss. The exact location will be optimized by balancing the minimizing of hot-ion loss through charge-exchange on injected gas by moving the injection away from the neutral beam injection location and towards the mirror or even outside of it; versus decreasing the efficiency of directconversion of the energy of ions reaching the end wall, which is increased by injecting gas at a higher potential, hence a higher density further inside of the mirror. The gas valves will have redundancy, and will preferably be located outside of the neutron shielding for long life and more convenient access for repair or replacement. If we use feedback control of the gas flow, from the measured electron temperature, end losses, or other warm plasma diagnostic (perhaps currents to end-wall direct convertors), then the minimum response time of the gas flow will be limited by the transit time of gas through the tubing between the valves and the injection ports.

The box must be a about an alpha-particle gyro-diameter outside the edge of the hot-ion plasma, far enough to keep alpha heating low enough that the gas box can be radiatively cooled for simplicity of cooling, and close enough that the box will operate at a high temperature so that gas does not condense on the surface. We can make a rough estimate of the required radial distance outside the hot-ion plasma: The mirror ratio of 6 (peak field of $15 \mathrm{~T}$ at mirrors, and $2.5 \mathrm{~T}$ at the midplane) results in ion trajectories, which make an angle with field lines of $\leq 24 \mathrm{deg}$ at the midplane can reach the mirror region where the gas box is located; the fraction of the $2 \pi$ sterradian solid angle subtended by one end mirror is $\left(2 \pi\left(r \sin 24^{\circ}\right)^{2}\right) /\left(4 \pi r^{2}\right)=0.04$. Alpha particles that are reflected near a mirror have their entire $3.5 \mathrm{MeV}$ energy as energy perpendicular to the magnetic field of $15 \mathrm{~T}$, yielding a gyroradius of $\rho_{i}=2.5 \mathrm{~cm}$. If we provide $4 \mathrm{~cm}$ separation between the hot ion plasma and the gas box, then $2 \rho_{\mathrm{i}}-1=4 \mathrm{~cm}$, so the only alphas that can impinge on the gas box are created within the flux tube that maps to a $1 \mathrm{~cm}$ thick annulus at the mirror, where the fraction of the plasma cross-sectional area is $\left(20^{2}-19^{2}\right) / 20^{2}=0.10$. Out of the total fusion power of $43 \mathrm{MW}$, the fraction of power that can reach the axial and radial position of the gas box will be $0.04 * 0.10 * 43 \mathrm{MW}=0.17 \mathrm{MW}$. The gas box area is approximately $2 \pi(0.24 \mathrm{~m}) * 1 \mathrm{~m}=1.5 \mathrm{~m}^{2}$, so the power density is $0.17 \mathrm{MW} / 1.5 \mathrm{~m}^{2}=$ $0.12 \mathrm{MW} / \mathrm{m}^{2}$. This is less than $1 \mathrm{MW} / \mathrm{m}^{2}$, so radiative cooling of the gas box is feasible.

The injected cold ions will be quickly accelerated to the ion sound speed by the axial potential profile. Distributed over a radius of $\sim 0.25 \mathrm{~m}$ (corresponding to a magnetic field 
of 4 times that at the midplane, or $10 \mathrm{~T}, 1000 \mathrm{~A}$ requires a warm ion density of $0.6 \times 10^{18}$ $\mathrm{m}^{-3}$.

We estimate that continuous gas injection can provide the fueling of the warm plasma, from the edge to the axis. By injecting gas around the circumference, at the center of a duct just outside the edge of the plasma; gas that charge exchanges with ions produces neutrals that can strike the duct. Here the neutral atoms will recombine into molecules and reenter the plasma. After several generations of charge exchange, nearly all the injected gas will have been ionized, thus a flow rate of slightly over 200 torr $l / \mathrm{s}$ will suffice. Similar gas boxes were used successfully on the Tandem-Mirror ExperimentUpgrade, TMX-U, at LLNL [Pickles 1983]. Whether a single gas box is used, or one near each mirror, is an engineering detail to be determined later.

Virtually all of the injected gas will be ionized and flow out the ends. This opens the possibility of injected gas other than a deuterium-tritium mix, which would have the advantage of reducing the tritium flow-rate. Possible alternative gases include hydrogen, helium, neon, or argon. Any of these would increase the need for gas processing, to separate deuterium and tritium from the other injected gas; selection of an alternative gas would require an optimization between reducing tritium flow rate and inventory versus requiring more gas processing. Sputtering of the end wall, discussed in the next section, would be reduced by a factor of $\sim 4$ for hydrogen; helium would become doubly ionized so half as many ions reach the end wall, but helium is harder to cryopump and has a larger sputtering coefficient; heavier gases such as neon and argon would have even higher sputtering coefficients. Choosing the gas to inject near the mirrors involves balancing several issues:

1. Minimizing the tritium throughput and inventory, which alternative gases help.

2. Minimizing gas reprocessing to separate deuterium-tritium from other gases, which becomes more difficult if we add other gases.

3. Minimizing sputtering - heavier gas have higher sputtering coefficients, but would become multiply ionized, so fewer ions would strike the end walls for sufficient electron injection to reduce Te to $3 \mathrm{keV}$.

4. Pump the gas in the end tank. All are readily pumped by cryosurfaces, with one exception: Helium is harder to cryopump, but can be pumped with surfaces below 4.6 $\mathrm{K}$, or by spraying Argon gas onto a cryosurface to weakly bond to helium, or by coating the cryosurface with activated carbon [Sedgley 1988, Dremel 2009].

\subsection{Tritium system}

Separation of tritium from deuterium, hydrogen, and other impurities has been demonstrated at Los Alamos on the Tritium Systems Test Assembly (TSTA) [Willms 2002]. This is a known technology, but is quite expensive for the large flow rates envisioned for a fusion-fission hybrid. We therefore propose to use an appropriate, near 50:50 mixture of deuterium and tritium, thereby minimizing the amount of isotope separation needed. 
The flow rate of tritium circulating in the system is $\sim 0.6 \mathrm{~kg} / \mathrm{hr}, \sim 0.22 \mathrm{~kg} / \mathrm{hr}$ to the end tank pumps, and $\sim 0.34 \mathrm{~kg} / \mathrm{hr}$ to the neutral beam line pumps. This is about $33 \%$ of the

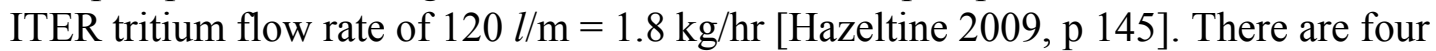
partially-isolated classes of gas-flow regions: plasma chamber, neutral beam line tanks, perhaps an equal number of beam-dump tanks, and two end tanks; each of these operates on a mixture of deuterium and tritium). We can tolerate mixtures of deuterium and tritium in neutral beam fueling of the hot ions and in gas fueling of the warm plasma; this results in a great simplification of gas processing by not having to separate tritium from deuterium. To maintain the desired fractions of each component, one can add either deuterium or tritium gas as required.

It will be possible in initial DT operation to gradually increase the tritium concentration from near zero to $\sim 50 \%$, as the commissioning of the tritium/gas system, fusion power, and fission and tritium blankets progresses.

Gases other than deuterium and tritium must be maintained below a level of the order of a few percent (the operating value to be determined). Dilution of the deuterium-tritium by impurities reduces the neutron production by the product of $n_{D} n_{T}$; that is, a $5 \%$ density of impurities reduces the neutron production by 10\%. Removing impurities (hydrogen, helium, and heavier gases) is likely to be the major issue for the gas-handling system.

One method of removing impurities, by analogy to fractional distillation, is to slowly vary the cryopanel temperature during recycling, perhaps in only one of the chambers; this evaporates one gas species at a time, allowing it to be pumped away. Together with adding deuterium or tritium gas as necessary, this should provide sufficient control of the deuterium and tritium densities.

\subsection{Maintenance}

Linear, axisymmetric systems like magnetic mirrors provide attractive options for maintenance. Cylindrical symmetry is convenient because all sides of the system are accessible, with no need to squeeze components into the donut hole of a torus. If we locate the vacuum walls outside of the blankets and neutron shields where it is protected from neutrons for a long-reliable life, then access to the blankets can be obtained by rolling the ends of the facility outwards on rails. Vacuum seals can be bolted hard seals, or edge-seam-welded sheet-metal. The latter can be opened by grinding off the weld; then rewelding after closing up; this is done daily on some industrial ovens. Vacuum walls inside the blankets, would enable more convenient blanket maintenance or replacement, but at a significant risk of rupturing a neutron-damaged vacuum wall.

\section{3. $Q$ required for favorable economics}

This section discusses the $\mathrm{Q}\left(\mathrm{Q}=\mathrm{P}_{\text {fusion }} / \mathrm{P}_{\text {input }}\right)$ required for various hybrid applications. The revenues from sales of electricity and fissile material or from sales of electricity and the revenues from the destruction of actinide wastes depends on $Q$ and nuclear 
performance of the particular hybrid blanket design. As Q drops, more electricity must be purchased (or equivalently not sold) thereby diminishing the revenues and lowering the economic attractiveness. Fission suppressed fuel producers might have a blanket energy multiplication $\mathrm{M}$ of only 2 and requires a $\mathrm{Q}>4$ whereas fissioning fuel producers might have an $\mathrm{M}$ of 10 or more and require a $\mathrm{Q}>1 / 2$ for good economics.

For good economics, the fraction of gross electrical power produced that must be recirculated as input power, called the recirculating power fraction, must be sufficiently small. Frecirculating $<0.1$ is good and $>0.2$ is bad. To judge what minimum value of $Q$ is required one needs a system model that allows calculating the cost of the two products: elecricity and fuel or destroying wastes. Lacking such a system model we will make less accurate calculations. A simplified power flow diagram is used to model the axisymmetric mirror as shown in Fig. 3.1.

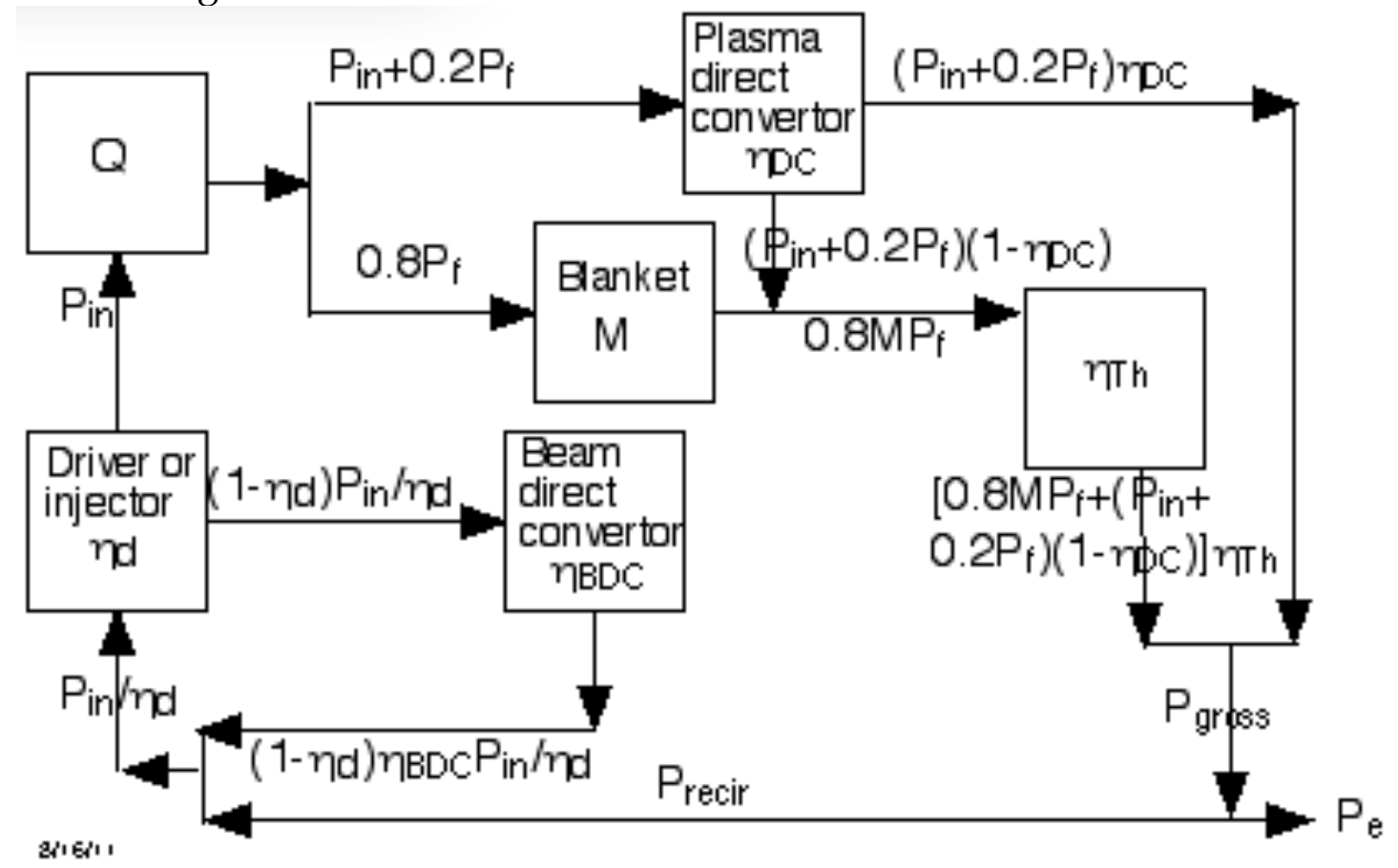

Fig. 3.1 Power flow diagram.

For low $\mathrm{Q}$ fusion, direct conversion to electricity where ever practical will be important for economics. The plasma leaking out the ends can be converted with a simple biased collector plate similar to the "depressed collector" on some microwave tubes. Grids are needed to repel electrons from the positive collector. Efficiencies can be $50 \%$ with one stage and over $65 \%$ with two stages. For all our examples we choose $50 \%$ as typical $\eta D C$. This direct current power can be used to augment the power supplied to neutral beam injectors with little power conditioning. The process in producing neutral beams to drive the fusion process results in unneutralized beam that can also be directly converted into DC electrical power and used to reduce the amount of power supplied to the ion 
accelerators. Since the beam direct converter is so intimately tied into the injector we do not account for this power in recirculating power, however, it could be so treated. Most of the unneutralized beam is of full energy of the accelerated ions and a single collector plate can be used similar to the depressed collector of some microwave tubes. The efficiency of beam direct conversion can be quite high such as over $80 \%$, however, when accelerating and neutralizing positive ions $\left(\mathrm{D}^{+}\right.$ and $\mathrm{T}^{+}$) molecular ions are made and dissociation resulting in ions of $1 / 3,1 / 2$ and $2 / 3$ of the full energy. Dealing with these fractional energy ions complicates the beam direct covertors and lowers the efficiency. We will take $50 \%$ as typical for our example beam direct converters, ๆBDC (Barr, 1977).

From Fig. 3.1 we define the following parameters:

$\eta_{T h}=$ thermal conversion efficiency, typically $=0.4$.

$\eta_{d}=$ efficiency of converting electrical energy into neutral beam energy and trapping the beam $=0.5$ typically for our examples.

$\eta_{B D C}=$ efficiency of conversion of unneutralized beam, i.e., beam direct conversion $=0.5$ typical for our examples.

$\eta_{D C}=$ efficiency of plasma direct conversion of end losses, typically 0.5 for our examples.

$P_{e}=P_{\text {gross }}-P_{\text {recir }}$

The recirculating power fraction is:

$F_{\text {recirculating }}=\frac{P_{\text {recir }}}{P_{\text {gross }}}$

$P_{e}=P_{\text {gross }}\left(1-F_{\text {recirculating }}\right)$

Both Pgross and Frecirculating are function of $Q$.

The fusion power comes $20 \%$ from ${ }^{4} \mathrm{He}$ producing reactions and $80 \%$ from $14 \mathrm{MeV}$ neutron producing reactions.

$$
\begin{aligned}
& P_{\text {nuclear }}=P_{f}(0.8 M+0.2) \\
& Q=\frac{P_{f}}{P_{\text {in }}}
\end{aligned}
$$




$$
\begin{aligned}
& P_{\text {recir }}=P_{i n} / \eta_{d}-\left(1-\eta_{d}\right) \eta_{B D C} P_{\text {in }} / \eta_{d} \\
& =\left[1-\left(1-\eta_{d}\right) \eta_{B D C}\right]\left(\frac{1}{\eta_{d} Q}\right)\left(\frac{P_{\text {nuclear }}}{0.8 M+0.2}\right) \\
& =\frac{P_{f}}{\eta_{d} Q} \text { for } \eta_{B D C}=0 \\
& P_{\text {gross }}=\left(P_{i n}+0.2 P_{f}\right) \eta_{D C}+\left[0.8 P_{f} M+\left(1-\eta_{D C}\right)\left(P_{i n}+0.2 P_{f}\right)\right] \eta_{T h} \\
& =\left[\frac{1}{Q}+0.2\right]\left(\frac{P_{\text {nuclear }} \eta_{D C}}{0.8 M+0.2}\right)+\left[0.8 M+\left(1-\eta_{D C}\right)\left(\frac{1}{Q}+0.2\right)\right]\left(\frac{P_{\text {nuclear }} \eta_{T h}}{0.8 M+0.2}\right) \\
& =\left(\frac{P_{\text {nuclear }}}{0.8 M+0.2}\right)\left(\eta_{D C}\left(\frac{1}{Q}+0.2\right)+\left(1-\eta_{D C}\right)\left(\frac{1}{Q}+0.2\right) \eta_{T h}+0.8 M \eta_{T h}\right) \\
& =(0.8 M+1 / Q+0.2) P_{f} \eta_{T h} \text { for } \eta_{D C}=0 \\
& F_{\text {recirculating }}=\frac{P_{\text {recir }}}{P_{\text {gross }}} \\
& {\left[1-\left(1-\eta_{d}\right) \eta_{B D C}\right]\left(\frac{1}{\eta_{d} Q}\right)\left(\frac{P_{\text {nuclear }}}{0.8 M+0.2}\right)}
\end{aligned}
$$

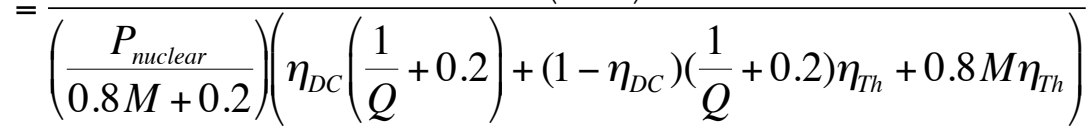

$$
\begin{aligned}
& {\left[1-\left(1-\eta_{d}\right) \eta_{B D C}\right]\left(\frac{1}{\eta_{d} Q}\right)} \\
& =\overline{\left(\eta_{D C}\left(\frac{1}{Q}+0.2\right)+\left(1-\eta_{D C}\right)\left(\frac{1}{Q}+0.2\right) \eta_{T h}+0.8 M \eta_{T h}\right)} \\
& =\frac{\left[1-\left(1-\eta_{d}\right) \eta_{B D C}\right] 1 / \eta_{d}}{\left(\eta_{D C}(1+0.2 Q)+\left(1-\eta_{D C}\right)(1+0.2 Q) \eta_{T h}+0.8 Q M \eta_{T h}\right)} \\
& =\frac{\left[1-\left(1-\eta_{d}\right) \eta_{B D C}\right]}{\eta_{d} \eta_{T h}\left[1-\eta_{D C}+Q\left(0.8 M+0.2-0.2 \eta_{D C}\right)\right]+\eta_{d} \eta_{D C}[1+0.2 Q]} \\
& =\frac{1}{\eta_{t h} \eta_{d}(1+Q[0.8 M+0.2])} \quad \text { for } \eta_{B D C}=\eta_{D C}=0
\end{aligned}
$$

With no direct coversion we present the recirculating power fraction in a combined way in Fig. 3.2. 


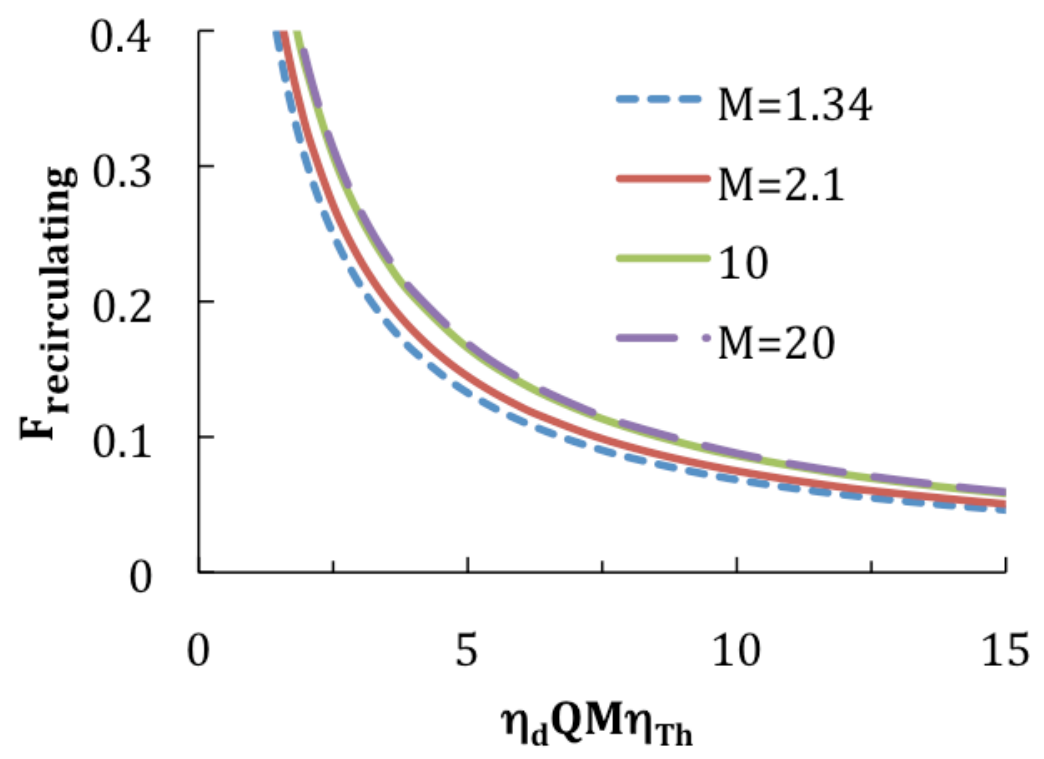

Fig. 3.2. Recirculating power fraction versus $\eta_{d} Q M \eta_{t h}$.

Using the relations we present the recirculating power fraction for two blanket types, $\mathrm{M}=2.1$ and 10 in Fig. 3.3 and 3.4.

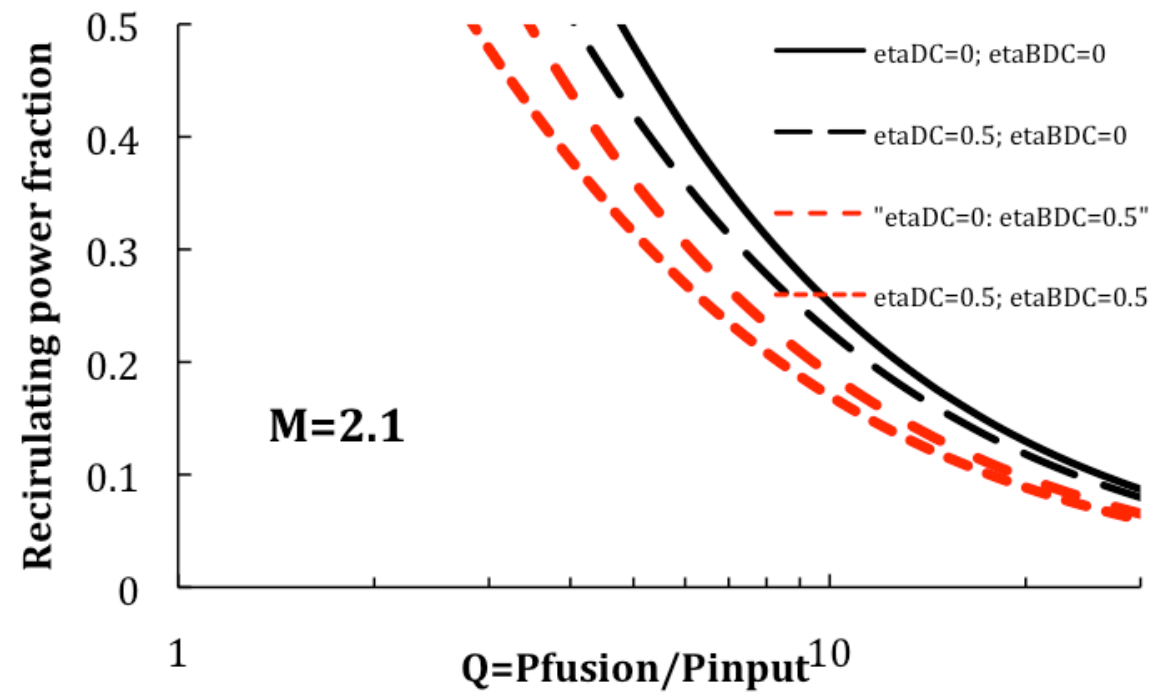

Fig. 3.3. Recirculating power fraction, $M=2.1$. 


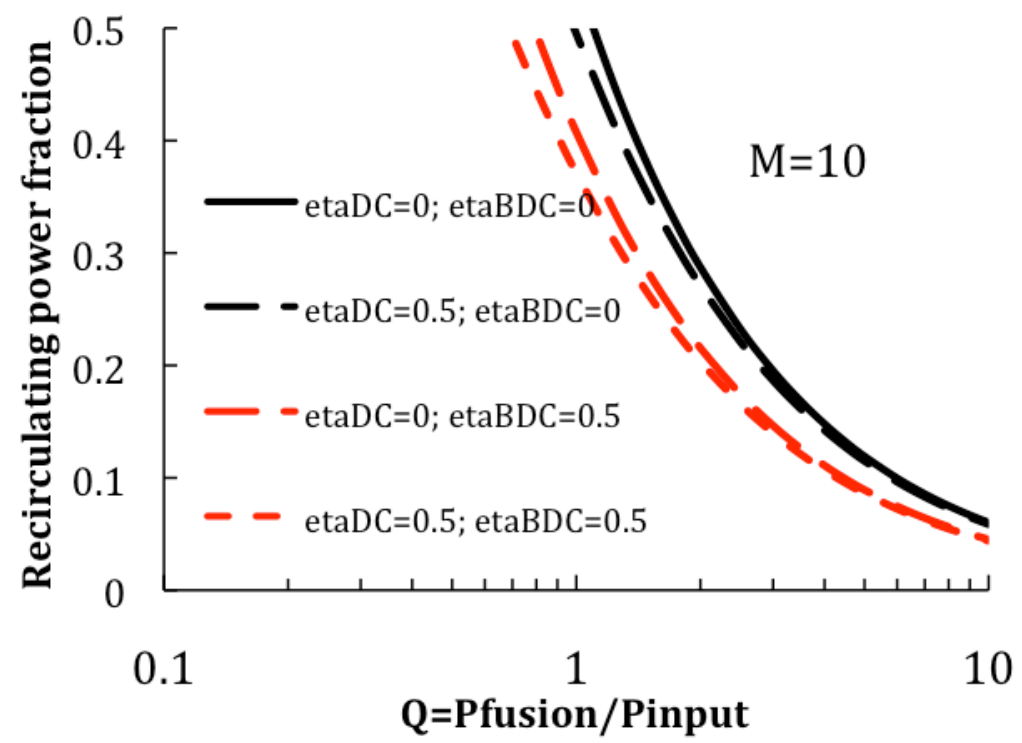

Fig. 3.4. Recirculating power fraction, $M=10$.

The above curve for $\mathrm{M}=2.1$ and $\mathrm{M}=10$ are based on not counting beam recovery as recirculating power because beam direct converters are part of the neutral beam injectors.

Based on the above plots of recirculating power fraction being less than $20 \%$ we get the approximate criterion on $\mathrm{Q}$ required

$\begin{array}{cc}\mathrm{Q}>8.3 ; \mathrm{M}=2.1 & \mathrm{MQ}>17 \\ \mathrm{Q}>2 ; \mathrm{M}=10 & \mathrm{MQ}>20 \\ \text { Without direct conversion } & \\ \mathrm{Q}>13.5 ; \mathrm{M}=2.1 & \mathrm{MQ}>28 \\ \mathrm{Q}>3 ; \mathrm{M}=10 & \mathrm{MQ}>30\end{array}$

For the fission-suppressed fuel producer with $\mathrm{M}=2.1$, plasma and beam direct conversion a required $Q>8$. Without direct conversion the required $Q>14$. 


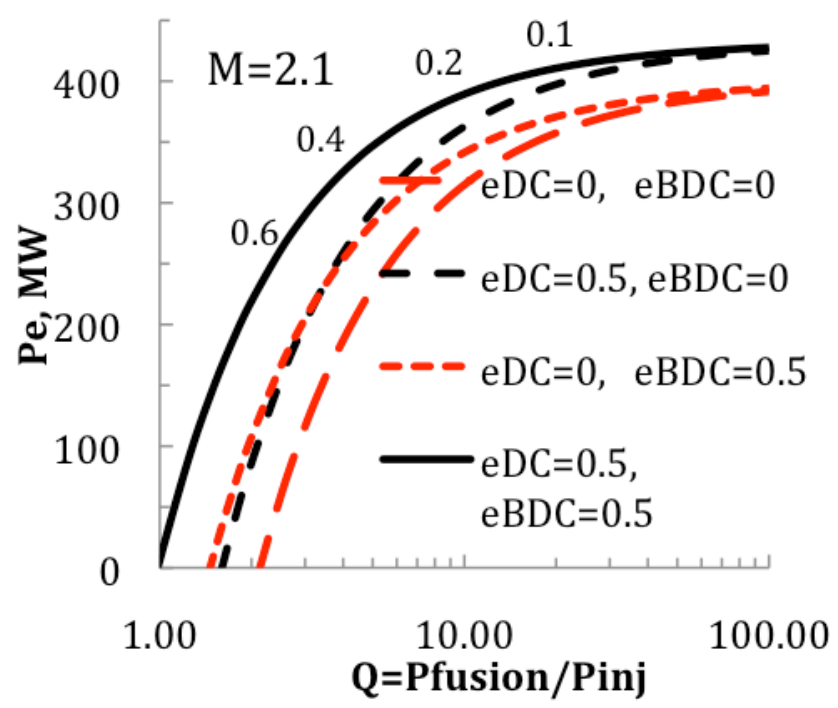

Fig. 3.5. The elecrical power produced for $1000 \mathrm{MWof}$ nuclear power versus $\mathrm{Q}$ for a fission suppressed hybrid. The recirculating power fraction is noted for the solid curve.

For fissioning blankets the required $\mathrm{Q}>2$ and direct conversion is helpful but not necessary.

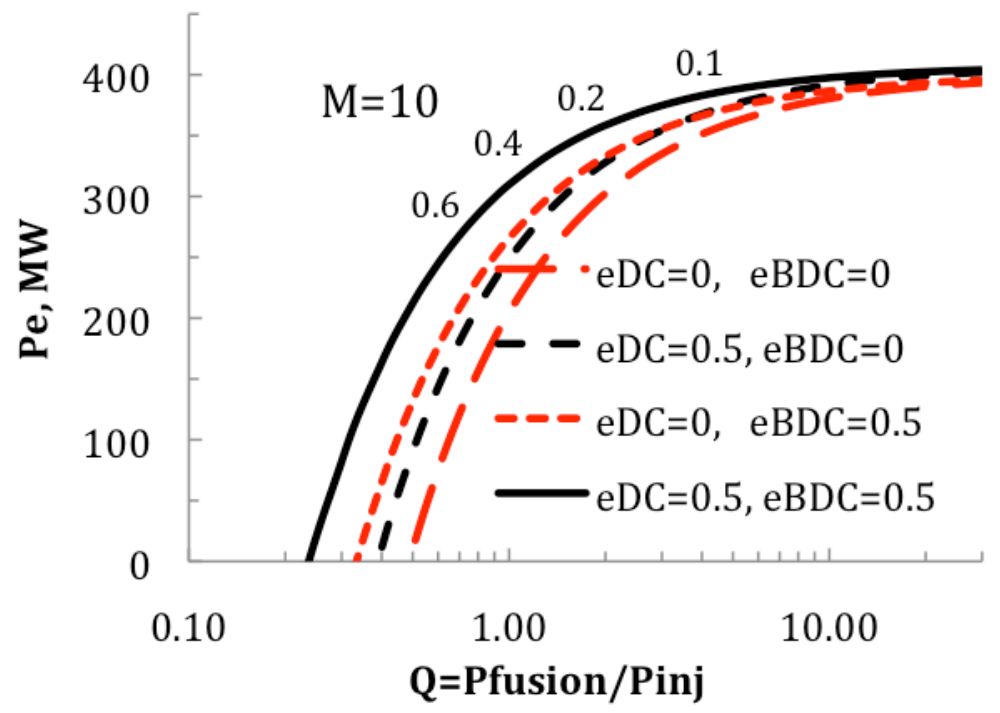

Fig. 3.6. The elecrical power produced for 1000 MWof nuclear power versus $Q$ for a fissioning hybrid.

\subsection{Value of the two products: electricity and fissile material produced or destroyed}

\subsubsection{Electricity value}

We now make estimates of the value of the two products. $\frac{C}{E}=\frac{50 \$}{M W e h}$ typical revenues from the sale of electrical energy at the power plant. The annual revenues from electricity sales would be : 
$=\frac{C}{E} P_{e} \cdot y$

The annual revenues per unit of nuclear power is:

$$
\begin{aligned}
& =\frac{C}{E} \frac{P_{e}}{P_{\text {nuclear }}} \cdot y=\frac{50 \$}{M W e h} \frac{P_{e}}{P_{\text {nuclear }}} 365.25 \times 24 h \times 10^{-6} \frac{M W}{W}=\frac{50 \$}{M W e h} \frac{P_{e}}{P_{\text {nuclear }}} 0.008766 \\
& =\frac{P_{e}}{P_{\text {nuclear }}} 0.4383 \$ / W_{\text {nuclear }} \cdot y
\end{aligned}
$$

This is plotted in Fig. 3.8 and 3.9.

\subsubsection{Fissile material value}

$\mathrm{F}$ is the number of fissile atoms bred per fusion reaction, typically ${ }^{233} \mathrm{U}$ or ${ }^{239} \mathrm{Pu}$. If $\mathrm{F}$ is negative it means the number of atoms burned by fissioning per fusion reaction such as transuranics $(\mathrm{Pu}, \mathrm{Np}, \mathrm{Am}, \mathrm{Cm} . .$.$) or minor actinides (transuranics less \mathrm{Pu}$ ).

$\frac{C}{m}=\frac{50 \$}{g}=$ typical revenues from the sale of fissile material per unit mass.

The value of ${ }^{233} \mathrm{U}$ and ${ }^{239} \mathrm{Pu}$ can be compared to the cost of mined and enriched ${ }^{235} \mathrm{U}$ as shown in Fig. 3.7. 50\$/g of ${ }^{235} \mathrm{U}$ is typical for mined uranium costing $\sim 100 \$ / \mathrm{kg}$.

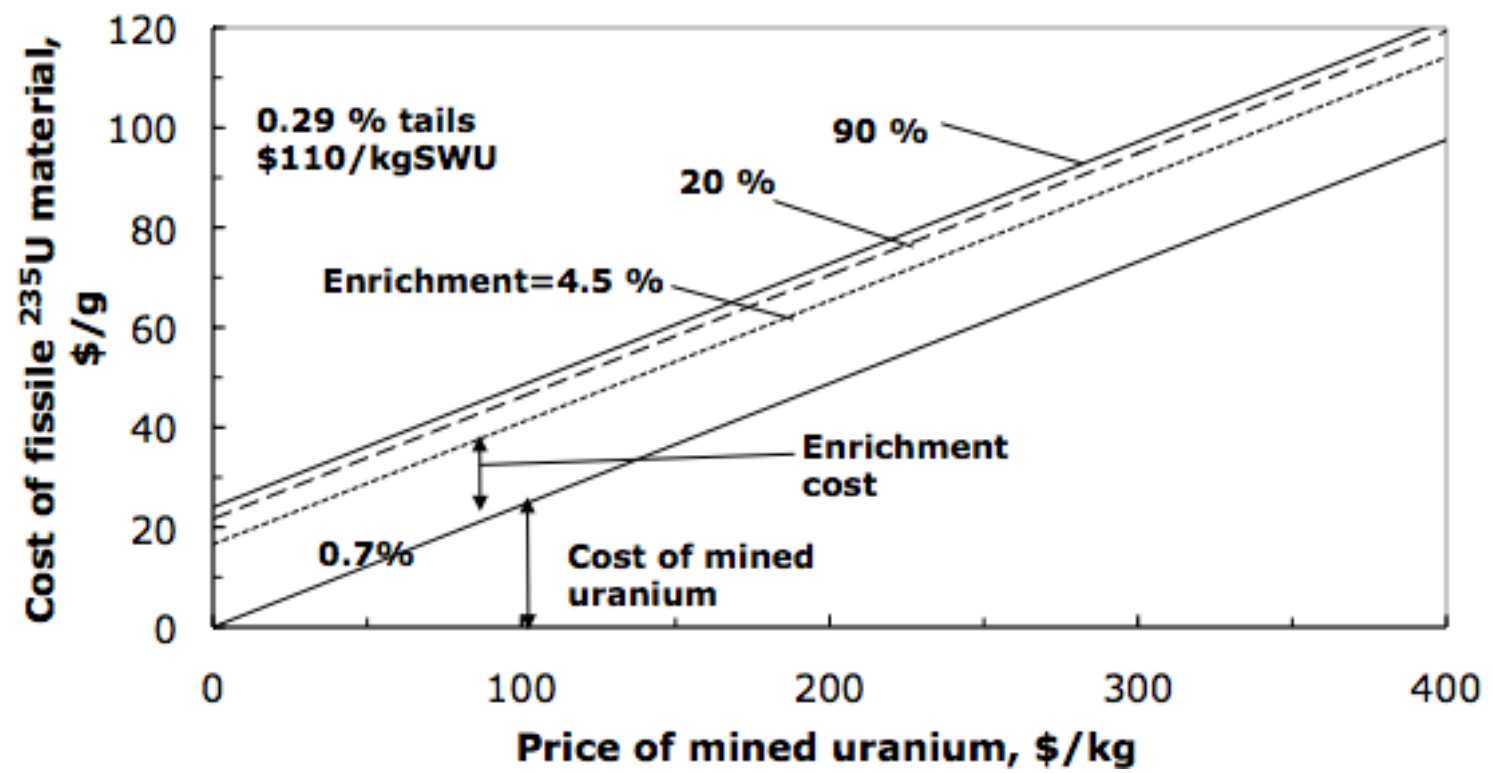

Fig. 3.7. Cost of mined and enriched ${ }^{235} \mathrm{U}$.

The amount of fissile material generated per full power year is: 


$$
\begin{aligned}
& \dot{m}=P_{\text {fusion }} F \frac{1.660554 \times 10^{-27} \mathrm{~kg} / \mathrm{amu} \times 233.0396 \mathrm{amu} \times 3.15576 \times 10^{7} \mathrm{~s} / \mathrm{y}}{(14.06 \mathrm{MeV}+3.52 \mathrm{MeV}) / \text { fusion reaction } \times 1.6021 \times 10^{-19} \mathrm{~J} / \mathrm{eV} \times 10^{6} \mathrm{eV} / \mathrm{MeV}} \\
& \dot{m}=P_{\text {fusion }} F \times 4.3358 \times 10^{-6} \frac{\mathrm{kg}}{\mathrm{W} \cdot \mathrm{y}}
\end{aligned}
$$

$\mathrm{F}$ is the number of fissile atoms per fusion reaction produced or the number of actinides fissioned per fusion reaction.

The revenues from a full power year of operation are:

$$
=P_{e} \frac{C}{E} \frac{8766 h / y}{10^{6} W / M W}+\frac{C}{m} \dot{m}=0.008766 P_{e} \frac{C}{E} M W h / y+0.00434 \frac{C}{m} P_{\text {fusion }} F
$$

For $\mathrm{M}=10, \mathrm{~F}=1.75 \mathrm{Pu}$ atoms, $\mathrm{P}_{\text {fusion }}=122 \mathrm{MW}$ for $\mathrm{P}_{\text {nuclear }}=1000 \mathrm{MW}$. Then the value of fissile material is

$$
=0.00434 \frac{C}{m} \frac{P_{\text {fusion }}}{P_{\text {nuclear }}} F=0.00434 \frac{50 \$}{g} \frac{122}{1000} 1.75=0.046 \$ / W \text { nuclear } \cdot y
$$

We can see in Fig. 3.7 that this level of fissile production is relatively small economically compared to electrical sales.

For burning of actinide wastes, we can calculate a number for $\mathrm{C} / \mathrm{m}$ from the $1 \mathrm{mill} / \mathrm{kWh}$ by law put into the Waste Management Fund that has been used for almost three decades. This number is projected to cover the future cost of Yucca Mt. Waste site if it were put into use, however, to cover unknowns we consider cases of $2 \mathrm{x}$ and $5 \mathrm{X}$ this number. $\mathrm{A}$ typical LWR produces $330 \mathrm{~kg}$ of transuranics wastes per year operating at a capacity factor of $80 \%$. Of this $30 \mathrm{~kg}$ are minor actinides.

$$
\frac{C}{m}=\frac{\frac{10^{-3} \$}{k W e h} \times 8766 h / y \times \frac{10^{6} k W}{G W}}{\frac{330,000 g}{0.8 G W e \cdot y}}=21.1 \$ / g
$$

For our example we use $20 \$ / \mathrm{g}$, twice this, $40 \$ / \mathrm{g}$ and five times this, $100 \$ / \mathrm{g}$ to cover a range for transuranics. If the above cost of $1 \mathrm{mill} / \mathrm{kWh}$ were allocated only to minor actinides then the cost would be $21.1 \$ / g \times 330 / 30=232 \$ / g$.

In Fig. 3.8 we show the fuel sales case for the range of $40 \$ / \mathrm{g}$ and $80 \$ / \mathrm{g}$ for fissile material sold. The value of electricity seems to be dominant, however, the value of fissile material is substantial, while not dominant. In Fig. 3.9 we show the transuranic burning values for 20,40 , and $100 \$ / \mathrm{g}$, and minor actinide values of $2304 / \mathrm{g}$ and twice this of 
$460 \$ / \mathrm{g}$. The value of burning transuranics is negligible, however, the value of burning minor actinides is substantial.

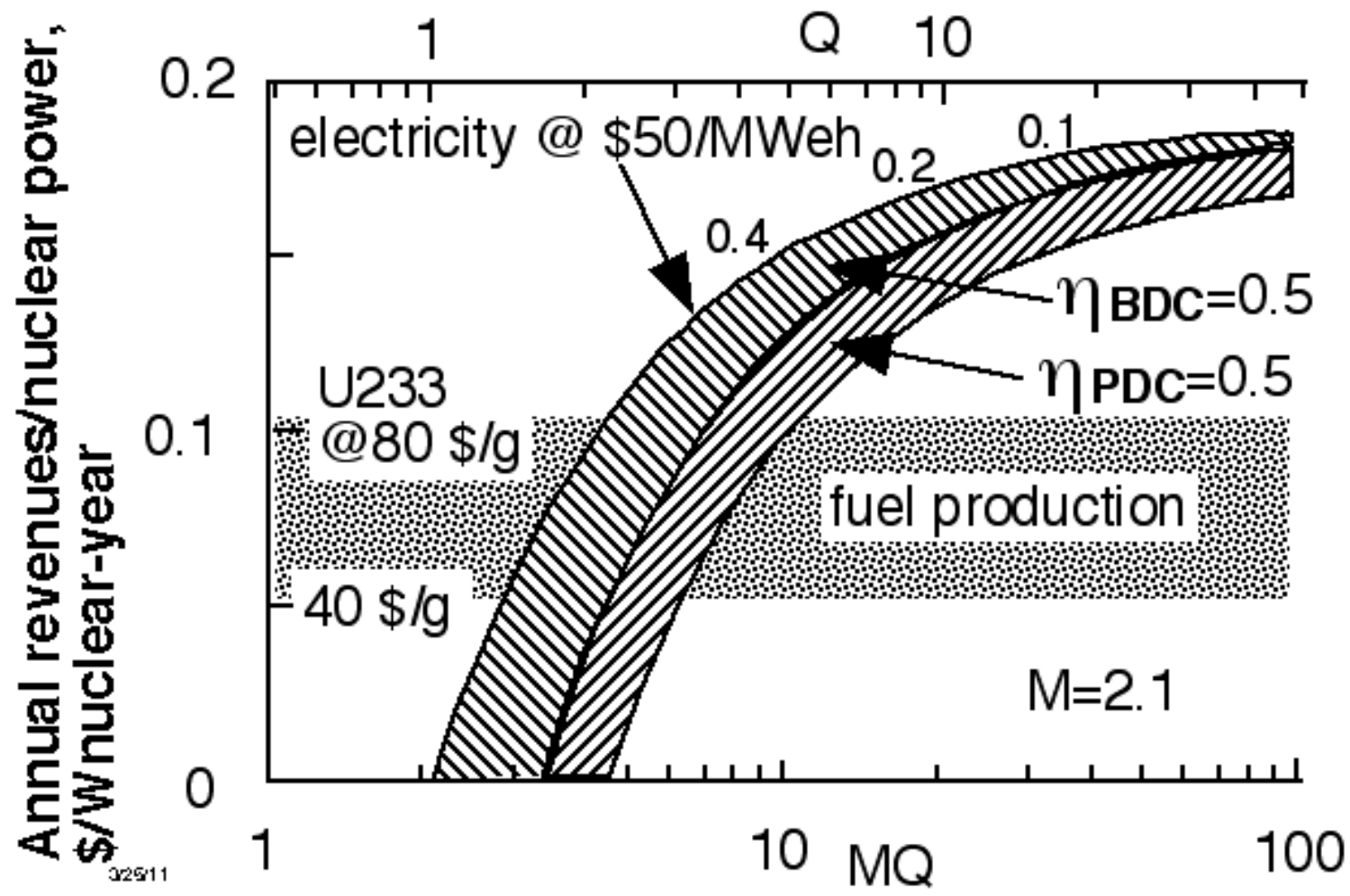

Fig. 3.8. Annual revenues from electrical power and sale of materials produced, $\mathrm{M}=2.1$. 


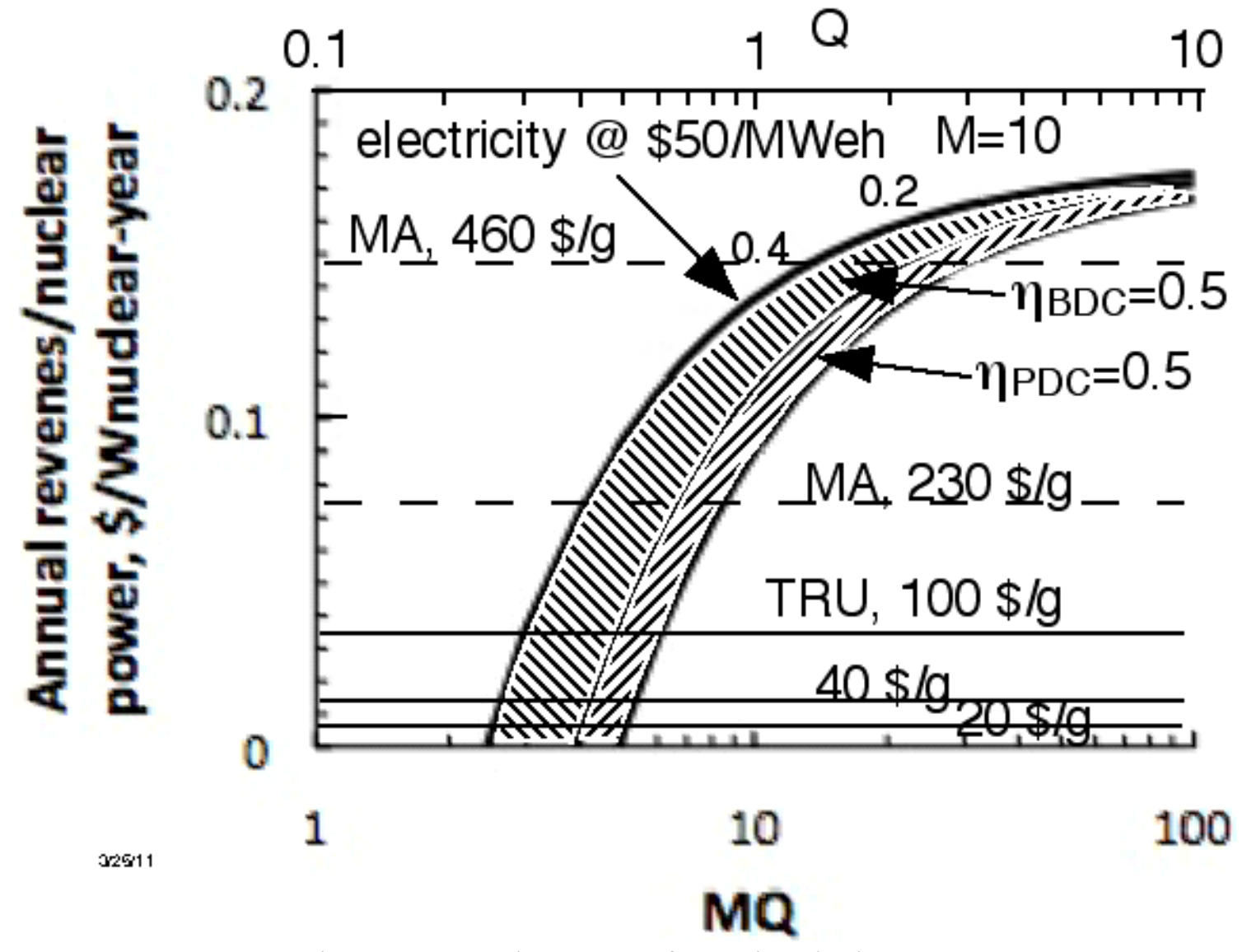

Fig. 3.9. Annual revenues from electrical power and sale of materials produced, $M=10$.

Estimates of the cost of producing ${ }^{233} \mathrm{U}$ versus $\eta_{\mathrm{d}} \mathrm{Q}$ are plotted in Fig. 3.10 Moir 2008). The knee of the curve is about $=1.5$; much above this, the cost is hardly changing and much below the cost rises rapidly. From Fig. 3.8 we get $Q=8$ and $\eta_{d} Q=4$.

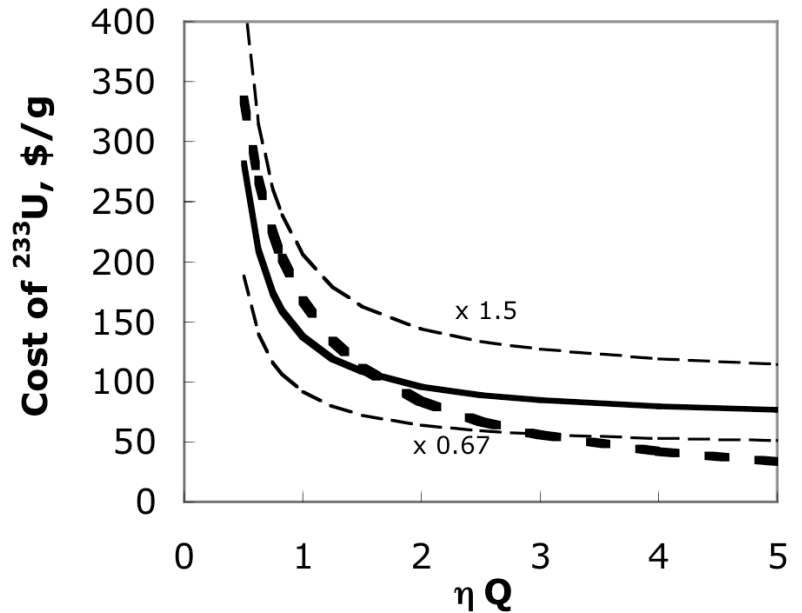

Fig. 3.10. Estimates of cost of ${ }^{233} U$ versus $\eta_{d} Q$. 
Revenues can be estimated at $\$ 50 / \mathrm{MWh}$ and $\$ 50 / \mathrm{g}$ of fissile material generated.

Revenues from fissioning wastes can be estimated based on the $\$ 0.001 / \mathrm{kWh}$ for LWR electricity in spent fuel where there is about $330 \mathrm{~kg}$ of transuranic wastes per GWe•year from a typical LWR. Since, the waste repository project at Yucca Mt. is all but dead, the old number cited above are obsolete and should probably be raised.

\subsection{Summary of $Q$ and other parameters for various blanket options}

In the table below a number of hybrid blankets from the literature are summarized. The values are all for $3000 \mathrm{MW}$ of nuclear power split between fusion power and fission power. The values for $\mathrm{F}$ are denoted as negative to remind ourselves when fissioning rather than breeding is involved. The values of $Q$ in the table are those used in our examples and are in several cases on the low side. That is, higher Q would reduce the amount of recirculating power that as can be seen is rather high and would improve the economics.

Table 3.1

Parameters for fusion power plants for $\mathrm{P}_{\text {nuclear }}=3000 \mathrm{MW}$

\begin{tabular}{|c|l|c|c|c|c|c|c|}
\hline $\begin{array}{c}\text { Case } \\
\#\end{array}$ & M & $\begin{array}{c}\text { F, fissile } \\
\text { atoms } \\
\text { produced }\end{array}$ & Q & $\mathrm{f}_{\text {recirulating }}$ & $\begin{array}{c}\mathrm{P}_{\text {fusion, }} \\
\mathrm{MW}\end{array}$ & $\begin{array}{c}\mathrm{P}_{\text {electric }} \\
\mathrm{MW}\end{array}$ \\
\hline 1 & Pure fusion & 1.34 & 0 & 11 & 0.22 & 2360 & 860 \\
\hline 2 & $\begin{array}{l}\text { Fission- } \\
\text { suppressed } \\
\text { breeder }\end{array}$ & 2.1 & $0.6^{233} \mathrm{U}$ & 8 & 0.21 & 1600 & 890 \\
\hline 3 & LIFE & 10 & 0 & 2 & 0.20 & 370 & 910 \\
\hline 4 & $\begin{array}{l}\text { Fast-fission } \\
\text { breeder }\end{array}$ & 11.7 & $\begin{array}{c}1.75 \\
239\end{array}$ & 1.7 & 0.21 & 315 & 910 \\
\hline 5 & $\begin{array}{l}\text { Transuranic } \\
\text { burner-Na } \\
\text { cooled }\end{array}$ & 18.5 & -1.21 & 1 & 0.22 & 200 & 880 \\
\hline 6 & $\begin{array}{l}\text { Minor } \\
\text { actinide } \\
\text { burner-UT }\end{array}$ & 60 & -4.1 & 0.29 & 0.23 & 62 & 870 \\
\hline 7 & $\begin{array}{l}\text { Transuranic } \\
\text { burner- } \\
\text { molten salt }\end{array}$ & 8.6 & -0.5 & 1.5 & 0.21 & 283 & 900 \\
\hline
\end{tabular}

The cases \#2, through 7 have required Q from 0.9 to 2 and have a fusion power ranging from $62 \mathrm{MW}$ to $370 \mathrm{MW}$. A midrange example is \#5 with $200 \mathrm{MW}$ of fusion power. The injected neutral beam power is $200 \mathrm{MW}$. The power to the injector would be $400 \mathrm{MW}$ at $50 \%$ efficiency with half of the $200 \mathrm{MW}$ of unneutralized beam being recovered to diminish the $400 \mathrm{MW}$ of power supplies to $300 \mathrm{MW}$. Thus the overall injection efficiency is $66 \%$. For a nominal wall loading of neutron power to the first wall of 1 $\mathrm{MW} / \mathrm{m}^{2}$ we need $160 \mathrm{~m}^{2}$ of area. For a first wall radius of $0.5 \mathrm{~m}$, the length would be 51 
m. This example is for a large plant of $3000 \mathrm{MW}$ of nuclear power. For smaller powers the numbers can be scaled downward.

\section{Hybrid Blanket Designs: actinide burner, fuel producer and power producer}

There are three types of hybrids: waste burners, fuel producers and power producers (Lidsky, 1975). The blanket can be designed to emphasis any one of the three processes, although all three take place. The goal of waste burners is to reduce the burden placed on geologic disposal of fission wastes by fissioning the long-lived actinides turning them into shorter lived fission products. The goal of fuel producers is to obtain most of the power from fission reactors sustained by makeup fuel from the hybrid. The competition is mined and enriched uranium and fission breeders. Power producers are designed to maximize fissioning and compete directly with fission reactors. The idea is to avoid or minimize mining, enrichment and processing.

\subsection{Blanket designs for fuel production}

A hybrid reactor blanket contains a neutron multipliers, lithium to breed tritium, and a "fertile" material ${ }^{238} \mathrm{U}$ or ${ }^{232} \mathrm{Th}$. A neutron absorption in ${ }^{238} \mathrm{U}$ can result in formation of "fissile" ${ }^{239} \mathrm{Pu}$ via the reactions

$n+{ }^{238} U \rightarrow{ }^{239} U-\underset{24 \min }{-\beta^{-}}->^{239} N p-\frac{\beta^{-}}{2.4 d}->^{239} P u \quad\left[\quad 238 U\left(n, \gamma+2 \beta^{-}\right)^{239} P u\right]$

where the symbols $(n, \gamma)$ mean that a neutron is absorbed and a gamma ray is emitted; $\beta^{-}$ indicates beta decay (electron emission), and the 24 minutes and 2.4 days are the halflives of the beta decays. The brackets show the condensed notation for this reaction. Thus, neutron absorption in ${ }^{238} \mathrm{U}$ produces ${ }^{239} \mathrm{Pu}$, which is a "fissile" fuel (meaning that it can be fissioned by low-energy neutrons). ${ }^{238} \mathrm{U}$ is called "fertile", because neutron absorption in it can breed fissile fuel.

Similarly, fertile ${ }^{232} \mathrm{Th}$ can breed fissile ${ }^{233} \mathrm{U}$ by the reactions

$$
n+{ }^{232} \mathrm{Th} \rightarrow{ }^{233} \mathrm{Th}-\underset{22 \min }{-\beta^{-}}->^{233} \mathrm{~Pa}-\frac{\beta^{-}}{27 d}->^{233} U \quad\left[\quad\left[232 \mathrm{Th}\left(n, \gamma+2 \beta^{-}\right)^{233} U\right]\right.
$$

Although the amount of ${ }^{235} \mathrm{U}$ available is limited, the reserves of the fertile isotopes ${ }^{238} \mathrm{U}$ and ${ }^{232}$ Th are vast. A sources of neutrons is needed to produce breeding.

Why consider hybrid fusion rather than fast fission breeders, which also convert fertile to fissile material? Fast fission breeders, such as Super Phoenix and the Integral Fast 
Reactor (IFR) are available now; hybrid fusion is still in the future. The answer is that hybrid fusion is a much more prolific source of nuclear fuel than fast breeders. It typically takes 2 IFR's to provide fuel for a light water reactor (LWR) of equal power [Chang, 2002; Chang, 2009]. But one fusion reactor can provide fuel for 10 LWR's of equal power, a factor of 20 increase over fission breeders. Furthermore, a 1 GWe IFR needs over 10 tons of fissile material to start up, and an LWR needs about 4 tons, [Garwin and Charpak, 2001], but a fusion breeder needs none.

A source of ${ }^{233} \mathrm{U}$ could enable fission reactors designed to operate with slow or thermal neutrons with thorium to be breeders or near breeders and having lower fissile inventories than even LWRs. Some designs require a fissile inventory of as little as $1000 \mathrm{~kg} / \mathrm{GWe}$ and once started up are self-sufficient or nearly so.

A fusion reactor needs $Q>10$ to be economical, but a fusion-fission hybrid may be economical with $\mathrm{Q} \sim 1$ or somewhat higher. The lower $\mathrm{Q}$ permits operation with shorter confinement times, which may relax the required values of some of the following parameters: plasma size, magnetic field, neutral beam injection energy, and energy conversion efficiency.

Axisymmetric mirrors can serve as a driver for modest- $Q$ version of hybrid systems for actinide burning. The schemes that provide MHD stability for axisymmetric mirrors are not limited to the stabilization by the outflowing plasma, Gas Dynamic Trap (GDT)-style. They include also other approaches that may be better suited to systems with a better axial confinement than GDT. Combined with a simple mirror (not using tandem mirror end plugs) they can become a basis for a mirror facility with $\mathrm{Q} \sim 1$ which, due to its simple geometry, easy access to the plasma and flexible dimensions can serve as a driver for hybrid systems.

\subsubsection{Choice of making ${ }^{233} \mathrm{U}$ or ${ }^{239} \mathrm{Pu}$}

With extra neutrons from fusion we can produce either ${ }^{233} \mathrm{U}$ or ${ }^{239} \mathrm{Pu}$. There are arguments pro and con for each. Plutonium is produced in LWRs and some separated plutonium is mixed with enriched uranium called MOX (mixed uranium and plutonium oxide fuel) and used to fuel other LWRs. Plutonium is also used in a number of fast reactor demonstrations projects. ${ }^{239} \mathrm{Pu}$ is desirable for weapons use. ${ }^{233} \mathrm{U}$ is not used in any reactors today but has been used in the Shippingport Light Water Breeder Reactor and in the Molten Salt Reactor Experiment. The required fissile inventory in thermal reactors is almost an order of magnitude lower than for ${ }^{239} \mathrm{Pu}$ in fast reactors. ${ }^{233} \mathrm{U}$ is not used for military purposes today because of the strong gamma emitter ${ }^{232} \mathrm{U}$, and ${ }^{239} \mathrm{Pu}$ can be obtained from reactors using natural or enriched uranium. We use as our example for $\mathrm{Q}>4,{ }^{233} \mathrm{U}$, which might encourage introduction of reactors on the thorium cycle and help phase out use of $\mathrm{Pu}$. However, our emphasis is on the axisymmetric mirror and its simplicity as a neutron source and should ${ }^{239} \mathrm{Pu}$ be wanted, the axisymmetric mirror could provide it and for $\mathrm{Q} \sim 1,{ }^{239} \mathrm{Pu}$ is preferred because of its high energy-multiplication that comes along with the fast-fission neutron multiplication reaction on ${ }^{238} \mathrm{U}$. 


\subsubsection{Proliferation considerations and the role of ${ }^{232} \mathrm{U}$}

Producing ${ }^{233} \mathrm{U}$ from thorium has both proliferation advantages and concerns. ${ }^{232} \mathrm{U}$ that inevitably accompanies ${ }^{233} \mathrm{U}$ production makes the material undesirable but not impossible for use in fission weapons. Fusion is unique compared to fission in its role of making ${ }^{233} \mathrm{U}$. Fusion's $14 \mathrm{MeV}$ neutron, being well above the threshold for making ${ }^{232} \mathrm{U}$, can enhance the ${ }^{232} \mathrm{U} /{ }^{233} \mathrm{U}$ ratio from its usual value of $\sim 0.1 \%$ to $>>1 \%$. This enhances the generation of both $2.6 \mathrm{MeV}$ gamma rays and decay heat that facilitates detection of stolen material and makes for weapon design problems.

\subsection{Molten-Salt Blanket Designs-Fission-suppressed fusion breeder}

Molten salt blankets have several advantages (Lidsky, 1969; Mills, 1974; and Blinkin and Novikov, 1977). Lee (1978a) suggests the use of beryllium to maximize fuel production. His idea is to flow a thorium and lithium-bearing molten salt over beryllium rods. The beryllium multiplies the fast $(14 \mathrm{MeV})$ neutron, and the thorium and lithium capture the neutrons, producing ${ }^{233} \mathrm{U}$ and $\mathrm{T}$. The total breeding is estimated by Lee to be 1 atom of $\mathrm{T}$ after all the losses and 0.6 of ${ }^{233} \mathrm{U}$ and the energy multiplication is 1.6 for engineered blankets. Later studies by Moir (2010) show that in steady state the fission process raises the energy multiplication of the $14 \mathrm{MeV}$ neutrons to 2.1 . The salt is continuously processed to remove bred fuel and some fission products. The radioactive inventory of the blanket is consequently much less than in the other blanket designs. Additionally, the fission product afterheat is low, so a loss of cooling is much less of an issue than for the other designs. Fast fission is suppressed by using beryllium to multiply and rapidly moderate energetic neutrons, and thermal fission is suppressed by processing to remove the fissile material before it has a chance to build up and fission. The performance is less, both in breeding (1.6 atoms versus 2.8 atoms) and in energy multiplication (1.6 compared to 10) compared to the fast-fission blankets. The goal is to provide fuel to a large number of fission reactors, where their energy release in effect multiplies fusion's energy by over an order of magnitude. The fissionsuppressed design with low energy release per reaction allows many more breeding reactions and hence far more fissile atoms produced than for a fast-fission reactor with the same power.

The molten-salt concept is a low-pressure system with a lower structural fraction than the liquid-metal case, but it has several problems. The thorium and uranium bearing molten salt react chemically with beryllium, so the beryllium had to be clad. Beryllium is the most prolific non-fissioning neutron multiplier, but it can swell up to $30 \mathrm{vol} \%$. The use of Be pebbles up to $\sim 10 \mathrm{~mm}$ diameter allows for this swelling and facilitates their removal for inspection, remanufacturing, and reuse.

In one design the molten salt was slowly circulated in steel tubes that prevented contact with beryllium and hence prevented chemical attack. Helium cooled both the beryllium pebbles and the tubes with molten salt inside. 
Fig. 4.1 shows a blanket designed both for a tandem mirror (Moir et al., 1984a, 1985) and a tokamak (Moir et al., 1984b) with pebbles and helium cooling.

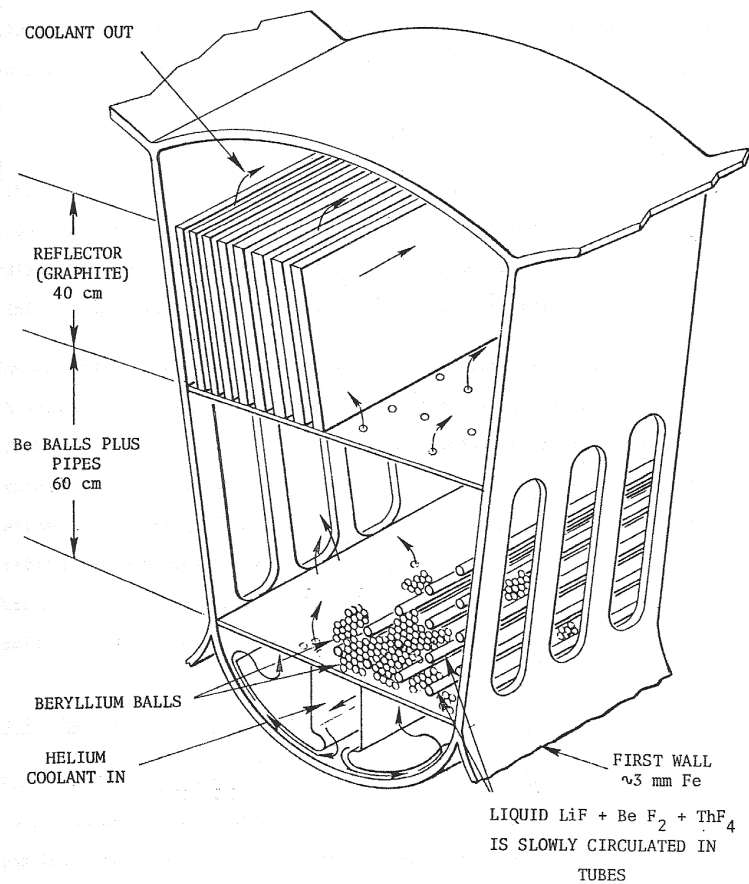

(a)

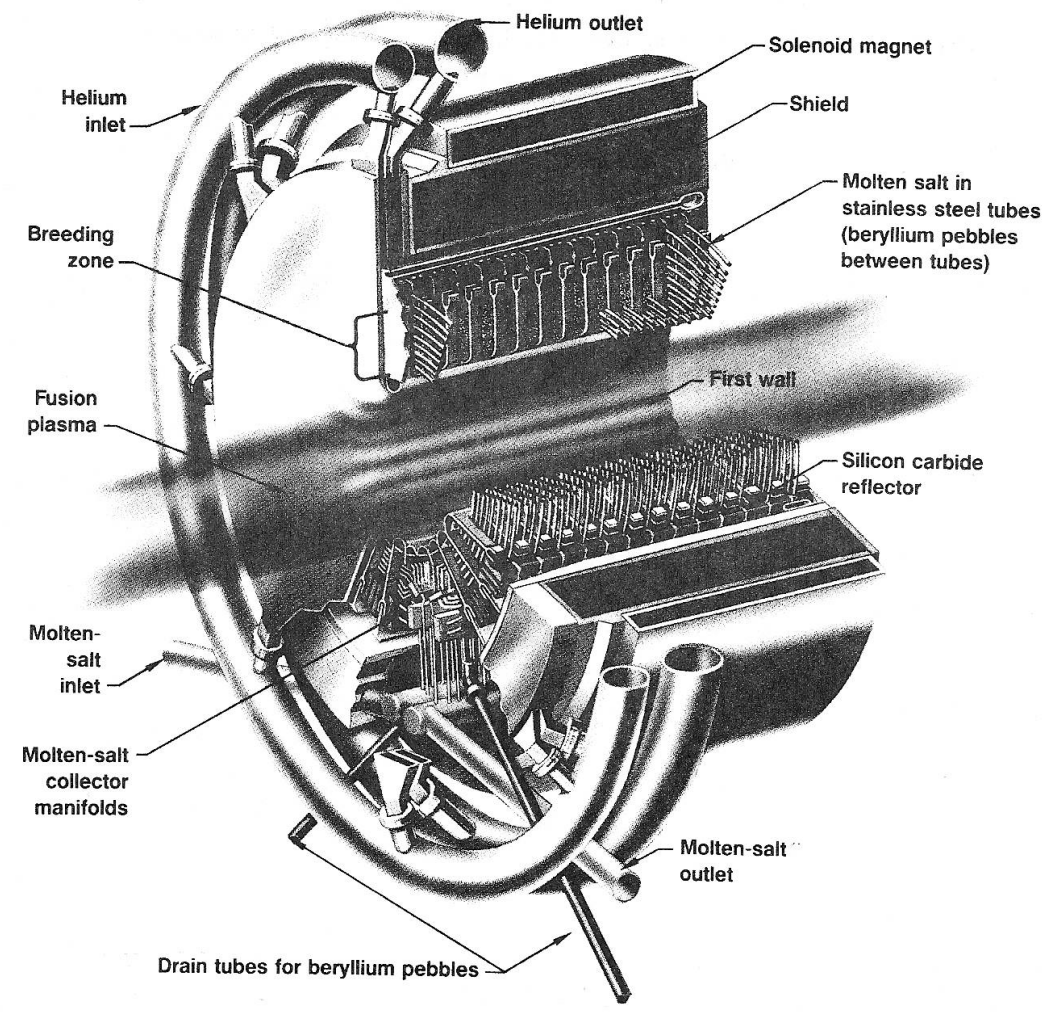

(b)

Figure 4.1. Fission-suppressed blanket based on beryllium pebbles, showing the sub-module (a) and the module (b). 
The thorium is slowly circulated through the blanket in the form of molten salt and processed at a slow rate to remove the bred ${ }^{233} \mathrm{U}$ along with the spikant ${ }^{232} \mathrm{U}$. Helium cooling has the advantage of not slowing the neutrons before they are multiplied by beryllium.

Typical parameters are given in Table 4.1.

Table 4.1. Be/molten salt blanket parameters.

\begin{tabular}{|c|c|c|}
\hline & Beginning & $\begin{array}{l}\text { Steady } \\
\text { state }\end{array}$ \\
\hline $\mathrm{P}_{\text {nuclear }}, \mathrm{MW}$ & 4440 & 5640 \\
\hline $\mathrm{P}_{\text {fusion}}, \mathrm{MW}$ & 3000 & 3000 \\
\hline $\mathrm{P}_{\text {alpha particle, }} \mathrm{MW}$ & 600 & 600 \\
\hline $\mathrm{P}_{\text {blanket }}, \mathrm{MW}$ & 3840 & 5040 \\
\hline $\mathrm{P}_{\text {electric }}, \mathrm{MW}$ & 1380 & 1860 \\
\hline $\mathrm{P}_{\text {wall load }}$ & $2 \mathrm{MW} / \mathrm{m}^{2}$ & \\
\hline Length of blanket & $127 \mathrm{~m}$ & \\
\hline First wall radius & $1.5 \mathrm{~m}$ & \\
\hline $\mathrm{T}$ & 1.1 & \\
\hline$F_{n e t}^{*}$ & 0.6 & \\
\hline $\mathrm{M}^{*}$ & 1.6 & 2.1 \\
\hline Fissile production & $\begin{array}{l}6380 \mathrm{~kg}{ }^{233} \mathrm{U} / \mathrm{yr} \text { at } \\
80 \% \text { capacity factor }\end{array}$ & \\
\hline Total cost & \$4870 M (1982\$) & \\
\hline
\end{tabular}

${ }^{*}$ Fnet is the fissile atoms bred/triton consumed. $\mathrm{M}$ is the energy released in the blanket per triton consumed divided by $14 \mathrm{MeV}$. More recent studies gives $\mathrm{M}=2.1$ as mentioned above.

The total cost includes the balance of plant but not the satellite LWRs.

Based on Fig. 3.8 the required Q is 8 for $20 \%$ recirculating power and Q $>4$ for $40 \%$ that might be appropriate when considering the value of fuel sales as discussed in chapter 3 .

\subsection{Fission-suppressed blanket based on liquid lithium multiplier}

Another blanket used ${ }^{7} \mathrm{Li}$ as a neutron multiplier to avoid feasibility issues associated with the use of beryllium (Lee et al., 1982). The configuration is shown in Fig. 4.2. 


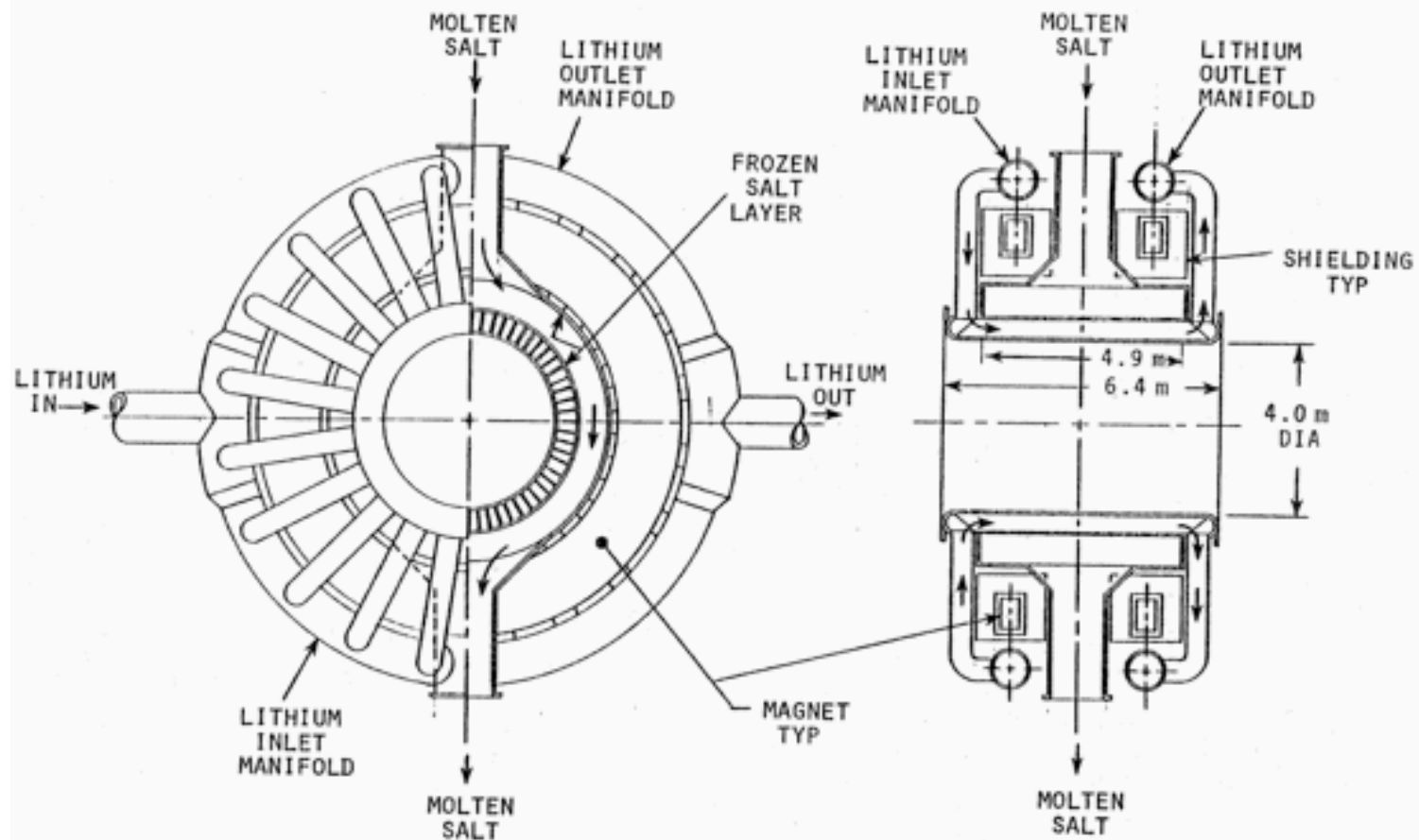

Figure 4.2. Two zone lithium neutron multiplier blanket with a molten salt second zone for the breeding media.

A $0.5 \mathrm{~m}$ thick first zone is flowing ${ }^{7} \mathrm{Li}$ followed by a molten salt zone. The breeding per unit of nuclear power was $20 \%$ less than for the previous one-region beryllium design (Table 4.1), due partly to heterogeneous effects of the 2 zones and partly due to the poorer neutron multiplication characteristics of ${ }^{7} \mathrm{Li}$. Steel was used as the structural material. Corrosion is greatly retarded by maintaining a frozen layer of salt on the steel, but calculations indicate that the steel could last many years even without this protective layer. Hastelloy might also be used with several years of service before radiation damage effects required its replacement. The piping and heat exchanger are made out of Hastelloy. The MHD pressure drop of the flowing lithium was found to be manageable ( $\sim 0.7 \mathrm{MPa}$ drop from the inlet to blanket) due to the low magnetic field $(\sim 3 \mathrm{~T})$.

The ${ }^{233} \mathrm{U}$ produced by this blanket, containing the strong gamma emitting ${ }^{232} \mathrm{U}$, could be used to fuel fission reactors without the isotope enrichment needed for ${ }^{235} \mathrm{U}$. Reactors specially designed to burn separated wastes (such as actinides) from other reactors might also use this ${ }^{233} \mathrm{U}$ to compensate for their reactivity loss due to the waste products.

By this means fission reactors can do the "heavy lifting" of making power and burning wastes, and fusion reactors can do what it does best: breeding fissile material with its energetic neutrons and with fissioning suppressed in its blanket (except for neutron multiplication). The ideas further evolved with examples using liquid lithium as a neutron multiplier (Berwald et al, 1982), and versions with $\mathrm{Pb}$ were studied at the University of Wisconsin (Badger et al., 1975).

Any of the tokamak or inertial fusion blanket designs can also be used on the mirror even more simply owing to the modularity allowed by the long cylindrical geometry as long as 
the neutron wall load is similar. Each module will have associated with it a first wall $(<10$ $\mathrm{mm}$ ), a vacuum seal, a tritium breeding region, an actinide-burning region, a superconducting magnet and heat transfer coolant lines. Like other fusion concepts the first wall must be cooled, however, most of the non-neutron power escapes out the end where the power density on the wall can be reduced as much as necessary so the first wall heat load is lower than in toroidal systems. The lack of disruptions means a thinner first wall that aids better neutron economy.

Operating the actinide burner at $\mathrm{Q} \sim 1$ and still keeping recirculating power low-enough (not to damage economics) may be achieved by developing and employing direct conversion of unneutralized beams to raise the injection efficiency to about $70 \%$ (Moir, 198?). Also developing and deploying direct conversion of end leakage can result in about $50 \%$ or somewhat more efficient conversion of the charged power and this power can be used to supply power to the neutral beam injectors (Barr, 1983).

In the 1970s the magnetic mirror program was seeing success in the laboratory and planning to build a large new facility called MFTF. This was a yin-yang magnet based machine whose prospects owing to end losses was for a $Q$ value of about unity. There was an effort to look to the hybrid to see if that application could aid commercializing the technology. Putting uranium around such a neutron source would multiply the fusion energy by about a factor of ten and this added energy was enough to largely overcome the high amount of recirculating power needed to power the injectors that sustained the fusion plasma. The uranium multiplied neutrons from fusion resulting in the breeding of plutonium along with the energy gain from fissioning. This extra fuel breeding could be in effect sold as fuel for client fission reactors. This hybrid had two revenue streams, electrical power and sales of fissile material. The combination appeared to make the low Q mirror technology a candidate for a commercial success. Safety of course was a design concern because of the large amount of fissioning going on. Cooling the blanket under all conditions to avoid a melt down was a major design problem. The designs were not passively safe. A number of conditions such as loss of power to circulator pumps (loss of cooling), broken pipes with loss of coolant were serious accidents to be avoided with assurance of high probability. Risk assessments were carried out, made more important after notorious reactor accidents.

When the tandem mirror ideas came along, the Q values being envisioned were increased by more than an order of magnitude. The recirculating power was low enough as to not preclude a commercial product as a pure fusion power plant. However, because of high estimated cost of the plant, the estimated cost of electrical power was much higher (typically double or more) that of fission power plants. The idea of the hybrid then was to increase revenues. Fuel could be produced by extra neutrons that were made by nuclear reactions other than fission such as beryllium neutron multiplication. These hybrids were called fission-suppressed fusion breeders, studied extensively in the early 1980s. The power production under abnormal conditions called decay heat was typically less by an order of magnitude than from the fast fission hybrids and importantly the power density was further diluted by the beryllium. Safety was enhanced by passive cooling systems. 
Now almost 30 years later we are relooking at tandem mirrors but with a more cautious view of performance that can be expected and low Q being $(\sim 1)$ almost assured, So we are motivated to look at energy multiplying hybrids again. This means a strong emphasis on safety we re-emerge. Another application is burning unwanted fission wastes by fissioning in the fusion hybrid. This application we multiply fusion's energy and might improve economics but has this safety issue to be delt with.

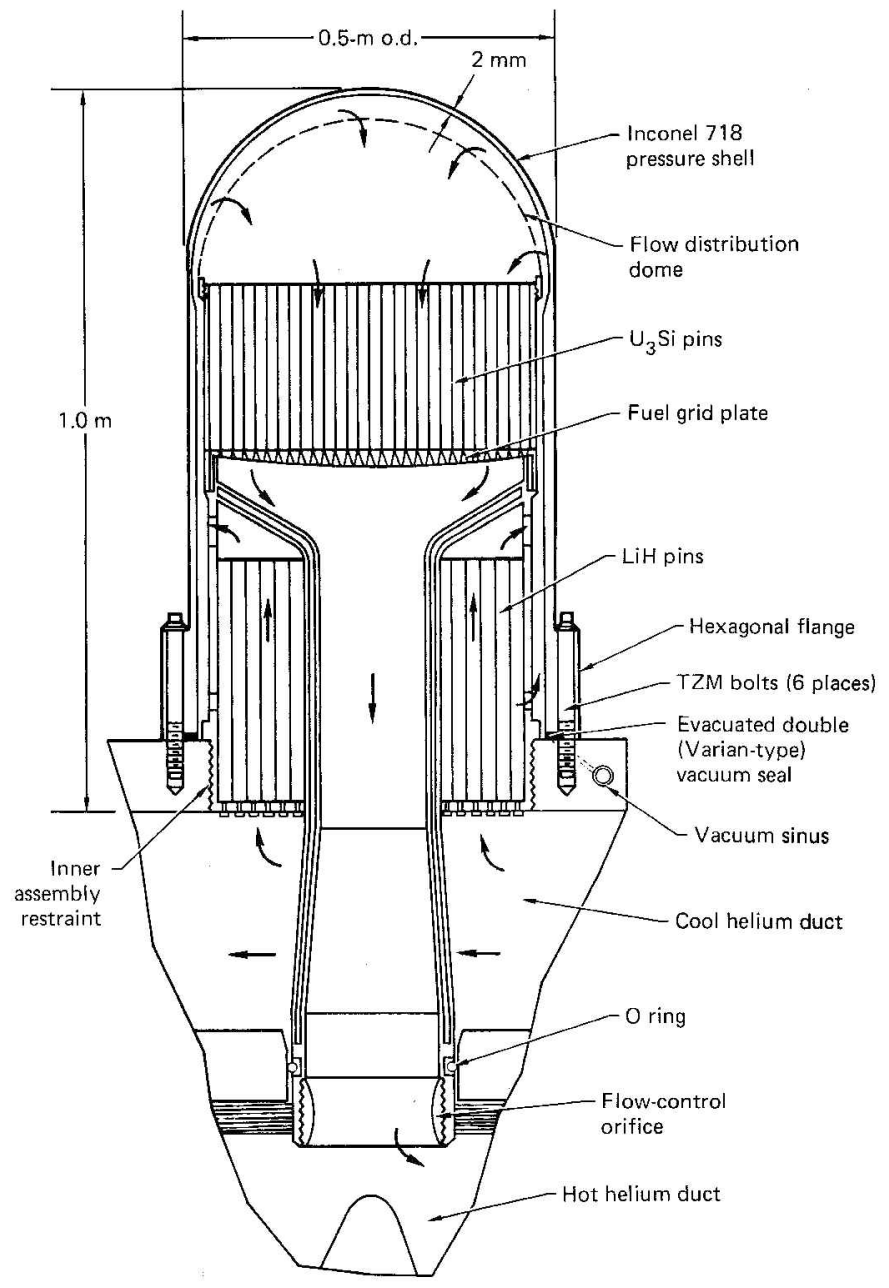

Figure 4.3. Blanket module based on pressure-cylinder concept. 
Table 4.2.

Fast-fission blanket parameters ( $\mathrm{U}_{3} \mathrm{Si}$ fuel).

\begin{tabular}{ll}
\hline$P_{\text {wall load }}$ & $3.3 \mathrm{MW} / \mathrm{m}^{2}$ \\
Exposure & $1.68 \mathrm{MW}-\mathrm{y} / \mathrm{m}^{2}$ \\
$\mathrm{Pu} / \mathrm{U}$ at discharge & 0.023 \\
$\mathrm{~T}^{*}$ & 1.17 \\
$\mathrm{~F}^{*}$ & $1.75^{239} \mathrm{Pu}$ \\
$\mathrm{M}^{*}$ & 11.7 \\
${ }^{*}$ Time averaged &
\end{tabular}

The $\mathrm{Q}$ required from a recirculation criterion of 0.2 is 2 .

\subsection{Blanket designs for waste incineration}

Some hybrids emphasize burning actinides left fission reactor spent fuel. The blanket can be kept subcritical at all times, in contrast to a fast fission reactor, where reactivity control is a safety issue. The harder neutron spectra from a $14 \mathrm{MeV}$ neutron source is also an advantage. Actinide wastes could be processed out of spent fuel and then be put in a fusion blanket in suitable form for incineration (fissioning). The revenues would come from both electrical power sales and waste disposal. It is desirable to estimate how many actinide atoms can be fissioned per fusion neutron.

Let $\mathrm{M}$ be the blanket energy gain for each $14 \mathrm{MeV}$ neutron entering the blanket and $\mathrm{F}$, the number of atoms fissioned for each $14 \mathrm{MeV}$ neutron. Since the neutron power is $0.8 \mathrm{P}_{\text {fusion, }}$,

$$
P_{\text {th }}=P_{\text {fusion }} \times 0.8 M+0.2 P_{\text {fusion }} \quad M=\frac{P_{\text {th }}-0.2 P_{\text {fusion }}}{0.8 P_{\text {fusion }}}
$$

A pure fusion reaction idealized is shown below:

$$
P_{t h}=14.06^{n} \mathrm{MeV}+3.52 \mathrm{\alpha} \mathrm{MeV}+4.79{ }^{6} \mathrm{Li(n, \alpha )T} \mathrm{MeV}=22.37 \mathrm{MeV}
$$

In this pure fusion case

$$
M=\frac{22.37 \mathrm{MeV}-3.52 \mathrm{MeV}}{14.06 \mathrm{MeV}}=1.34
$$

When burning wastes by fission, $\mathrm{F}$ atoms fissioned per fusion event releases $\mathrm{F} \times 200 \mathrm{MeV}$. Then: 
$P_{\text {th }}=P_{\text {fusion }} \times(0.8 \mathrm{M}+0.2)=14.06 \mathrm{MeV}+3.52 \mathrm{MeV}+4.79 \mathrm{MeV}+F \times 200 \mathrm{MeV}$

$(14.06 \mathrm{MeV}+3.52 \mathrm{MeV}) \times(0.8 \mathrm{M}+0.2)=14.06 \mathrm{MeV}+3.52 \mathrm{MeV}+4.79 \mathrm{MeV}+F \times 200 \mathrm{MeV}$

Solving for F, we get:

$F=\frac{14.06 \mathrm{MeV} \times M-18.85 \mathrm{MeV}}{200 \mathrm{MeV}}$

Let $\varepsilon=$ ratio of the number of source neutrons per each fusion event to the number of fission produced neutrons.

$\varepsilon=\frac{1}{F v}$

where $v=$ number of neutrons released per fission. The parameter $\varepsilon$ is a figure of merit of how important fusion's neutrons are compared to those from fission. For a very weak fusion neutron source, $\varepsilon$ small, the fission assembly will have to be near critical and $\mathrm{F}$ will be large. As $\varepsilon$ grows the importance of fusion's neutrons is enhanced. Another figure of merit might be the number of fission reactors whose wastes are disposed of by one waste-burning fission reactor of the same nuclear power. The ultimate figure of merit is decided by the market place, which decides what option to favor.

\subsubsection{Hard spectrum sodium-cooled, minor-actinide burner (University of Texas)}

The University of Texas waste burner (Kotschenreuther, Valanju, Mahajan, Schneider 2009) - a driven copper tokamak - takes wastes that come from an LWR and first burns $75 \%$ of the transuranics in one pass through another LWR. The $25 \%$ remaining then goes to the fusion waste burner blanket. This blanket has a $25 \mathrm{~cm}$ thick zone around the outside of the tokamak toroidal magnet coils, cooled by liquid sodium. The input power to sustain the plasma is $50 \mathrm{MW}$ (which might consume $100 \mathrm{MWe}$ at $50 \%$ efficiency) and there is more power for the magnets. For $3000 \mathrm{MW}$ total thermal power, the fusion power varies from 100 MW dropping to $25 \mathrm{MW}$ after $15 \%$ of the transuranics fed are fissioned and rises to $100 \mathrm{MW}$ after $50 \%$ of the transuranics have been burned. The discharged fuel is then processed and fed back for another burn cycle repeatedly until less than $1 \%$ of the remaining original transuranics remain. The $14 \mathrm{MeV}$ fusion neutrons are multiplied in a lead region where they produce 0.6 extra neutrons (one being used to breed tritium).

The blanket energy is produced primarily by fission reactions. The fusion neutron power ( $80 \%$ of the fusion power) is multiplied by fission and other reactions. This multiplication, $\mathrm{M}$, varies from 38 to 150 during the burn time. 


$$
\begin{aligned}
& M=\frac{P_{\text {th }}-0.2 P_{\text {fusion }}}{0.8 P_{\text {fusion }}}=\frac{3000 \mathrm{MW}-0.2 \times 100 \mathrm{MW}}{0.8 \times 100 \mathrm{MW}}=38 \\
& M=\frac{P_{\text {th }}-0.2 P_{\text {fusion }}}{0.8 P_{\text {fusion }}}=\frac{3000 \mathrm{MW}-0.2 \times 25 \mathrm{MW}}{0.8 \times 25 \mathrm{MW}}=150
\end{aligned}
$$

and $\mathrm{F}$ varies as follows for two typical operating point during a burn cycle:

$$
\begin{aligned}
& F=\frac{14.06 \times 37.5-18.85 \mathrm{MeV}}{200 \mathrm{MeV}}=2.54 \\
& F=\frac{14.06 \times 150-18.85 \mathrm{MeV}}{200 \mathrm{MeV}}=10.45
\end{aligned}
$$

Based on the criterion on recirculating power less than 0.2 , Q can vary in time between 0.1 and 0.5 . Various schemes of fuel shuffling could achieve a steadier energy multiplication of 50 or so and Q required of about 0.2

The fission multiplication factor $\mathrm{k}_{\mathrm{eff}}$ is reported to vary from 0.93 to 0.98 . Then

$$
\begin{aligned}
& \varepsilon=\frac{1}{F v}=\frac{1}{2.54 \times 2.8}=0.14 \\
& \varepsilon=\frac{1}{F v}=\frac{1}{10.45 \times 2.8}=0.034
\end{aligned}
$$

There are many more fission neutrons than fusion neutrons so this blanket is dominated by the fission process.

The small fraction of neutrons that are external supplied during the part of the burn cycle where $k_{\text {eff }}$ is close to unity will require attention to criticality safety under abnormal conditions such as loss of coolant and reconfiguration into a more compact fuel arrangement. Use of sodium implies that water-cooling must be excluded in the tokamak systems for safety reasons.

If we take an average energy multiplication of 75 and 5.16 fissions per fusion and make guesses as to the leakage and (n, 2n) type reactions we can estimate the neutron sources and sinks, Table 4.3 .

Table 4.3.

Neutron sources and sinks for UT example average burn

\begin{tabular}{|l|l|l|l|}
\hline \multicolumn{3}{|l|}{ Sources } & \multicolumn{2}{l|}{ Sinks } \\
\hline D-T & 1 & $(\mathrm{n}, \gamma)$ & 10.24 \\
\hline$(\mathrm{n}, \mathrm{f})^{*}$ & 14.45 & $(\mathrm{n}, \mathrm{f})$ & 5.16 \\
\hline$(\mathrm{n}, 2 \mathrm{n}$ etc) & 0.2 & ${ }^{6} \operatorname{Li}(\mathrm{n}, \alpha) \mathrm{T}$ & 1.1 \\
\hline & & captures & 0.3 \\
\hline & & leakage & 0.05 \\
\hline
\end{tabular}




\begin{tabular}{|c|c|c|c|}
\hline Total & 16.85 & Total & 16.85 \\
\hline$*^{*}=2.8$
\end{tabular}

A similar study assumes a fusion power of $150 \mathrm{MW}$, a $\mathrm{k}_{\mathrm{eff}}$ of 0.93 , an energy multiplication of 118, and the hybrid blanket would burn Pu and minor actinides from spent LWR fuel. (Wu et al., 2006)

\subsubsection{Hard spectrum, sodium cooled, all transuranics (Georgia Tech University)}

Another waste burner design is based on an ITER-like superconducting tokamak (Stacey, 2008 and 2009). In this case all the transuranics from an LWR are burned in the hybrid. The blanket uses fast reactor metal fuel elements, sodium cooled. A burnup of $25 \%$ per cycle is limited by fuel damage of $200 \mathrm{dpa}$. A fusion power varying from 180 to $240 \mathrm{MW}$ results in $3000 \mathrm{MW}$ total thermal power. The criticality constant varies from 0.85 to 0.90 during the cycle. In this way one hybrid can burn up the transuranics from 3 to 5 LWRs of equal power.

$$
M=\frac{P_{\text {th }}-0.2 P_{\text {fusion }}}{0.8 P_{\text {fusion }}}=\frac{3000 M W-0.2 \times 200 M W}{0.8 \times 200 M W}=18.5
$$

The recirculating power criterion less than 0.2 requires $\mathrm{Q}>1$.

$$
\begin{aligned}
& F=\frac{14.06 \times 18.5-18.85 \mathrm{MeV}}{200 \mathrm{MeV}}=1.21 \\
& \varepsilon=\frac{1}{F v}=\frac{1}{1.21 \times 2.9}=0.28
\end{aligned}
$$

This value of $\varepsilon$ is larger than the prior example, showing that the fission process is a little less dominant, as also shown by the lower $\mathrm{k}_{\text {eff }}$ of 0.85 to 0.9 . The neutron balance of this system is shown in Table 4.4 .

Table 4.4.

Neutron sources and sinks for Georgia Tech example average burn, $\mathrm{M}=18.5, \mathrm{~F}=1.21$

\begin{tabular}{|l|l|l|l|}
\hline \multicolumn{3}{|l|}{ Sources } & \multicolumn{2}{l|}{ Sinks } \\
\hline D-T & 1 & $(\mathrm{n}, \gamma)$ & 2.05 \\
\hline$(\mathrm{n}, \mathrm{f}) *$ & 3.51 & $(\mathrm{n}, \mathrm{f})$ & 1.21 \\
\hline$(\mathrm{n}, 2 \mathrm{n}$ etc $)$ & 0.2 & ${ }^{6}$ Li $(\mathrm{n}, \alpha) \mathrm{T}$ & 1.1 \\
\hline & & captures & 0.3 \\
\hline & & leakage & 0.05 \\
\hline & 4.71 & Total & 4.71 \\
\hline Total & $*_{v}=2.9$ & \multicolumn{3}{l}{} \\
\hline
\end{tabular}




\subsubsection{Molten salt waste burner, all transuranics}

Cheng (2005) has studied actinide burning with a blanket design where separated transuranics from light water reactors are fed to the fusion blanket as they are fissioned. He includes structures, a first wall, a fissioning zone and a reflector zone. In the fissioning zone, in the case called hard spectra there is only molten salt with the dissolved actinides and in the case called soft spectra $50 \%$ of the volume is taken up by beryllium that both multiplies neutrons and moderates them. After the initial inventory is burned and continuously replaced about three times a quasi-steady state is achieved.

$$
\begin{aligned}
& \varepsilon=\frac{1}{F v}=\frac{1}{0.83 \times 2.6}=0.46
\end{aligned}
$$

The recirculating power fraction less than 0.2 criterion requires $\mathrm{Q}>1.5$.

\subsubsection{Hard spectra case-steady state: $M=8.6, F=0.51, k_{\text {eff }}$}

$=0.56$,

The required $\mathrm{Q}=2.3$.

$$
\varepsilon=\frac{1}{F v}=\frac{1}{0.51 \times 2.7}=0.73
$$

These two cases show even less dominance of the fission process as is shown by the still lower $\mathrm{k}_{\mathrm{eff}}$ values and larger values of $\varepsilon$.

A $3000 \mathrm{MW}_{\text {fusion }}$ plant with a neutron wall load of $1 \mathrm{MW} / \mathrm{m}^{2}$ would burnup $\sim 1 \mathrm{ton} /$ full power year of actinides with an inventory of 2.3 tons and 13 tons for the soft and hard spectra cases for a fusion power of 230 and $350 \mathrm{MW}_{\text {fusion }}$ respectively. Chemical attack of the beryllium by the molten salt was not discussed but must be prevented by coatings or by separate zones. The fission-suppressed breeder discussed earlier illustrated one means to avoid this attack. Table 4.5 shows the neutron balance for these cases.

Table 4.5.

Neutron sources and sinks for Molten Salt example

Average burn, Soft spectra, $\mathrm{M}=13, \mathrm{~F}=0.83$

\begin{tabular}{|l|l|l|l|}
\hline \multicolumn{2}{|l|}{ Sources } & \multicolumn{2}{l|}{ Sinks } \\
\hline D-T & 1 & $(\mathrm{n}, \gamma)$ & 1.08 \\
\hline$(\mathrm{n}, \mathrm{f})$ & 2.16 & $(\mathrm{n}, \mathrm{f})$ & 0.83 \\
\hline$(\mathrm{n}, 2 \mathrm{n}$ etc) & 0.2 & ${ }^{6} \operatorname{Li}(\mathrm{n}, \alpha) \mathrm{T}$ & 1.1 \\
\hline & & captures & 0.3 \\
\hline
\end{tabular}




\begin{tabular}{|l|l|l|l|}
\hline & & leakage & 0.05 \\
\hline Total & 3.36 & Total & 3.36 \\
\hline
\end{tabular}

Hard spectra, $\mathrm{M}=8.6, \mathrm{~F}=0.51$

\begin{tabular}{|l|l|l|l|}
\hline \multicolumn{3}{|l|}{ Sources } & \multicolumn{2}{l|}{ Sinks } \\
\hline D-T & 1 & $(\mathrm{n}, \gamma)$ & 0.57 \\
\hline$(\mathrm{n}, \mathrm{f})$ & 1.33 & $(\mathrm{n}, \mathrm{f})$ & 0.51 \\
\hline$(\mathrm{n}, 2 \mathrm{n}$ etc $)$ & 0.2 & ${ }^{6}$ Li $(\mathrm{n}, \alpha) \mathrm{T}$ & 1.1 \\
\hline & & captures & 0.3 \\
\hline & & leakage & 0.05 \\
\hline Total & 2.53 & Total & 2.53 \\
\hline
\end{tabular}

\subsection{Blanket designs for power production}

As fuel produced is allowed to build up, the fission process results in more energy from fission. Criticality can be approached with obvious safety implications. An extensive study published by Tenney et al (1978), found economics required power approaching 3 GWe before economy of scale became favorable. More recently, studies of laser inertial fusion made power production the goal in designs called LIFE (Moses et al, 2009) with power of $\sim 1 \mathrm{GWe}$.

In order to get recirculating power manageable and achieve revenues from sale of electricity only, based on the results of Fig. 3.9 for the case of $M=10$ that seems typical of power producing blankets, we require:

$$
Q>2
$$

The required $\mathrm{Q}$ is roughly proportional to $1 / \mathrm{M}$.

\section{Axisymmetric mirror as a pure fusion device}

In order to be economical a pure fusion reactor must have sufficiently small amount of recirculating power. As can be seen from Fig. 3.2, in order to keep the recirculating power between 10 and $20 \%$, we get the following requirement on $\mathrm{Q}$ :

$$
\begin{aligned}
& \eta_{d} Q M \eta_{T h}=7 \text { to } 3 \\
& \text { for } \eta_{d}=0.7 ; M=1.34 ; \eta_{T h}=0.4 \quad Q>11 \text { to } 26
\end{aligned}
$$

To develop a mirror into an attractive pure-fusion reactor, that is, to achieve $\mathrm{Q}>11$, one has to use ambipolar end plugs (see for example Post, 1999, 2010). As these plugs will now be axisymmetric, their magnetic field can be made significantly higher than in 1980s designs, and their volume much smaller. This allows using a simple tandem mirror plugs, without resorting to more sophisticated concepts like thermal barriers. The MHD stabilization schemes (of which many have been proposed and some have even underwent 
preliminary tests) would have to be tested at a small-scale (similar to the existing GDT) facility.

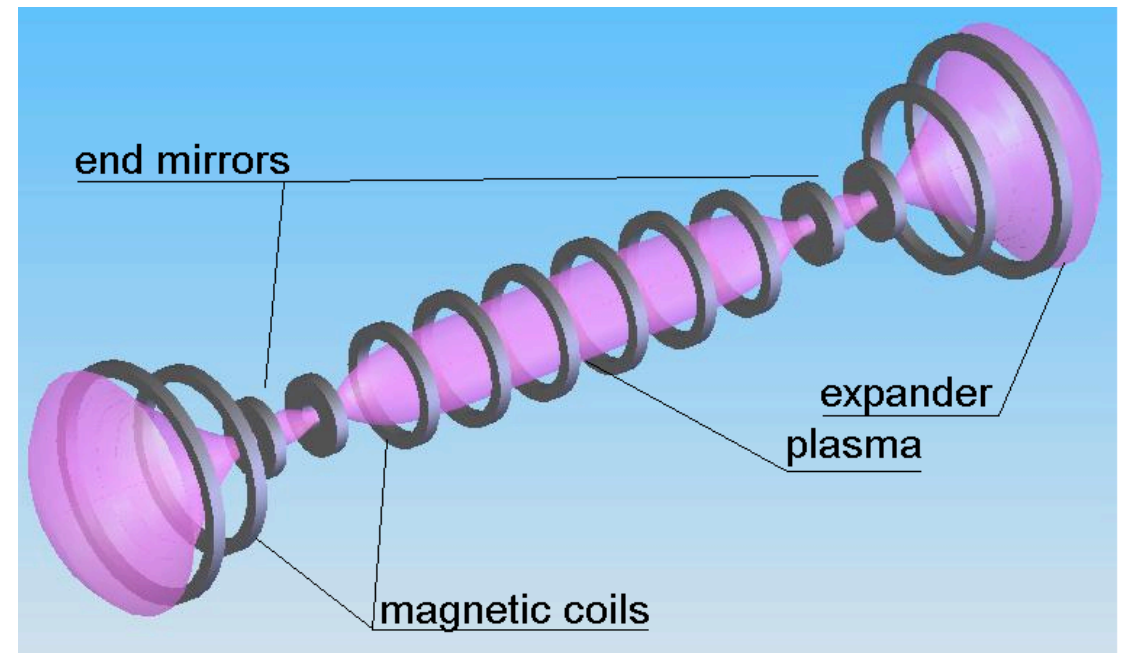

Fig. 5.1. Axisymmetric tandem mirror.

\section{Development path for neutron source, hybrid, and pure- fusion devices}

We expect that a neutron source will be developed and operated before a hybrid device, in order to ensure reliable operation of steady-state neutral beams, cryopumps with regeneration techniques to achieve steady-state pumping, tritium generating lithium blankets, and fission-materials blankets. Whether the neutron source is a mirror or a tokamak, technology developments equivalent to those discussed above are necessary.

Development of axisymmetric mirrors for the aforementioned applications can be achieved at a relatively low cost due to the engineering simplicity of axisymmetric mirrors. These facilities are remarkably flexible: adding or removing axisymmetric coils, to test new configurations, can be done without changing the overall structure of the device. As an example, a small-volume ambipolar plug was installed and successfully tested at the GDT facility. In the past, construction of more complex facilities, like TMX, took about 1.5 years after decision to build them. The GDT facility at Novosibirsk was built in about 1 year.

One of the paths to construction of the neutron source could be as follows. Building a pulsed (20 ms) hydrogen model and demonstrating that absolute (not scaled!) values of the plasma parameter are achievable (3 years); developing steady-state technology (common to all MFE systems) and building a source (5 years). The source will be first operated with hydrogen and will later be switched to a DT mode. The times here are counted from the decision point.

Performance tests of the mirror as a driver for the actinide burner can be carried out at the same facility as that built to reach design values of parameters for the neutron source. 
This can be done by small modifications of the geometry and reconfiguring the beam injectors, in parallel or after the neutron source-related experiments.

Stabilization techniques required for a pure-fusion reactor can be tested in an experiment of the scale of the present GDT device.

\section{Summary and discussion}

The $\mathrm{Q}$ required for several different hybrid blankets designed for different purposes are given in Table 7.1. Actinide waste incineration or burning by fissioning can be accomplished with fusion neutrons. Blankets can use solid fuel forms or molten salt fuel form. With solid fuel forms, cooling of after-heat requires active or engineered safety systems. By comparison, with molten salt fuel forms, the fuel can be drained passively during off-normal conditions to passively cooled dump or storage tanks.

Table 7.1

Require $\mathrm{Q}$ for various versions of the hybrid for the recirculating power fraction $=0.2, \mathrm{P}_{\text {nuclear }}=3000 \mathrm{MW}$

\begin{tabular}{|c|c|c|c|}
\hline \multicolumn{3}{|c|}{ Actinide burner } & \multirow[b]{2}{*}{ Comments } \\
\hline $\begin{array}{c}\text { Blanket } \\
\text { multiplication, } \\
\text { M }\end{array}$ & $\begin{array}{l}\text { Minimum } \\
\text { Q required }\end{array}$ & $\mathrm{P}_{\text {fusion }}, \mathrm{MW}$ & \\
\hline $\begin{array}{c}\text { Transuranics, } \\
\mathrm{M}=19\end{array}$ & 1 & 200 & $\begin{array}{l}\text { solid fuel, } \\
\text { engineered or } \\
\text { active safety }\end{array}$ \\
\hline $\begin{array}{c}\text { Minor actinides, } \\
\mathrm{M}=38 \text { to } 150\end{array}$ & $\begin{array}{c}0.1 \text { to } 0.5 \\
0.2 \text { av. }\end{array}$ & $\begin{array}{l}25 \text { to } 100 \\
50 \mathrm{av} \text {. }\end{array}$ & “ \\
\hline $\begin{array}{c}\text { Transuranics, } \\
\text { Molten salt, } \\
\mathrm{M}=13\end{array}$ & 1.5 & 280 & passive safety \\
\hline \multicolumn{4}{|c|}{ Fuel producer } \\
\hline $\begin{array}{c}\text { Fission- } \\
\text { suppressed, } \\
\mathrm{M}=2.1,{ }^{233} \mathrm{U}\end{array}$ & prosion & 1600 & passive safety \\
\hline $\begin{array}{l}\text { Fast-fission, } \\
\mathrm{M}=10,{ }^{239} \mathrm{Pu}\end{array}$ & 2 & 370 & engineered safety \\
\hline \multicolumn{4}{|c|}{ Power producer } \\
\hline $\mathrm{M}=10$ & 2 & 370 & $\begin{array}{c}\text { molten salt- } \\
\text { passive safety; } \\
\text { solid fuel- } \\
\text { engineered safety }\end{array}$ \\
\hline \multicolumn{3}{|c|}{ Pure fusion } & \\
\hline $\mathrm{M}=1.34$ & 11 & 2300 & passive safety \\
\hline
\end{tabular}

The condition of recirculating power fraction no more than $20 \%$ is restrictive resulting in the require $\mathrm{Q}$ values given above. If the recirculating power fraction could be allowed as 
high as $40 \%$, the required Q values given above would drop approximately in half. A more detailed economic model that fully includes the value of the dual product of both electricity and fuel production or waste burning might result in a higher value of the combined products and therefore a lower required Q. Such a model would include the fleet of fission reactors the hybrid supplies fuel for or the fleet of fission reactors whose wastes are incinerated by fissioning in the hybrid.

The various hybrid options from Table 7.1 with their corresponding $Q$ values required for good economics are shown in Fig. 7.1 along with the various mirror physics operating modes or regimes.

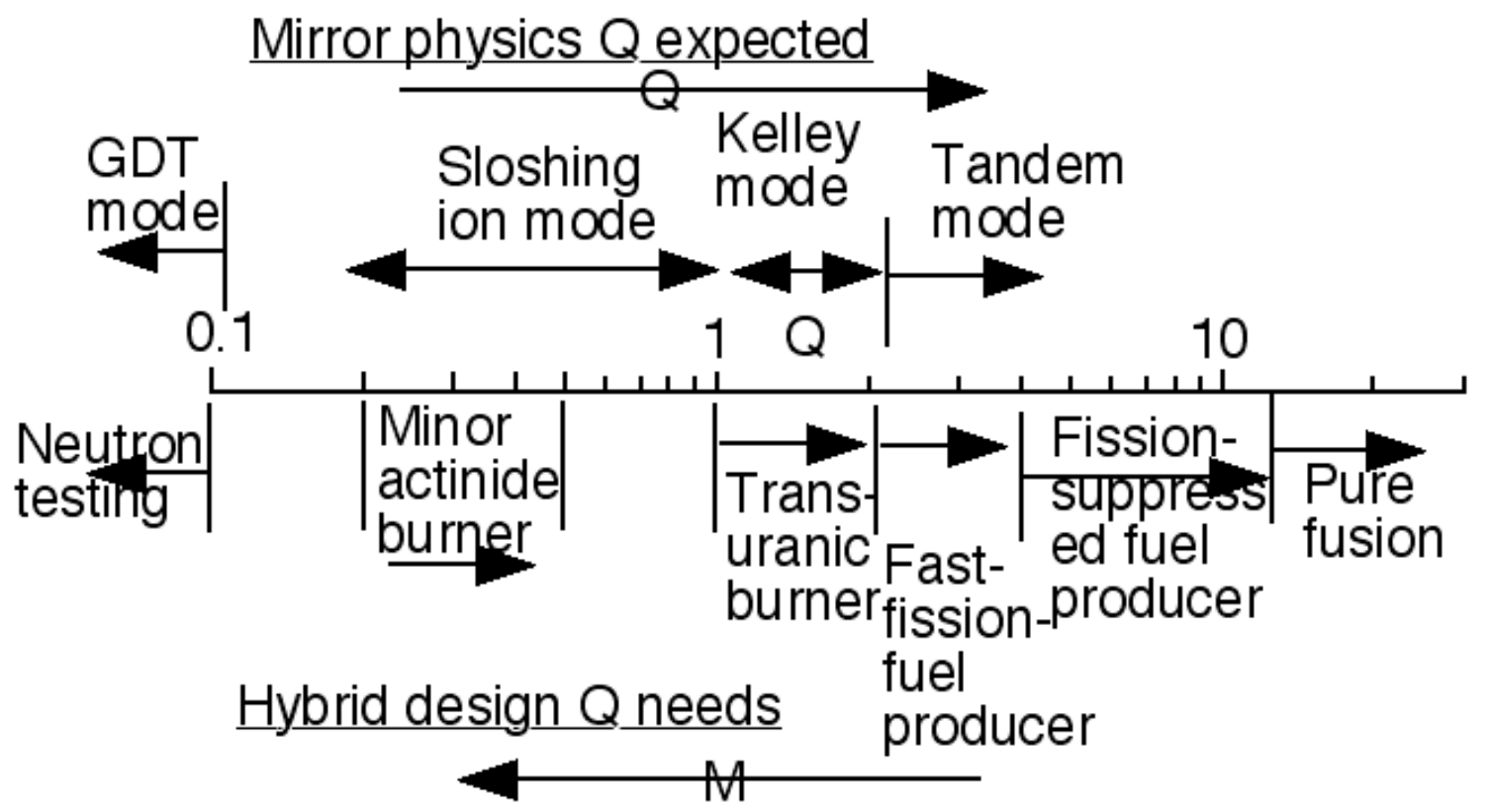

Fig. 7.1. Hybrid options and corresponding mirror operating regimes.

The main finding of our study is that, based largely on the experimentally proven results, one can create a simple and reliable driver for the fusion-fission hybrids. It will have a linear geometry facilitating simple blanket design, and will avoid any problems with too high heat loads: its compatibility with large expansion tanks allows one to reduce the heat load to as low values as needed. It does not carry any externally driven current, thereby eliminating any chance of disruption-like events. As a corollary to that, there is no need in the current-drive systems and the facility is naturally steady-state.

The magnetic system consists of axisymmetric coils, the majority of which operate at quite a low field strength: the on-axis field in the confinement zone is $2.5 \mathrm{~T}$. A stronger field is required in the mirrors, where the field strength has to be $15 \mathrm{~T}$, but such coils are also feasible, as experience of the ITER design and coil tests shows. 
One element that requires significant engineering effort is the neutral beam injection system, which will have to operate in a steady-state regime. The existing prototypes produce the beams with the necessary parameters (energy, beam equivalent current, beam divergence), but they have been tested only for relatively short pulses of a few seconds. On the other hand, the steady-state operation is required for the majority of various magnetic fusion systems, including tokamaks and the effort in this direction would continue independently of the proposed mirror driver.

The simplicity and reliability of the proposed driver come at a cost of a relatively low value of the fusion gain factor Q, which is somewhat below unity. This is still sufficient to have a good driver for the minor actinide burning system. To make it attractive in other versions of hybrids, one will need to deploy direct energy convertors, which do not affect the performance of the confinement system but allow recovery of about half of the energy lost through the ends. Fuel producing hybrids will need better confinement physic than the sloshing ion mode.

Physics-wise, the proposed driver does not require any major physics extrapolation from the existing GDT facility in terms of the dimensionless parameters. However, the absolute values of the parameters, in particular, the geometrical scale, increase significantly. Therefore, the development path should include construction of a nonradioactive (hydrogen/deuterium facility) allowing for hands-on maintenance and having a relatively low cost. Such a facility is quite simple, especially if it operates in pulsed mode ( $\sim 5 \mathrm{~s}$, sufficient for reaching the steady-state in plasma confinement). In this case, one can even use a water-cooled solenoid for the confinement zone and a simple combined mirror coil (superconducting outer coil, water-cooled inner coil, however, the powr consumption can be significant).

The proposed concept of a simple mirror driver can be further improved in terms of the plasma confinement by adding end-plugs, in particular, ambipolar plugs [Dimov et al, 1976; Fowler \& Logan, 1977]. The research is underway on the compatibility of such plugs with the axisymmetric system [Prikhod'ko, 2011]. With a modest increase of the plasma gain to the values $\mathrm{Q} \sim 3$ would allow development of an attractive fusion-fission breeder. The basic elements of the driver for such a breeder would be the same as in our analysis, just two end-plugs added. So, the development of the proposed simple and reliable system would make an important contribution to the further progress of the mirror-based hybrids.

The next step would include more ambitious end-plugs, providing for Q values in excess of 10 needed for the pure fusion systems. Again, the basic elements of this more ambitious project would still remain the same as those discussed in our paper. This circumstance justifies a more detailed design analysis of the proposed simple mirror driver and possible steps to building a non-radioactive test stand.

\subsection{Follow-on studies}

A follow-on to this study would include a number of items:

1-a design of all the components integrated into a system 
2-design injector with beam direct converters, beam dumps, ports, magnets

3 -raise injection energy from $80 \mathrm{keV}$ to increase the overall power balance

4-increase atomic fraction by source modifications suggested in this paper

5-work end tank pumping to lower charge exchange losses

6-sketch end loss direct converter layout

7-compute ion energy distribution and radial variation as it enters the direct converter

\section{Conclusions}

A fusion neutron source can be based on an all axisymmetric set of magnet employing existing neutral beams at $80 \mathrm{keV}$ to achieve plasma conditions modestly extended from those already achieved. The predicted Q of $\sim 0.6$ would be sufficient for applications to burn minor actinide wastes (elements beyond $\mathrm{Pu}$ ). The system would be steady state requiring neutral beam technology development to extend lifetime from the present to about a year. The heat load is spread over as much area as needed in end tanks and therefore is within the state-of-the-art. The solenoidal magnets at $2.5 \mathrm{~T}$ are common and even the $15 \mathrm{~T}$ mirror magnets are similar to those tested for ITER. Pumping would be by well know cryogenic condensation pumping that would need to be made steady by proposed techniques of cycling a portion of the pumps for outgassing at any one time. With tandem mirror end cells added, the $\mathrm{Q}$ might $\mathrm{b}$ raised to about 1 or more to permit burning all actinides or even to $>3$ to allow fuel production in the fission suppressed mode. Fusion applications such as a materials-testing neutron source and other fusion technology will likely be developed independently and can be used by this hybrid application.

\section{Acknowledgment}

The authors are grateful to Curt Bolton for valuable discussions and encouragement. Work performed under the auspices of the U.S. Department of Energy, Oak Ridge Associated Universities, the University of California, Berkeley, and by Lawrence Livermore National Laboratory under Contract DE-AC52-07NA27344.

\section{References}

H. H. Andersen and H. L. Bay, "Sputtering yield measurements" in "Sputtering by Particle Bombardment I," Springer Topics in Applied Physics, Vol. 47, 145-218 (1981).

P. A. BAGRYANSKY, A. A. IVANOV, E. P. KRUGLYAKOV, A. M.

KUDRYAVTSEV, YU. A. TSIDULKO, A. V. ANDRIYASH, A. L. LUKIN, and YU. N. ZOUEV, "Gas dynamic trap as high power $14 \mathrm{MeV}$ neutron source," Fusion Engineering and Design 70, 13 (2004). Fig. 13.

P.A. Bagryansky, A.A. Lizunov, A.A. Zuev, E. Yu. Kolesnikov, A.L. Solomachin. "Experiments with Controllable Application of Radial Electroc Fields in GDT Central 
Cell.” Fusion Sci. and Technology 43, 152 (2003)

P.A. Bagryansky, A.D. Beklemishev, E.I. Soldatkina. "Influence of radial electric field on high-beta plasma confinement in the Gas-Dynamic Trap." Fusion Sci. Technol. 51, 340 (2007).

D. F. Barnett, editor, "Collisions of H, H2, He and Li Atoms and Ions with Atoms and Molecules,” Oak Ridge National Laboratory Report ORNL-6086 Vol. 1 (1990).

William L Barr, James N. Doggett, John D. Kinney, Ralph W. Moir, "Engineering of Beam Direct Conversion for a 120-kV, 1-MW Ion Beam", Proceedings of the 7th Symposium on Engineering Problems of Fusion Research, October 25-28 1977.

W. L. Barr, R. W. Moir, G. W. Hamilton, "Experimental results from a beam direct converter at $100 \mathrm{kV}$," J. of Fusion Energy 2, 131 (1982).

W. L. Barr and R. W. Moir, "Test results on plasma direct conversion," Nuclear Technology/Fusion 3 (1983) 98-111.

D. J. Bender, K. R. Schultz, et al., "Reference design for the standard mirror hybrid reactor," UCRL-52478, GA-A14796 (1978). 542 pages.

http://ralphmoir.com/benUCRL52478sm.pdf

H.L. Berk, M.N. Rosenbluth, R.H. Cohen, W.M. Nevins. Phys. Fluids, 28, 2824 (1985). D. D. Blackwell, F. F. Chen, "Two-dimensional imaging of a helicon discharge," Plasma sources Science \& Technology 11, A74 (1997).

M.Bird, NHMFL, Director of Science and Technology Department, private communication, 27 April 2011.

J. Bohdansky, in R. A. Langley, J. Bohdansky, W. Eckstein, et al., "Data Compendium for Plasma-Surface Interactions,” Nucl. Fusion 24, 9 (1984).

B.N. Breizman. In: “Rev. Plasma Phys.” B.B. Kadomtsev, Ed., v. 15, p 61, 1990.

C. F. Chan, C. F. Burrell, W. S. Cooper, "Model of positive ion sources fro neutral beam injection," J. Appl. Phys. 54, 6119 (1983).

E. T. Cheng, "Performance characteristics of actinide-burning fusion power plants," Fusion Science \& Technology, 47, 1219-1223 (2005).

J. KIM, R. W. CALLIS, A. P. COLLERAINE, et al., Performance of the DIIID neutral beam injection system," Proc. 12th Symposium on fusion engineering, IEEE (1987), p. 290.

B.I. Cohen, N. Maron, W.M. Nevins. Phys. Fluids, 27, 642 (1984). 
S. J. Cox, A. Bickley, T. T. C. Jones, and J. Milnes, "Operating limits of the upgraded JET Neutral Beam Injector from duct re-ionization and beam shine-through," Proc. 17th Symp. on Fusion Engineering, IEEE, 60 (2002).

C. DAY, et al., "Hydrogen inventories in the vacuum pumping sytems of ITER," Fusion Engineering and Design 81, 777-84 (2006).

M. Decreton, T. Shikama, E. Hodgson, "Performance of functional materials and components in a fusion reactor: the issue of radiation effects in ceramics and glass materials for diagnostics," J. Nuclear Materials 329-333, 125 (2004).

M. DREMEL, C. DAY, R. HEMSWORTH, R. PEARCE and C. MAYAUX, "Cryopump design for the ITER heating neutral beam injector," Nucl. Fusion 49, 075035 (2009).

G. Duesing, H. Altmann, H. Falter, et al., "Neutral Beam injection system for JET," Fusion Tech. 11, 163 (1987).

U. Fischer, A. Moslang, A.A. Ivanov. Fus. Technol., 35, T160 (1999).

U. FISCHER, A. MÖSLANG, and A.A. IVANOV, "Assessment of the gas dynamic trap mirror facility as intense neutron source for fusion material test irradiations," Fusion Engineering and Design 48, 307 (2000);

J. Freidberg, P. Finck, C. Bolton, Eds. Report "Research Needs for Fusion-Fission Hybrid Systems," Report of the Research Needs Workshop) ReNeW) Gaithersburg, Maryland Sept 30-Oct 2, 2009. MIT, January 2010.

S-L. Fu, J-F. Chen, S-J. Hu, et al., "Study on the characteristics of ECR plasma spatial distribution," Plasma sources Science \& Technology 15, 187 (2006).

A. M. Garofalo, V. S. Chan, R. D. Stambaugh, et al., "Mission and Overview of a Fusion Development Facility," IEEE Transactions on Plasma Science 38, 461 (2010).

Greenwald report to FESAC on "Priorities, Gaps and Opportunities: Towards a LongRange Strategic Plan for Magnetic Fusion Energy" (2007), available at: http://www.sc.doe.gov/ofes/fesac.shtml.

S. K. Hahto, S. T. Hahto, Q. Ji. K. N. Leung, S. Wilde, E. L. Foley, L. R. Grisham, F. M. Levinton, "Multicusp ion source with external rf antenna for production of protons," Rev. Sci. Instrum. 75, 355 (2004).

V. Hauer, J. C. Boissin, C. Day, et al., "Design of the ITER torus prototype cryopump," Fusion Engin. and Design 82, 2113 (2007). 
R. Hazeltine, et al., "Research Needs for Magnetic Fusion Energy Sciences,” Report of Research Needs Workshop; http://fire.pppl.gov/renew_final_report_2009.pdf.

A. Herve, “The CMS detector magent", IEEE Trans. Appl. Supercon., vol 10, No. 1, pp. 389-394, 2000.

E. R. Hodgson, "Challenges for insulating materials in fusion applications," Nuclear Instrum. And Methods in Physics Research B 191, 744 (2002).

R. Hong and H. K. Chiu, "Effects of operating parameters on the beam species of DIII-D neutral beam ion sources," Proc. 17th Symp. on Fusion Engineering, IEEE, 40 (2002).

J. Hopwood, "Review of inductively-coupled plasmas for plasma processing," Plasma sources Science \& Technology 1, 109 (1992).

W. Horton, J. Pratt, H.L. Berk, et al. J. Fusion Energy, 26, 77 (2007).

J. Hovingh and R. W. Moir, "Efficiency of Injection of Neutral Beams into Thermonuclear Reactors", Nuclear Fusion, 14, 629 (1974).

A.A. Ivanov, A.V. Anikeev, P.A. Bagryansky et al., Paper EX/P5-43, IAEA Fusion Energy Conference, Geneva, Switzerland, Oct. 13-18, 2008.

A.A. Ivanov, A.V. Anikeev, P.A. Bagryansky et al., Paper EX/P5-43, IAEA Fusion Energy Conference, Geneva, Switzerland, Oct. 13-18, 2008; T.C. Simonen. This volume.

A. A. Ivanov, A. d. Beklemishev, E. P. Kruglyakov, P. A. Bagryansky, A. A. Lizunov, V. V. Maximov, S. B. Murakhtin, V. V. Prikhodko, "Results of Recent experiments on GDT Device after upgrade of heating neutral beams," Fusion Sci. Technol., 57, 320-325 (2010).

T.B. Kaiser, B.I. Cohen. Phys. Fluids, 30, 1564, 1987.

J. Kesner, B. Lane. Phys. Fluids, 28, 634 (1985).

M. Kotschenreuther, P.M. Valanju, S.M. Mahajan, E.A. Schneider, "Fusion-Fission Transmutation Scheme-Efficient Destruction of Nuclear Waste." Fusion Engineering and Design 84 (2009) 83-88.

W.B. Kunkel, J.U. Guillory. Proceeding of the Seventh Conference on the Phenomena in Ionized Gases, Belgrade, 1965, edited by B. Perovic and D. Tosic (Gradevinska Knjiga, Belgrade, Yugoslavia, 1966), V. II, p. 702.

L. M. Lidsky, "Fission-fusion systems: hybrid, symbiotic and augean", Nuclear Fusion 15, 151-173 (1975). 
N. Martovetsky, J. Minervini, A. Radovinsky et al., "Test of the ITER Central Solenoid Model Coil and CS Insert", IEEE Transactions on Applied Superconductivity v.12, N 1 March 2002, p. 600-605.

R. W. Moir, et al., "Helium-Cooled Molten Salt Fusion Breeder", Lawrence Livermore National Laboratory, Livermore, CA, UCID-20153 (1984a).

R. W. Moir, et al., "Feasibility Study of a Fission-Suppressed Tokamak Fusion Breeder", Lawrence Livermore National Laboratory, Livermore, CA, UCID-20154 (1984b).

R. W. Moir, et al., "Design of a Helium-Cooled Molten Salt Fusion Breeder", Fusion Technology, 8, 1985, 465-473.

R. W. Moir, "Recommendations development," Energy Conversion and Management 49 (2008) 1849-1858. for a restart of molten salt reactor

R. W. Moir. "Production of U-232 and U-233 in a fusion-fission hybrid" Vallecitos Molten Salt Research Report No. 3 (December 21, 2010), 37 pages.

A. W. Molvik, "Testing of Developmental Neutral Beam Sources for MFTF," Proceedings of the 8th Symposium on Engineering Problems of Fusion Research, (IEEE) p661 (1979).

A.W. Molvik, R.A. Breun, S.N. Golovato, N. Hershkovitz, B. McVey, R.S. Post, D. Smatlak, L. Yujiri. "Modification of the macroscopic stability of a tandem mirror by parallel line-tying.” Phys. Fluids, 27, 2711 (1984).

A. W. MOLVIK, R. H. MUNGER, T. J. DUFFY, and D. L. CORRELL, "Geometrically focused neutral beam accelerators," Rev. Sci. Instrum. 52, 965 (1981).

A. W. MOLVIK, "Impurity radiation from a beam-plasma neutron source," Nuclear Fusion 35, 1247 (1995).

A. W. Molvik, A. Ivanov, G. L. Kulcinski, D. Ryutov, J. Santarius, T. Sionen, B. D. Wirth, A. Ying, "A Gas Dynamic Trap Neutron Source for Fusion Material and Subcomponent Testing," Fusion Sci. Technol., 57, 369 (2010).

E. Moses et al, A sustainable nuclear fuel cycle based on laser inertial fusion energy, fusion Science and Technology, 56, 547, 2009

Y.K. M. Peng, P. J. Fogarty, T. W. Burgess, et al., "A component test facility based on the spherical tokamak," Plasma Physics and Controlled Fusion 47, Suppl. 12B, B263 (2005).

L. Petrizzi, M. Loughlin, A. Marin, F. Moro, et al., "Neutronic analysis of ITER cryopump system," Fusion Engineering and Design 84, 1505 (2009). 
W. L. Pickles, M. O. Calderon, M. R. Carter, C. A. Clower, et al., "Dynamic gas flow during plasma oeration in TMX-U,” J. Vac. Sci. Technol. A 1, 1288 (1983).

G. D. Porter, "Effect of gas recycling and secondary-electron emission on the axial power flow in an open-ended device," Nuc. Fusion 22, 1279 (1982).

M.N. Rosenbluth, C.L. Longmire, "Stability of plasmas confined by magnetic fields." Annals of Physics, 1, 120 (1957).

R. F. Post, "Mirror-based fusion: some possible new directions," Trans. Fusion Sci. Technol, 35, \#1T, 40 (1999).

R.F. Post, "Magnetohydrodynamic stabilization of axisymmetric mirror systems using pulsed ECRH,” Fusion Sci. Technol, 57, 335 (2010).

E. W. Rothe, L. L. Marino, R. H. Neynaber, and S. M. Trujillo, "Electron impact ionization of atomic hydrogen and atomic oxygen," Phys. Rev. 125, 582 (1962).

M. E. Rudd, R. D. DuBois, L. H. Toburen, C. A. Ratcliffe, and T. V. Goffe, "Cross sections for ionization of gases by $5-4000 \mathrm{keV}$ prtons and for electron capture by 5-150 keV protons," Phys. Rev. A 28, 3244 (1983).

D. D. Ryutov, “Axisymmetric MHD-Stable Mirrors," Proceedings of the Course and Workshop, Varenna, Italy, Vol. II, 791 (1987).

D.D. Ryutov. "Mirror type neutron source". Plasma Physics and Contr. Fusion, 32, 999 (1990).

D. D. Ryutov, "Axial electron heat loss from mirror devices revisited," Trans. Fusion Science Technol., 47, 1T, 148-154 (2005).

D.D. Ryutov. In: "Hybrid Fusion Fission Systems," Courant Institute and Brookings Institution, May 2009, p. A.1.

D.D. Ryutov, A.W. Molvik, T.C. Simonen. "Axisymmetric Mirror as a Driver for a Fusion-Fission Hybrid: Physics Issues,” J. Fusion Energy, 29 (2010).

D. W. Sedgley, T. H. Batzer, and W. R. Call, "Helium cryopumping for fusion applications," J. Vac. Sci. Technol. A 6, 1209 (1988).

T.C. Simonen, S.L. Allen, T.A. Casper, et. al., "Operation of the tandem-mirror plasma experiment with skew neutral-beam injection.” PRL, 50, 1668 (1983).

T. C. Simonen, "Development and Applications of Axisymmetric Magnetic Mirror Concepts," Fusion Sci. Technol., 57, 305 (2010). 
W.M. Stacey et. Al., A TRU-Zr metal-fuel sodium-cooled fast subcritical advanced burner reactor, Nuclear Technology, 162, 53, 2008.

T. Stevenson, K. Silber, L. Lagin, et al., "The TFTR Neutral Beam Performance Database," Fusion Technology 21, 1644, Part 2A (1992).

F. Tenney et al., "A systems study of tokamak fusion-fission reactors," PPPL-1450 (1978) 544 pages

E. W. Thomas, editor, "Particle interactions with surfaces," Oak Ridge National Laboratory Report ORNL-6086 Vol. 3 (1985).

M. C. VELLA, W. S. COOPER, P. A. PINCOSY, R. V. PYLE, P. D. WEBER, and R. P. WELLS, "Development testing of the U.S. common long pulse source at $120 \mathrm{keV}$," Rev. Sci. Instrum. 59, 2357 (1988).

R.S. Willms, K. Kobayashi, Y. Iwai, T. Hayashi, S. O'hira, M. Nishi, D. Hyatt and R.V. Carlson; "Behavior of tritium in the TSTA test cell combined with operation of the Experimental Tritium Cleanup (ETC) system"; Fusion Engineering and Design, 61-62, $575-583(2002)$.

Y. Wu, M. A. Lieberman, "The influence of antenna configuration and standing wave effects on the density profile in a large-area inductive plasma source," Plasma sources Science \& Technology 9, 210 (2000).

R. Xu, J. Zhao, S. X. Peng, Z. X. Yuan, et al., "Study on proton fraction of beams extracted from electron cyclotron resonance ion sources," RSI 79, 02B713 (2008).

S. J. Zinkle, V. A. Skuratov, and D. T. Hoelzer, "On the conflicting roles of ionizing radiation in ceramics," Nuclear Instrum. And Methods in Physics Research B 191, 758 (2002).

For tandem mirror blankets for hybrids http://www.geocities.com/rmoir2003/fusFisHyb.htm and for direct conversion for mirrors - http://www.askmar.com/Direct_Energy.html 